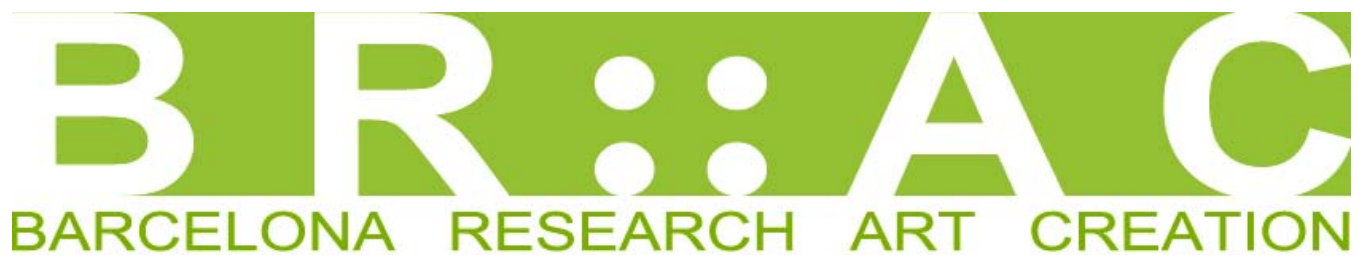

\title{
Volume 2, Number 1
}

\section{Hipatia Press \\ www.hipatiapress.com}

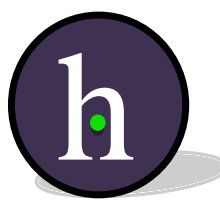

\section{Articles}

Intersecciones Semánticas entre Visión Artificial y Mirada Artística -

Pilar Rosado, Eva Figueras \& Ferran Reverter.

Der Baum in der Gegenwartskunst: Nachhaltigkeitsindikator -

Ángels Viladomiu

Constructed News: Events and Rituals of Political Life -

Ramon Girona \& Àngel Quintana

Teresa Margolles. Reiterar la Violencia -

Maria Campiglia

Reviews

Oriol Vaz-Romero Trueba, El Artista y el Juguete. Viajes al Imaginario Occidental, desde la Antigüedad al Romanticismo -

Michel Manson

List of Reviewers 
Instructions for authors, subscriptions and further details:

http://brac.hipatiapress.com

\section{Intersecciones Semánticas entre Visión Artificial y Mirada} Artística

Pilar Rosado ${ }^{1}$, Eva Figueras ${ }^{2}$ \& Ferran Reverter ${ }^{3}$

$1,2,3)$ University of Barcelona. Spain

Date of publication: February $3^{\text {th }}, 2014$

Edition period: October 2013-February 2014

To cite this article: Rosado, P., Figueras, E.\& Reverter, F. (2014).

Intersecciones semánticas entre visión artificial y mirada artística.

Barcelona, Research, Art, Creation, Vol 2(1), 1-54.

doi:10.4471/brac.2014.01

To link this article: http://dx.doi.org/10.4471/brac.2014.01

\section{PLEASE SCROLL DOWN FOR ARTICLE}

The terms and conditions of use are related to the Open Journal System and to Creative Commons Attribution License (CC-BY). 


\section{Semantic Intersections between Artificial and Artistic Vision}

Pilar Rosado

University of Barcelona
Eva Figueras

University of Barcelona

Ferran Reverter

University of Barcelona

(Received: 13 November 2013; Accepted: 2 January 2014; Published: 3 February 2014)

\section{Abstract}

In our project we have approached the difficulties of automatic classification of images on which the conception and design of sculptor M. Planas artistic production are based. This artist constantly generates images in his creative process. The methodology used is based on local characteristics. In order to build up a visual vocabulary for basing image description on, we followed a procedure similar to the one used in automatic text analysis. The method is known as the "Bag-of-Words" (BOW) model because every document is represented as a distribution of frequencies of the words in the text, without considering the syntactic relationships among them. In the sphere of images we refer to "Bag-of-Visual Terms" (BOV) representations. This approach consists in analysing images as a group of regions, describing only their appearance without taking into account their spatial structure. To overcome the disadvantages of polysemy and synonymy that this methodology has associated, we have used probabilistic latent semantic analysis (PLSA), that detects underlying topic in images. The outcomes are promising, the described cataloguing method may provide the artist with new viewpoints for future works.

Keywords: Artificial vision, Bag-of-visterms, SIFT descriptors, image cataloging, automated image analysis, probabilistic latent semantic analysis.

2014 Hipatia Press

ISSN: 2014-8992

DOI: $10.4471 /$ brac. 2014.01 


\section{Intersecciones Semánticas entre Visión Artificial y Mirada Artística}

\author{
Pilar Rosado \\ Universidad de Barcelona
}

Ferran Reverter

Universidad de Barcelona

\author{
Eva Figueras \\ Universidad de Barcelona
}

(Recibido: 13 Noviembre 2013; Aceptado: 2 Enero 2013; Publicado: 3 Febrero 2014) Resumen

En el presente artículo se ha desarrollado un sistema capaz de categorizar de forma automática la base de datos de imágenes que sirven de punto de partida para la ideación y diseño en la producción artística del escultor M. Planas. La metodología utilizada está basada en características locales. Para la construcción de un vocabulario visual se sigue un procedimiento análogo al que se utiliza en el análisis automático de textos (modelo "Bag-ofWords"-BOW) y en el ámbito de las imágenes nos referiremos a representaciones "Bag-ofVisual Terms" (BOV). En este enfoque se analizan las imágenes como un conjunto de regiones, describiendo solamente su apariencia e ignorando su estructura espacial. Para superar los inconvenientes de polisemia y sinonimia que lleva asociados esta metodología, se utiliza el análisis probabilístico de aspectos latentes (PLSA) que detecta aspectos subyacentes en las imágenes, patrones formales. Los resultados obtenidos son prometedores y, además de la utilidad intrínseca de la categorización automática de imágenes, este método puede proporcionar al artista un punto de vista auxiliar muy interesante.

Palabras clave: Visión artificial, Bag-of-visterms, descriptores SIFT, catalogación de imágenes, análisis automático de imágenes, análisis probabilístico de aspectos latentes

2014 Hipatia Press

ISSN: 2014-8992

DOI: $10.4471 /$ brac.2014.01

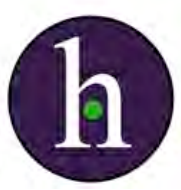


e ha dejado adormecer nuestra capacidad innata de entender con los ojos, y hay que volver a despertarla" (Arnheim, 1983, p.13). Quizá una forma de conseguirlo sea con la ayuda de los métodos de visión artificial que tenemos a nuestro alcance en la actualidad, y a ello pretendemos contribuir con este trabajo.

Muchas veces resulta difícil expresar con palabras lo que se percibe en una imagen. Es normal que podamos ver y sentir las cualidades de una obra sin poder explicarlas. El problema no sólo reside en el lenguaje, sino en que aún no hemos sido capaces de plasmar esas cualidades percibidas en las categorías adecuadas. Para poder nombrar algo debemos haberlo visto, oído, pensado o sentido con anterioridad (Arnheim, 1983, p.15). A estas consideraciones se suma el hecho de que la mirada hacia el mundo es un juego de equilibrio entre las propiedades del objeto observado y la naturaleza del sujeto que observa.

El artista visual hace uso de sus categorías formales para capturar desde lo particular aquello universalmente significativo, desde una forma necesariamente personal. Muchos artistas utilizan la fotografía como herramienta de proyectación y éste sería el caso del escultor M. Planas (Planas, 2014). Las imágenes que utiliza conforman una parte esencial de su proceso creativo, las plantea como un gran fondo documental sobre el que trabajar posteriormente, de manera especial en el campo escultórico. Las imágenes que el artista captura pueden formar parte, tanto de las fases iniciales de su proceso creativo, y también convertirse en el resultado de su trayecto artístico; pueden ser tanto la herramienta de trabajo como el producto de éste.

El objetivo que nos proponemos en el presente estudio es analizar la base de datos de imágenes que ha generado el artista mediante metodologías de visión artificial e intentar dilucidar si éstas generan de forma automática categorías distinguibles en este conjunto, si son significativas para el artista y si guardan algún tipo de relación con otras obras producidas por él, y así poder determinar si el método descrito es capaz de detectar contenidos semánticos en la colección de imágenes.

Al poner de manifiesto estas categorías visuales resulta más fácil apreciar las relaciones estructurales latentes en las imágenes. No se intenta 
substituir la intuición espontánea o el criterio experto, sino agudizar, reforzar o evidenciar nuevos elementos de utilidad para la mirada (o percepción visual). La categorización automática de imágenes, además de su utilidad intrínseca, puede proporcionar al artista un punto de vista auxiliar muy interesante.

Para realizar este estudio ha sido fundamental tener al alcance un fondo consolidado de aproximadamente 3.000 imágenes digitales, todas ellas pertenecientes al mismo autor y con un perfil coherente, pero de estructura y características formales, conceptuales y temáticas diversas. La participación e implicación directa en este proceso del propio autor también ha permitido contrastar los resultados.

Al proponer una investigación de estas características dentro del ámbito de las Bellas Artes se planteó que los resultados obtenidos se podrían extrapolar a todo tipo de acciones entorno a la creación, en las que la comparación entre imágenes fuera su característica principal, logrando aplicaciones encaminadas al aprendizaje, al conocimiento y a la investigación en imágenes.

\section{Metodología}

La representación de la imagen digital es un elemento clave para su clasificación, anotación, segmentación o recuperación. Casi todos los métodos de visión por computador, cuando se enfrentan al problema del análisis del contenido de una imagen, recurren a funciones adecuadas para describirlo de forma compacta. Este sería el caso de los procedimientos basados en características locales que producen una representación de la imagen versátil y sólida capaz de mostrar el contenido global y local al mismo tiempo, y a la vez hacen robusta la descripción ante la oclusión parcial de objetos contenidos y la transformación de la propia imagen.

\section{Representación de la imagen}

Para la construcción de un vocabulario visual en el que basar la descripción de las imágenes, seguimos un procedimiento análogo al que se utiliza en el análisis automático de textos (Joachims, 1998). Se conoce como modelo "Bag-of-Words" (BOW) porque cada documento está representado como 
una distribución de frecuencias de las palabras presentes en el texto, sin tener en cuenta las relaciones sintácticas existentes entre ellas.

En el ámbito de las imágenes nos referiremos a representaciones "Bag-ofVisual Terms" (BOV). Este enfoque consiste en analizar las imágenes como un conjunto de regiones, describiendo solamente su apariencia e ignorando su estructura espacial. La representación BOV se construye a partir de la extracción y cuantización automática de descriptores locales y ha demostrado ser una de las mejores técnicas para resolver diferentes tareas en la visión por computador. La representación BOV fue implementada por primera vez (Willamowski, Arregui, Csurka, Dance \& Fan, 2004) en el desarrollo de una sistema experto de reconocimiento de objetos.

La construcción BOV requiere dos decisiones principales de diseño:

a. La elección de los descriptores locales que aplicamos en nuestras imágenes (Ver anexo A).

b. La elección del método que se utilice para obtener el vocabulario visual (Ver anexo B).

Ambas decisiones pueden influir en el rendimiento del sistema resultante, sin embargo la representación BOV es robusta, conserva su buen comportamiento en un amplio rango de opciones de los parámetros.

La Fig. 1 resume el proceso para obtener la representación BOV de las imágenes de una colección.

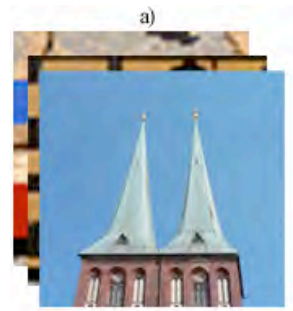

e)

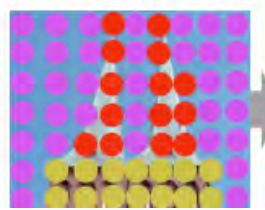

b)

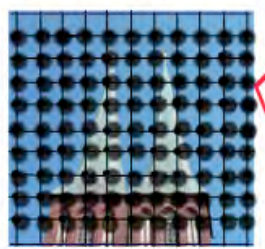

f)

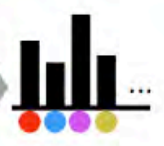

c)

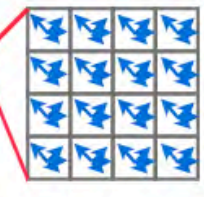

g)

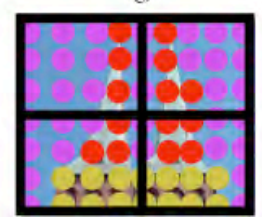

d)

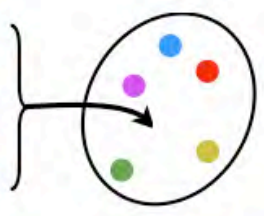

h)

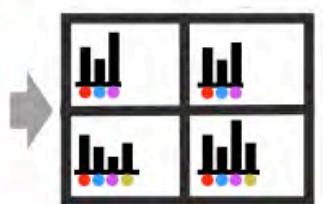

Figura 1. a) Colección de imágenes. b) Se localizan los nodos en una malla regular. c) Se calculan los descriptores SIFT de los nodos. d) Se cuantizan los descriptores de todos los nodos en $\mathrm{M}$ clústeres, los cuales definirán un vocabulario visual de $\mathrm{M}$ 
palabras visuales. e) Una vez se dispone del vocabulario, los descriptores de cada imagen se asignan a la palabra visual más cercana. f) Para obtener la representación BOV de una imagen dada, se calcula la frecuencia de cada palabra visual en la imagen. g) Secuencia de cuadrículas sobre la imagen para elaborar los histogramas en pirámide h) para así tener en cuenta la relación espacial entre palabras visuales.

Esta representación de una imagen no contiene información acerca de las relaciones espaciales entre palabras visuales, del mismo modo que la representación BOW no tiene en cuenta la información relativa al orden de las palabras en los documentos (Fig. 2).

No obstante, los métodos BOV, que representan una imagen como una colección desordenada de características locales, han demostrado impresionantes niveles de rendimiento en tareas de categorización de imágenes completas. Sin embargo, debido a que estos métodos no tienen en cuenta toda la información acerca de la disposición espacial de las características, se ha visto limitada su capacidad descriptiva. En particular, son incapaces de capturar formas o de separar un objeto de su fondo.
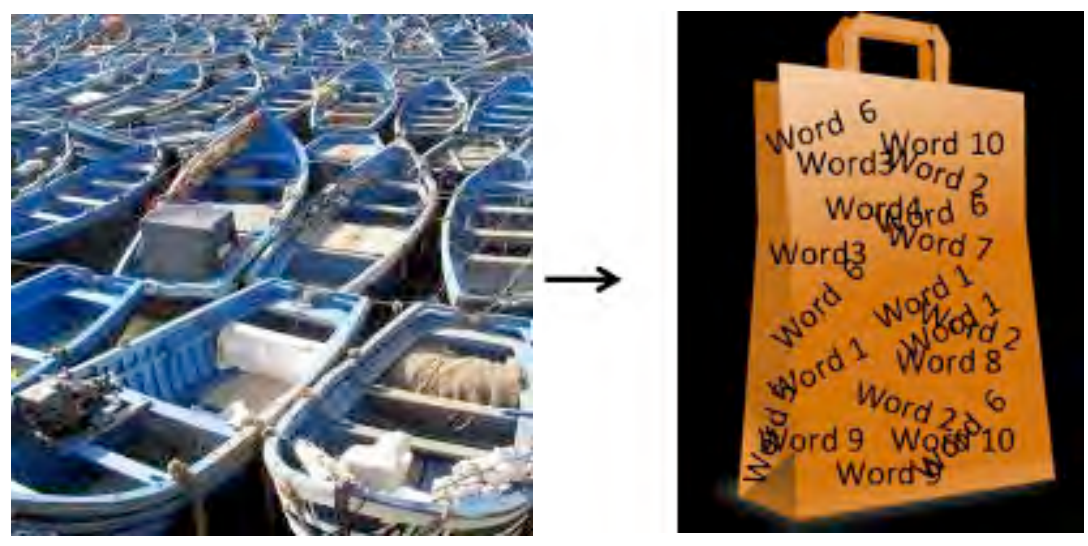

Figura 2. La representación BOV de una imagen no contiene información acerca de las relaciones espaciales entre palabras visuales que la componen. 
Para superar las limitaciones del enfoque BOV hemos implementado una metodología de histogramas en pirámide que configura una secuencia cada vez más fina de cuadrículas sobre la imagen y lleva a cabo un análisis tipo BOV en cada una de las cuadrículas, obteniendo finalmente una suma ponderada de la cantidad de coincidencias que ocurren en cada nivel de resolución de la pirámide (Grauman, K. \& Darrel, T., 2005).

\section{Representación de aspectos latentes}

La representación BOV es fácil de construir. Sin embargo, adolece de dos inconvenientes (Fig. 3): polisemia (una sola palabra visual puede representar diferentes contenidos de la escena) y sinonimia (varias palabras visuales pueden caracterizar el mismo contenido de la imagen).

Palabra 1
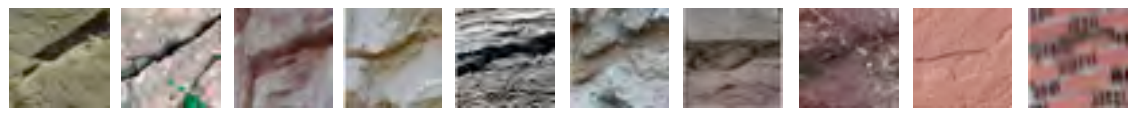

Palabra 2
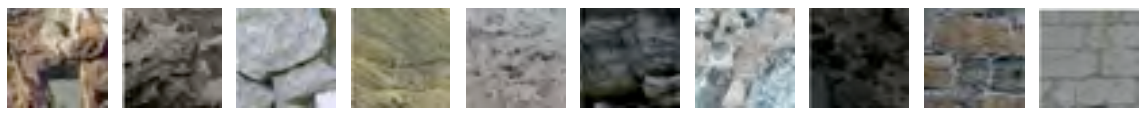

Figura 3. Muestras de regiones de imágenes correspondientes a dos palabras visuales de un vocabulario de 300 palabras. Podemos considerar que ambas palabras describen un contenido común; textura rocosa no homogénea, y en este sentido representan una sinonimia. Además, vemos que dentro de una misma palabra hay regiones que representan contenidos distintos, en unos casos el contenido es roca y en otros es muro, por tanto podríamos considerarlas polisémicas.

Para solventar en parte los inconvenientes anteriores, utilizaremos el análisis probabilístico de aspectos latentes (PLSA), una metodología original de la minería de textos (Hofmann, 2001).

Las aplicaciones del PLSA en el análisis estadístico de textos están orientadas a descubrir automáticamente los temas tratados en un 


\section{$8 \quad$ Rosado et al. - Intersecciones semánticas}

documento, tomando como punto de partida la representación BOW de documentos.

La extensión del PLSA hacia el análisis de imágenes pasa por considerar las imágenes como documentos con un vocabulario visual establecido a partir de un proceso de cuantización como se señala en el anexo B.

El PLSA detectará en las imágenes categorías de objetos, patrones formales, de modo que una imagen que contiene varias tipos de objetos se modela como una mezcla de temas (Fig. 4).

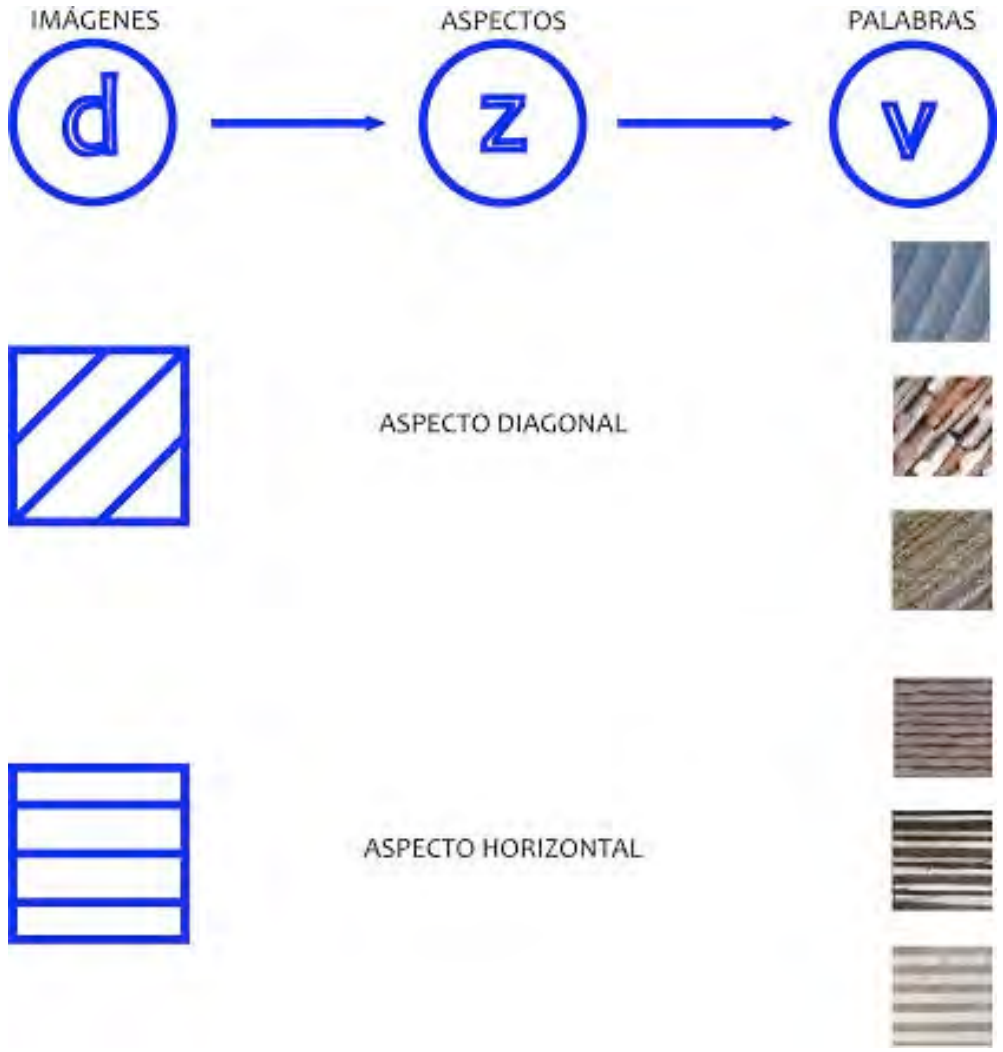

Figura 4. El método PLSA captura la co-ocurrencia de palabras visuales entre imágenes. 
El método PLSA está descrito de forma más exhaustiva en el anexo C.

A partir de esta metodología nos ha sido posible analizar la colección de imágenes y encontrar aspectos subyacentes mediante los cuales catalogar toda la colección y también contrastar dichos aspectos o patrones con los propuestos por el autor.

\section{Implementación}

El desarrollo se ha llevado a cabo mediante scripts escritos en MATLAB, versión 2013a (The MathWorks) (8.1.0.604). Los descriptores SIFT y el vocabulario de palabras visuales se han implementado mediante funciones disponibles en la biblioteca de código abierto VLFeat, versión 0.9.16 (Vedaldi \& Fulkerson, 2008). El PLSA ha sido implementado mediante funciones desarrolladas por los propios autores.

\section{Resultados}

La muestra inicial de nuestro estudio está compuesta por un total de 2.846 imágenes fotográficas capturadas por el propio artista. Se trata de un conjunto de imágenes tomadas, la mayoría, de exteriores y captadas desde diferentes ángulos y detalles (llegando a fragmentos y particularidades que se pueden captar como elementos abstractos y/o texturados). El tamaño de las imágenes del artista está entre 480 x 480 píxeles y 1400 x 1400 píxeles, pero el proceso reescala a 480 píxeles las imágenes que superan este tamaño para garantizar un tratamiento homogéneo de la colección de fotografías.

Con el total de imágenes se han realizado diversas pruebas del sistema fijando el número de aspectos a encontrar en 20,15, 10 y finalmente 5. Los resultados obtenidos con 5 aspectos mostraban que algunas tipologías no resultaban visibles, y con 20 y 15 aspectos las categorías quedaban poco representadas y algo dispersas. Por lo tanto, se decidió que la prueba más representativa para el total de imágenes analizadas era la que clasificaba la muestra en 10 aspectos.

Para la evaluación del resultado de esta agrupación se consideran prioritariamente imágenes tipificadas en un determinado aspecto con una probabilidad igual o superior a 0.6 . La forma en que se calcula dicha 
probabilidad está detallada en el anexo C de este trabajo. A pesar de esta consideración, en la discusión de cada aspecto se muestran las 3 imágenes con mayor probabilidad de estar asociadas a ese aspecto porque se considera que así el lector puede hacerse más fácilmente a la idea de la consistencia visual del mismo. Los casos que tienen alguna característica conflictiva o dudosa se comentan de forma más concreta para facilitar la comprensión.

Recordamos que la evaluación computacional se efectúa en escala de grises.

Ha resultado complicado asignar un descriptor textual a los aspectos hallados por el sistema, ya que no siempre es fácil y directo asociar el contenido visual del conjunto de imágenes de un aspecto con una descripción literal. Los aspectos hallados por la máquina no sólo deben entenderse compositivamente sino que se debe tener presente que se basan en encontrar co-ocurrencias de palabras visuales. A modo de ejemplo aclaratorio, este método sería capaz de detectar y agrupar en el mismo aspecto las imágenes que contengan un rostro, por la co-ocurrencia de las palabras visuales ojos, nariz, boca, etc.

A raíz del primer análisis de los resultados considerando 10 aspectos percibimos que la muestra consta de dos tipologías de imágenes muy marcadas; un tipo de fotografías que presenta un único aspecto muy destacado (las llamaremos imágenes de menos entropía) que son las que aparecen representadas en estas 10 primeras categorías, y otro que presenta varios aspectos asociados simultáneamente (las llamaremos imágenes de más entropía) y que no resulta visible en este primer análisis.

Para poder distinguir y tratar separadamente estas dos tipologías hemos utilizado el índice de entropía de Shannon (Cover \& Thomas, 2006).

La metodología PLSA (véase anexo C) proporciona una distribución de probabilidad de los aspectos en las imágenes. Esto es, para una imagen dada $d$, tenemos un vector de probabilidades:

$$
\left(p\left(z_{1} / d\right), . p\left(z_{2} / d\right), \ldots, p\left(z_{K} / d\right)\right)
$$

De donde, podemos calcular el índice de Entropía de Shannon de la imagen $d$, mediante: 


$$
H(d)=-\sum_{i=1}^{K} p\left(z_{i} / d\right) \log \left(p\left(z_{i} / d\right)\right.
$$

De esta manera una imagen que esté asociada a un único aspecto, es decir, una imagen con vector de probabilidades con todo ceros excepto un uno, su valor de entropía será mínimo e igual a $\mathrm{H}(\mathrm{d})=0$, contrariamente, una imagen que esté asociada por igual a todos los aspectos, es decir, con vector de probabilidades con 1/10 en cada componente, su valor de entropía será máximo e igual a $\mathrm{H}(\mathrm{d})=2.3026$.

Los rangos de entropía teóricos respecto a 10 aspectos irían de 0 a 2.3026. Los observados en nuestra muestra van de prácticamente 0 a 2,17. Las imágenes que tienen una entropía elevada son aquellas que el procedimiento ha asociado de manera equiprobable a cada uno de los aspectos.

De esta forma se decide seleccionar del total de la muestra las imágenes con un valor de entropía superior a 1,4 y repetir de nuevo la búsqueda de aspectos en este nuevo conjunto formado por 1.482 imágenes. Se repite de nuevo todo el proceso generando los descriptores locales, el vocabulario visual y se intenta así que el sistema sea capaz de establecer nuevas relaciones entre imágenes visualmente más complejas dando lugar a nuevos aspectos latentes distintos de las 10 primeros. La prueba resulta un éxito y se generan otro conjunto distinto de 10 aspectos sobre la nueva muestra. En total el sistema es capaz de categorizar en 20 grupos el total de imágenes analizadas y estos son los resultados que pasaremos a discutir en el resto del apartado.

A continuación se muestra una selección de las categorías de imágenes menos entrópicas y más entrópicas acompañadas por los respectivos histogramas de aspectos, numerados del 1 al 10 en el eje de abscisas y en el eje de ordenadas se indica la probabilidad asociada a cada aspecto.

En el caso de las imágenes de la categoría menos entrópica, se observa que la probabilidad se concentra mayoritariamente en un aspecto (Fig. 5). 
12 Rosado et al. - Intersecciones semánticas

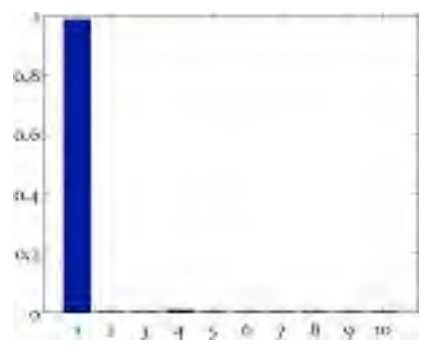

Figura 5. Histograma de una imagen de la categoría menos entrópica.

En el caso de las imágenes de la categoría más entrópica la distribución de probabilidad se reparte entre diversos aspectos (Fig. 6).

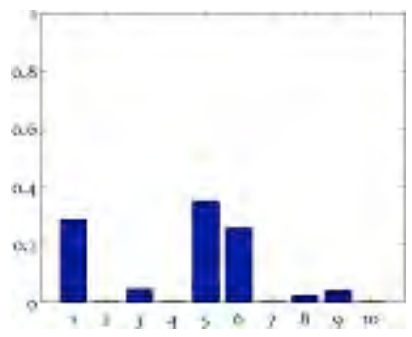

Figura 6. Histograma de una imagen de la categoría más entrópica. 
Imágenes e histogramas de las imágenes menos entrópicas:
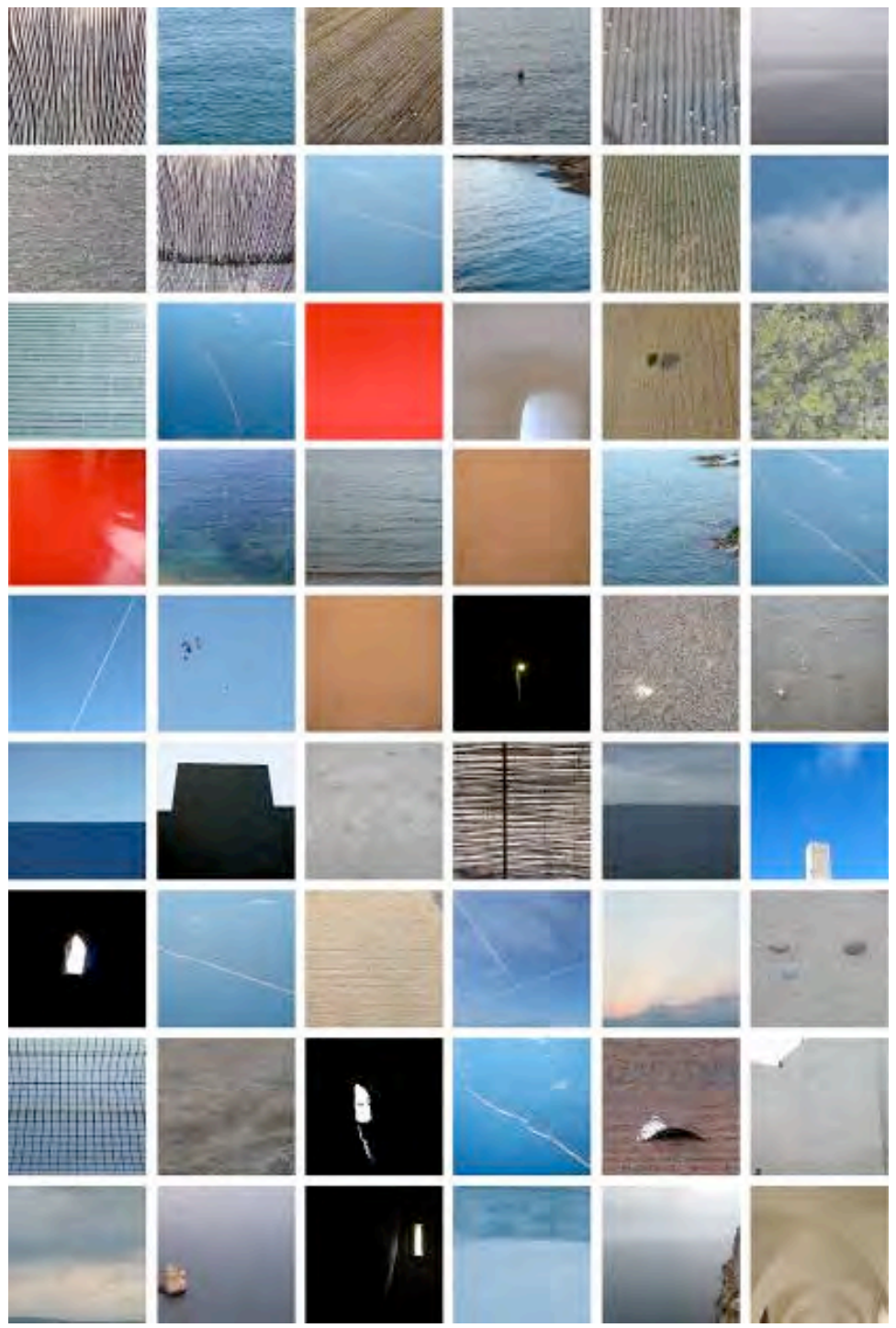

Figura 7. Conjunto de imágenes de la categoría menos entrópica. 
14 Rosado et al. - Intersecciones semánticas
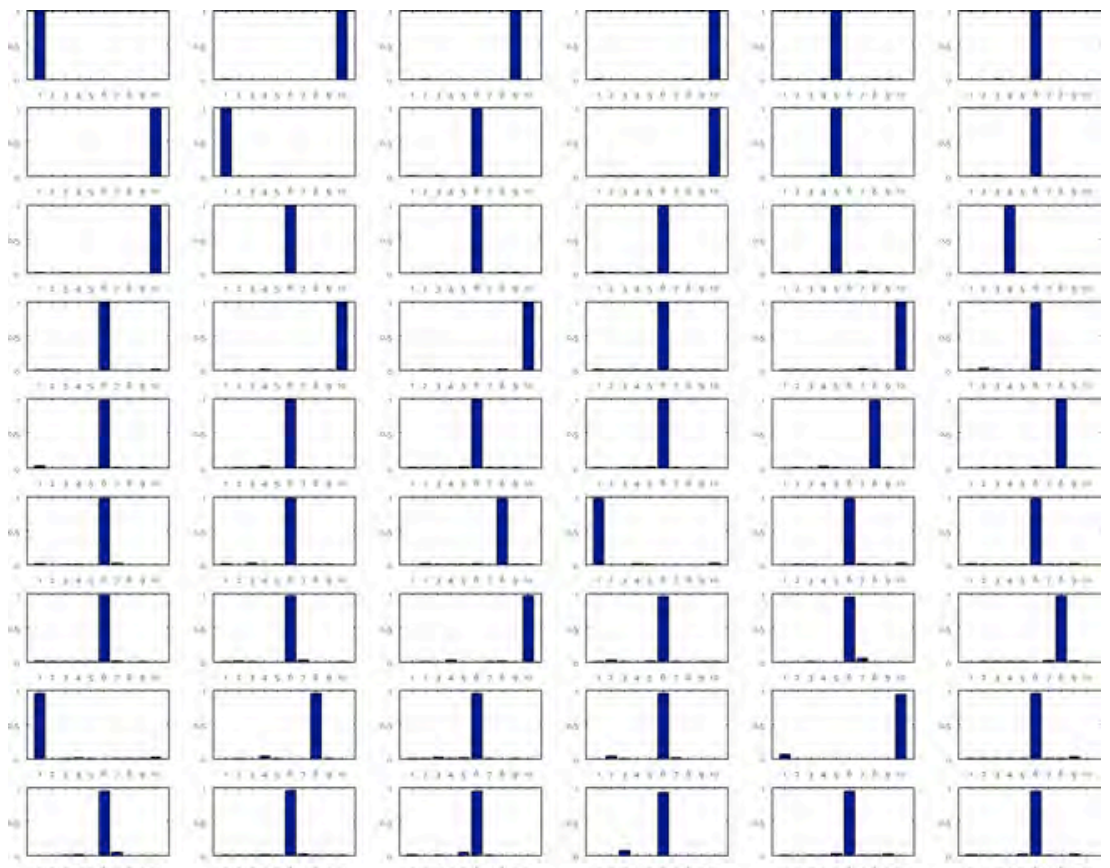

Figura 8. Conjunto de histogramas de las imágenes de la categoría menos entrópica. 
Imágenes e histogramas de las imágenes más entrópicas:
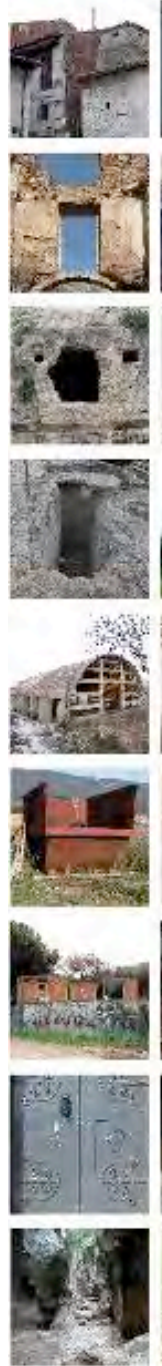
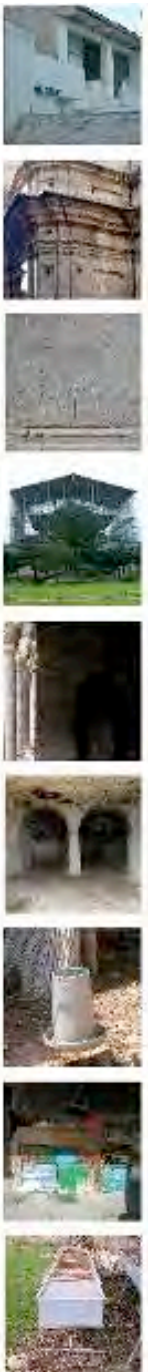
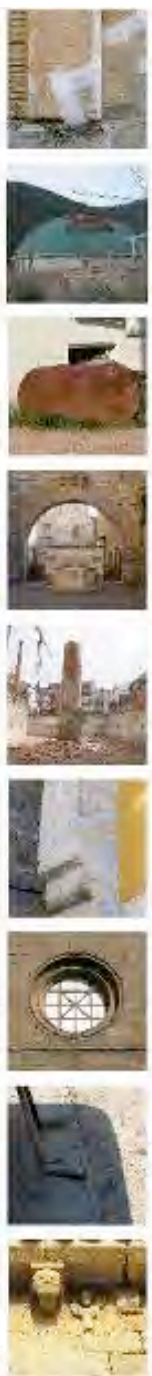
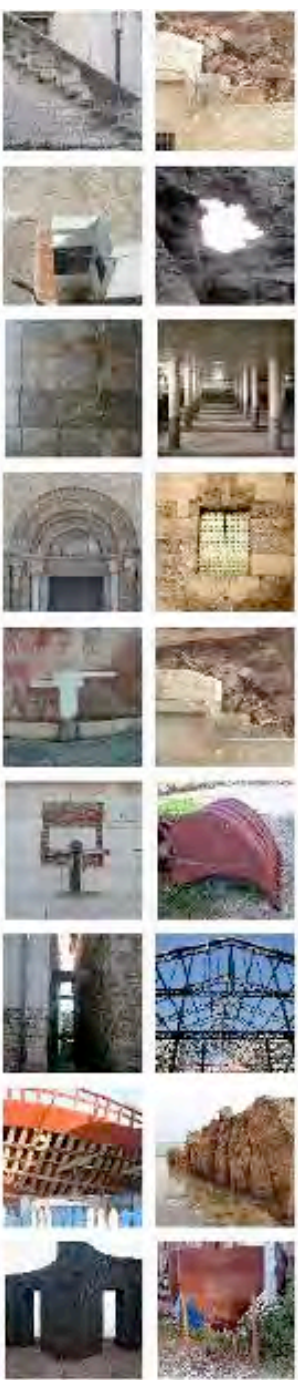
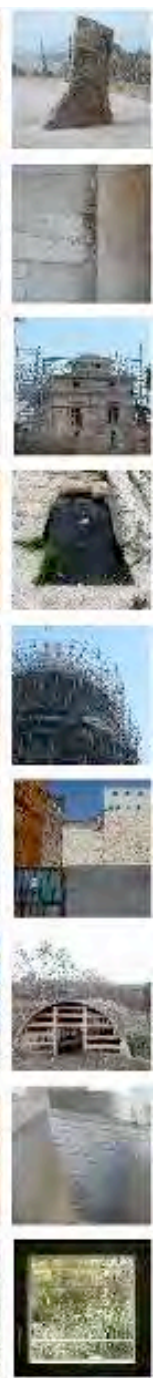

Figura 9. Conjunto de imágenes de la categoría más entrópica. 

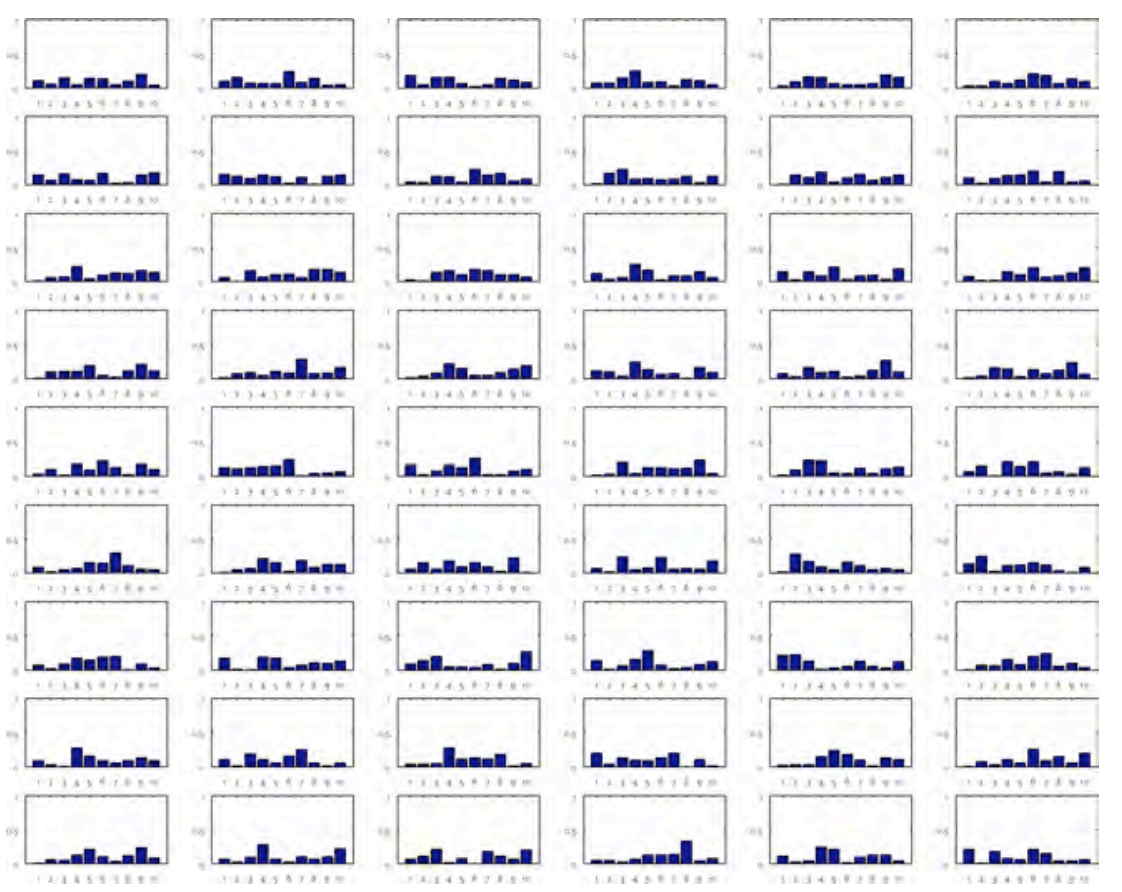

Figura 10. Conjunto de histogramas de las imágenes de la categoría más entrópica.

\section{Aspectos de imágenes menos entrópicas}

A partir de ahora los aspectos pertenecientes a esta categoría de imágenes menos entrópicas los nombraremos abreviados como LE (Low entropy).

1. Aspecto-LE1: Líneas Finas Definidas. El aspecto-LE1 Líneas Finas Definidas agrupa un conjunto de imágenes que contienen trazos lineales en las que predomina una dirección, que puede ser horizontal, vertical o ambos (Fig. 11). 

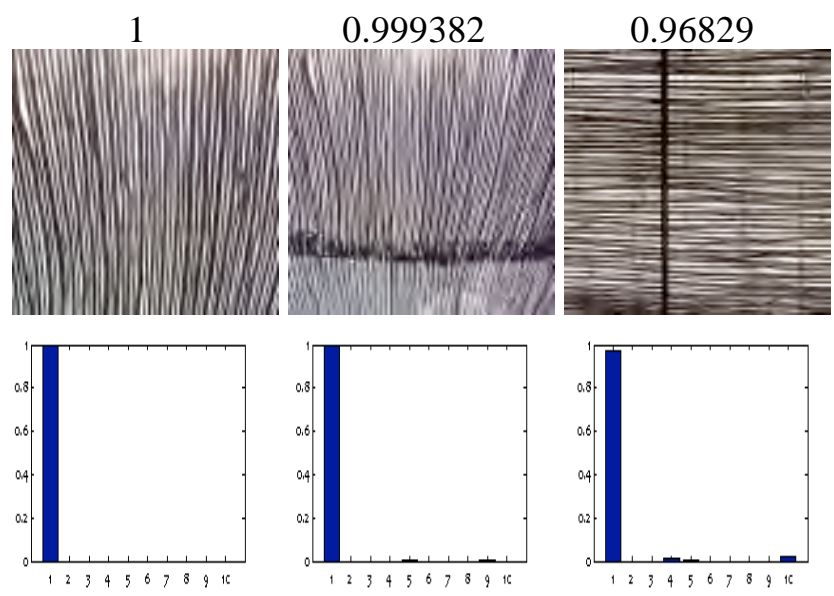

Figura 11. Imágenes tipificadas en el Aspecto-LE1 con mayor probabilidad y los histogramas de aspectos correspondientes.

Vemos que en el histograma de la tercera imagen aumenta ligeramente la probabilidad del aspecto-LE10 Horizontal Vibrante. Para clarificar un poco este aspecto y determinar la importancia de la verticalidad hemos girado al tercera imagen $90^{\circ}$ a la izquierda y hemos vuelto a comprobar el aspecto mayoritario (Fig. 12). El resultado se muestra a continuación:
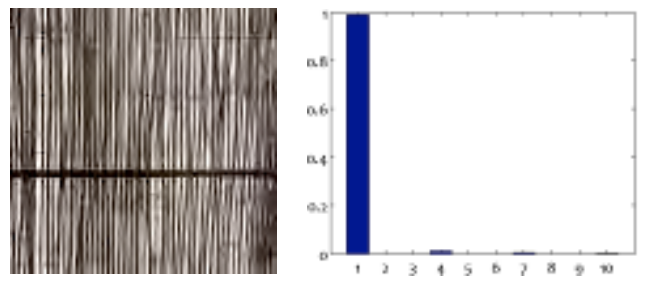

Figura 12. Tercera imagen de la Fig. 11 girada $90^{\circ}$ a la izquierda y el histograma de aspectos correspondiente.

Se puede concluir que la verticalidad no es determinante para este aspecto. 
2. Aspecto-LE2: Diagonal Descendente. El aspecto-LE2 Diagonal Descendente agrupa las imágenes en las que predomina básicamente una direccionalidad de bajada desde el ángulo superior izquierdo al ángulo inferior derecho (Fig. 13).
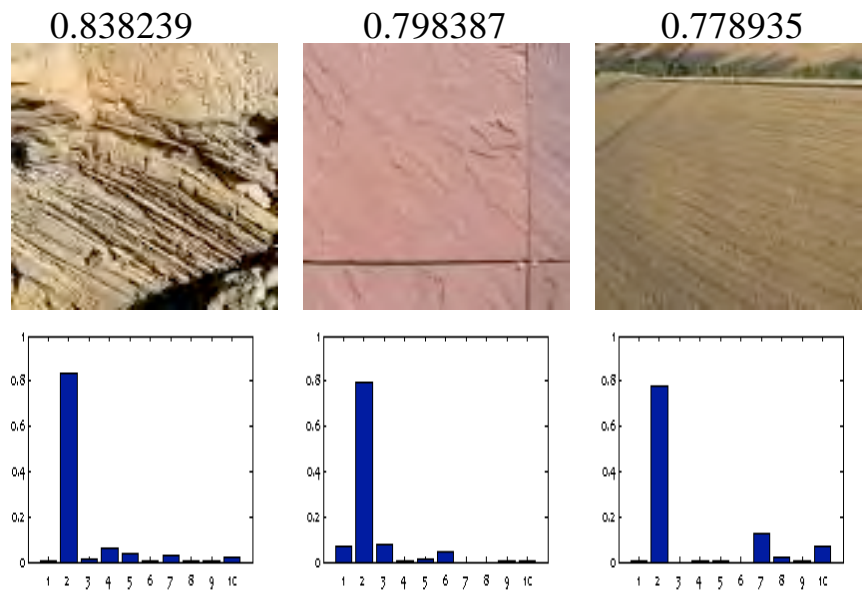

Figura 13. Imágenes tipificadas en el Aspecto-LE2 con mayor probabilidad y los histogramas de aspectos correspondientes.

También observamos en la primera imagen componentes del aspectoLE4 Textura Heterogénea, que se corresponderían con la zona superior de la imagen. En la segunda imagen vemos una componente perteneciente al aspecto-LE1 Líneas Finas Definidas y en la tercera imagen componentes de los aspectos-LE7 Horizontal Estrecha y aspecto-LE10 Horizontal Vibrante.

3. Aspecto-LE3: Horizontal Amplia. El aspecto-LE3 Horizontal Amplia reúne un conjunto de imágenes caracterizadas por presentar una bandas horizontales anchas muy marcadas (Fig. 14).

Se puede destacar el componente de aspecto-LE10 Horizontal Vibrante de la primera imagen. En la segunda imagen las componentes de aspectoLE1 Líneas Finas Definidas y aspecto-LE9 Diagonal Ascendente y el aspecto-LE1 Líneas Definidas de la tercera imagen. 

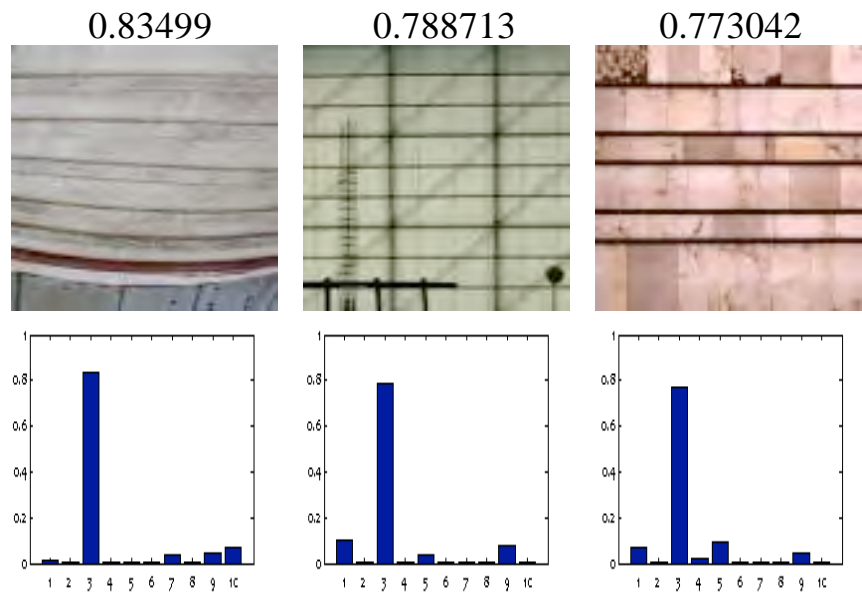

Figura 14. Imágenes tipificadas en el Aspecto-LE3 con mayor probabilidad y los histogramas de aspectos correspondientes.

4. Aspecto-LE4: Textura Heterogénea. El aspecto-LE4 Textura Heterogénea presenta una agrupación bastante sólida, sobre todo teniendo en cuenta la percepción en escala de grises de la computadora (Fig. 15).
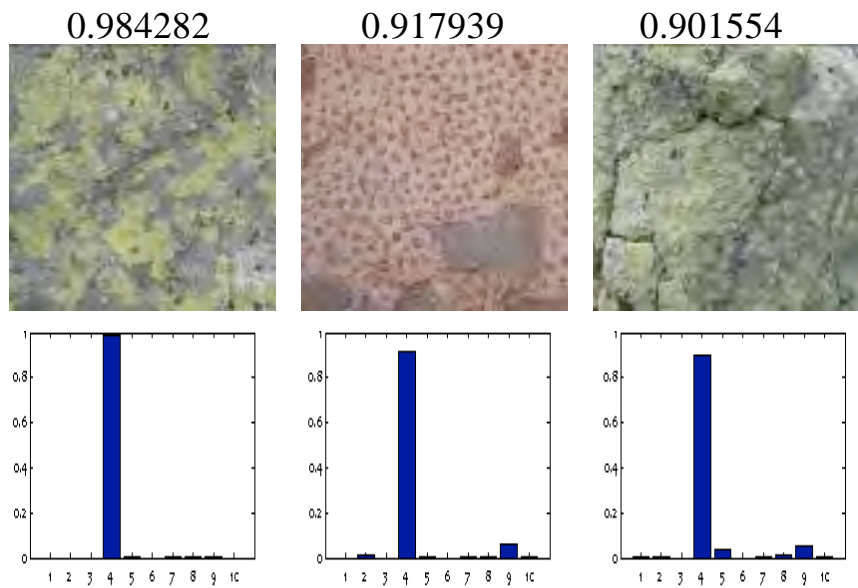

Figura 15. Imágenes tipificadas en el Aspecto-LE4 con mayor probabilidad y los histogramas de aspectos correspondientes. 
5. Aspecto-LE5: Vertical Irregular Texturada. El aspecto-LE5 Vertical Irregular Texturada es un aspecto muy compacto y fácilmente identificable (Fig. 16).
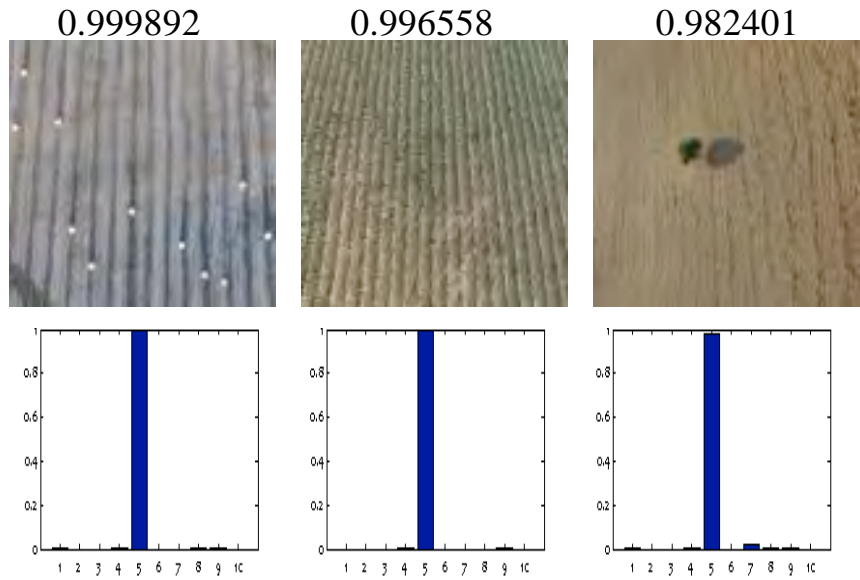

Figura 16. Imágenes tipificadas en el Aspecto-LE5 con mayor probabilidad y los histogramas de aspectos correspondientes.

6. Aspecto-LE6: Liso. Aspecto-LE6 Liso, carente de textura. Para valorar este aspecto en su justa medida hemos de recordar que la máquina sólo considera la escala de grises (Fig. 17). 

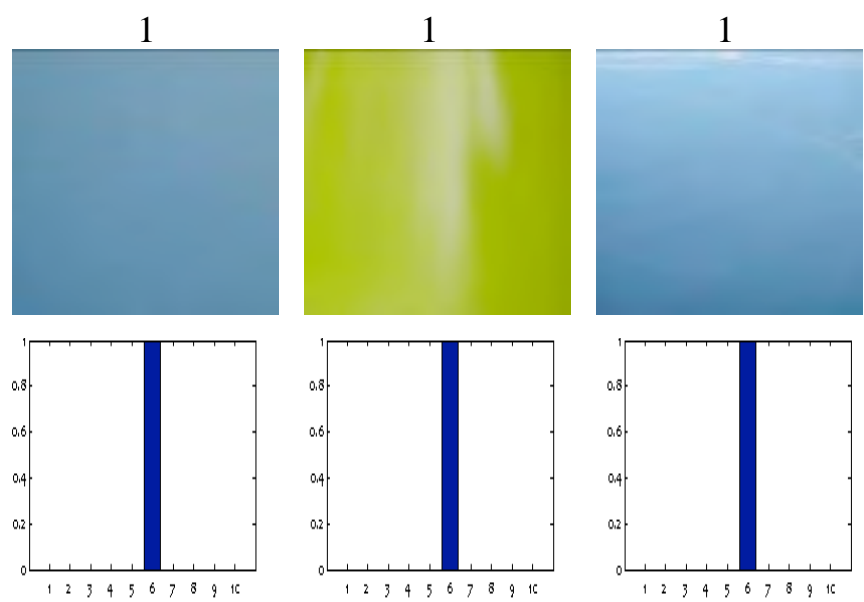

Figura 17. Imágenes tipificadas en el Aspecto-LE6 con mayor probabilidad y los histogramas de aspectos correspondientes.

7. Aspecto-LE7: Horizontal Estrecha. El aspecto-LE7 Horizontal Estrecha presenta unas bandas horizontales más comprimidas que en el aspecto-LE3 Horizontal Amplia descrito con anterioridad (Fig. 18).
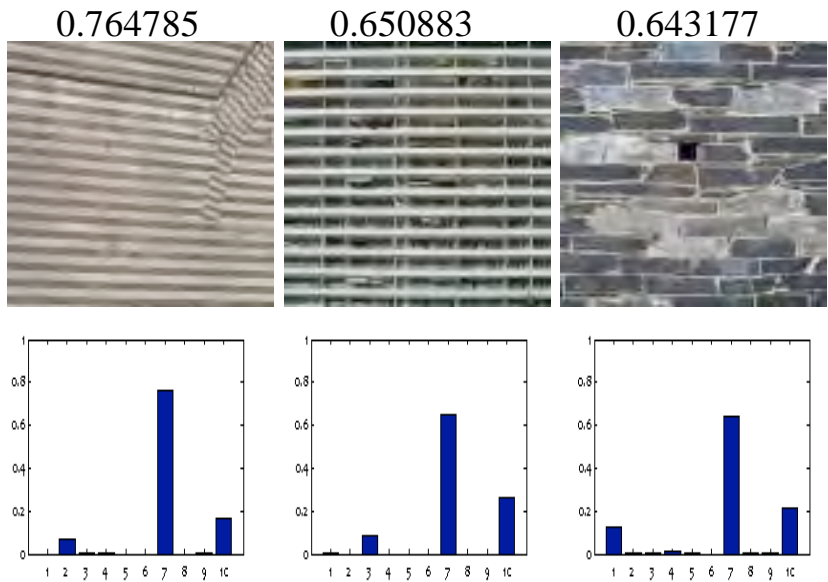

Figura 18. Imágenes tipificadas en el Aspecto-LE7 con mayor probabilidad y los histogramas de aspectos correspondientes. 
Cabe destacar la importante componente en las 3 imágenes del aspectoLE10 Horizontal Vibrante, que por el contrario no está presente en las imágenes del aspecto-LE3 Horizontal Amplia, ya que aquellas presentan líneas horizontales muy bien definidas.

8. Aspecto-LE8: Textura Homogénea. El aspecto-LE8 Textura Homogénea es también compacto y definido, parecido al aspecto-LE6 Liso aunque es ligeramente rugoso. Observamos pequeños elementos que son los responsables de la disminución de la probabilidad (Fig. 19).
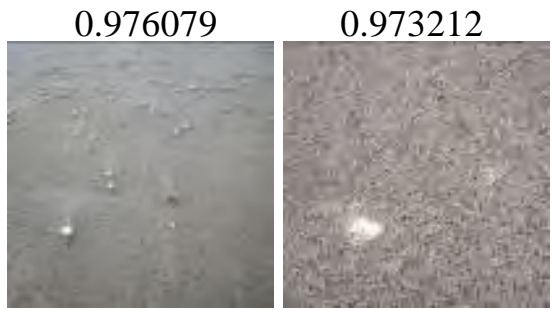

0.972526
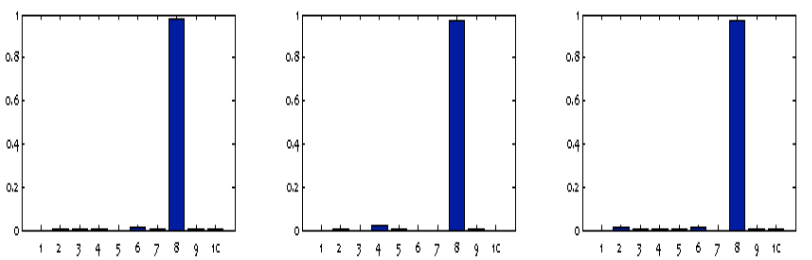

Figura 19. Imágenes tipificadas en el Aspecto-LE8 con mayor probabilidad y los histogramas de aspectos correspondientes.

9. Aspecto-LE9: Diagonal Ascendente. El aspecto-LE9 Diagonal Ascendente agrupa las imágenes en las que predomina básicamente una direccionalidad de subida desde el ángulo inferior izquierdo al ángulo superior derecho (Fig. 20). 

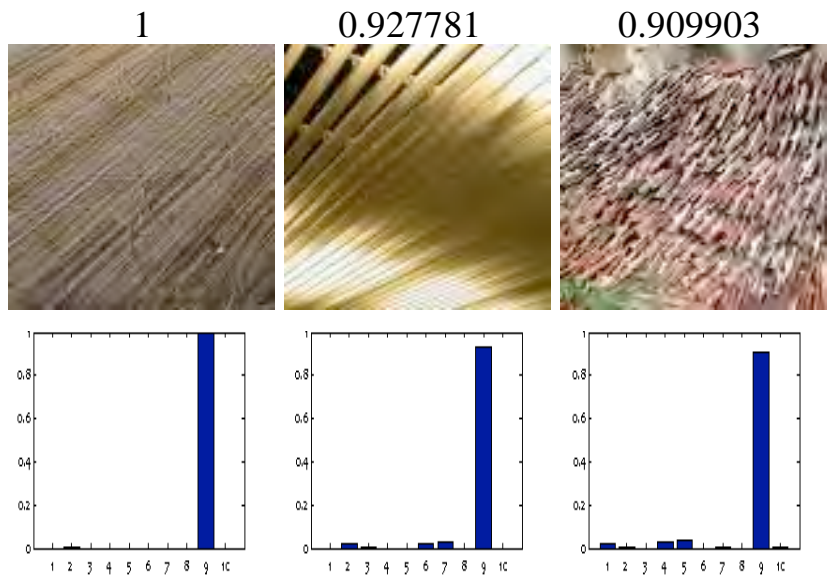

Figura 20. Imágenes tipificadas en el Aspecto-LE9 con mayor probabilidad y los histogramas de aspectos correspondientes.

Es interesante destacar el modo en que la probabilidad disminuye a la vez que la diagonal es menos perfecta y cómo aumentan en la tercera imagen el aspecto-LE4 Textura Heterogénea que se correspondería con las zonas superior e inferior de la imagen, y el aumento también de la probabilidad del aspecto-LE5 Vertical Irregular Texturada que pertenece a la parte derecha de la imagen en donde la diagonal ya es prácticamente una vertical.

10. Aspecto-LE10: Horizontal Vibrante. Este aspecto-LE10 Horizontal Vibrante presenta una textura de marcada horizontalidad de aspecto más bien rugoso y vibrante (Fig. 21). 

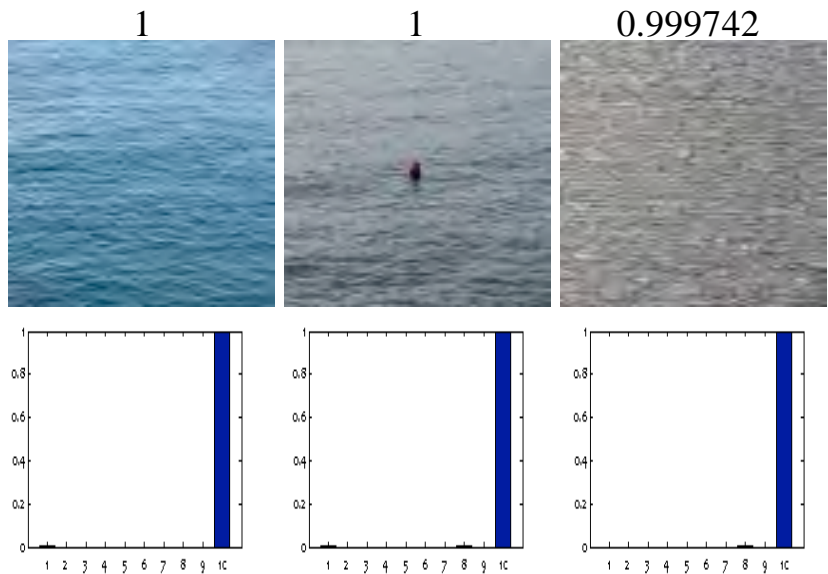

Figura 21. Imágenes tipificadas en el Aspecto-LE10 con mayor probabilidad y los histogramas correspondientes.

\section{Aspectos de imágenes más entrópicas}

La complejidad de esta categoría de imágenes es mucho mayor que la de imágenes poco entrópicas y el análisis de los resultados es complicado dado que ya no predomina de forma muy marcada un solo aspecto, sino que las imágenes están constituidas por multitud de ellos. A partir de ahora los aspectos pertenecientes a esta categoría de imágenes más entrópicas los nombraremos abreviados como HE (High entropy).

1. Aspecto-HE1: Figura-Fondo. Denominamos aspecto-HE1 FiguraFondo al conjunto de imágenes en las que predomina una figura central en primer plano sobre un fondo bastante homogéneo. A pesar de tener probabilidades moderadamente superiores a 0,6 , es un aspecto difícil de interpretar (Fig. 22). 

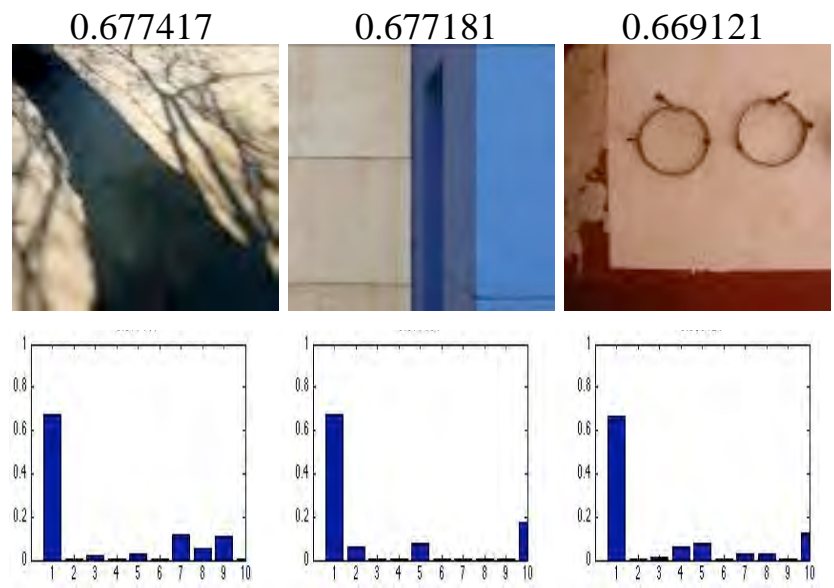

Figura 22. Imágenes tipificadas en el Aspecto-HE1 con mayor probabilidad y los histogramas de aspectos correspondientes.

2. Aspecto-HE2: Textura Homogénea Bipolar. Este aspecto pasado a escala de grises presenta dos tonalidades marcadas que dividen la imagen en dos secciones o polos tonales y/o estructurales de composición (Fig. 23).
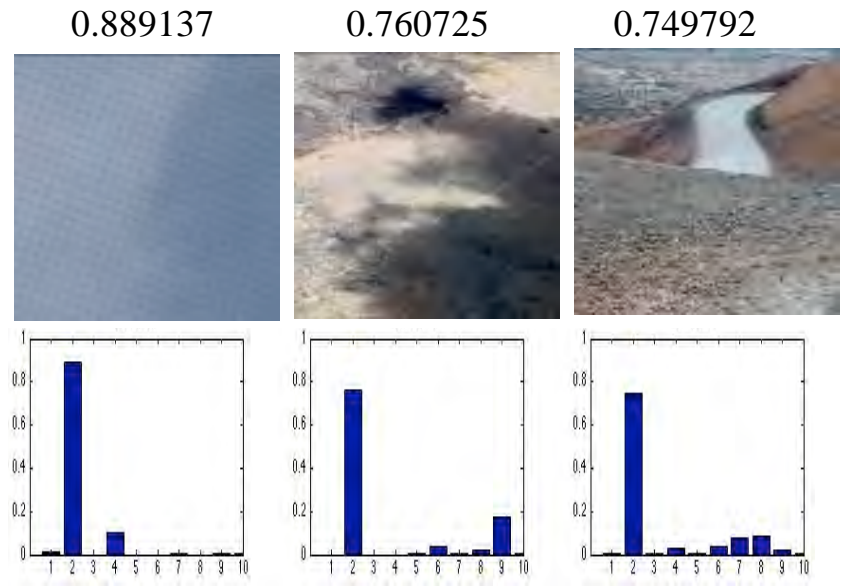

Figura 23. Imágenes tipificadas en el Aspecto-HE2 con mayor probabilidad y los histogramas de aspectos correspondientes. 
A destacar en la primera imagen la componente del aspecto-HE4 Imagen Bipartita, en la segunda imagen el aspecto-HE9 Estructura Heterogénea Contrastada y en la tercera imagen la componente del aspectoHE8 Planos Interseccionados.

3. Aspecto-HE3: Estructuras Verticales. En el aspecto-HE3 Estructuras Verticales se notan claramente unas franjas o columnas verticales en algún caso con una pequeña inclinación. Especialmente en las primeras imágenes se percibe un cierto predominio central en la composición (Fig. 24).
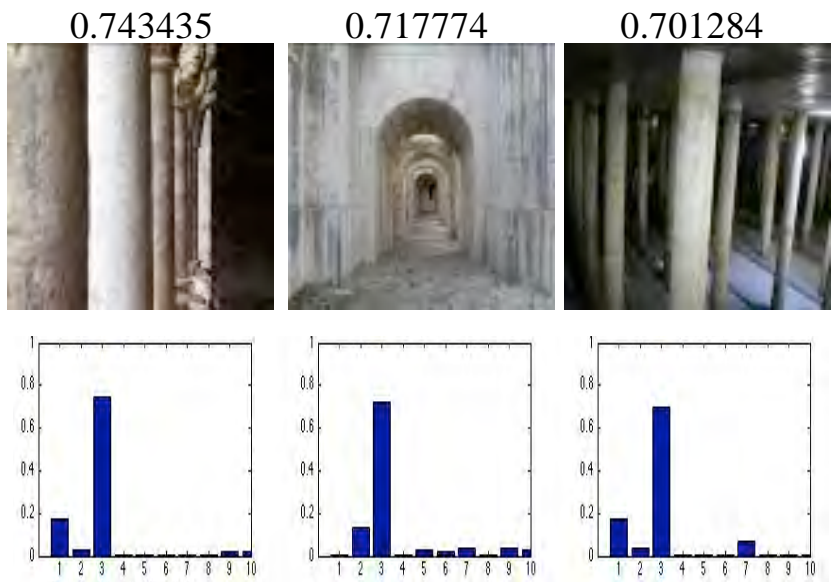

Figura 24. Imágenes tipificadas en el Aspecto-HE3 con mayor probabilidad y los histogramas de aspectos correspondientes.

En la primera y tercera foto aparece una componente importante del aspecto-HE1 Figura-Fondo posiblemente debido a las columnas que aparecen en el primer término.

4. Aspecto-HE4: Imagen Bipartita. El aspecto-HE4 Imagen Bipartita presenta claramente dos tipologías de textura dentro de la misma composición que suele coincidir con un paisaje de horizonte marcado (Fig. 25). 

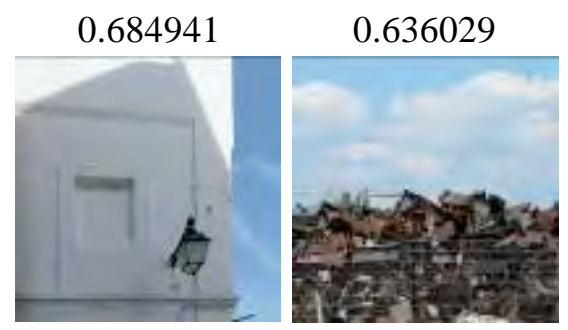

$$
0.625617
$$
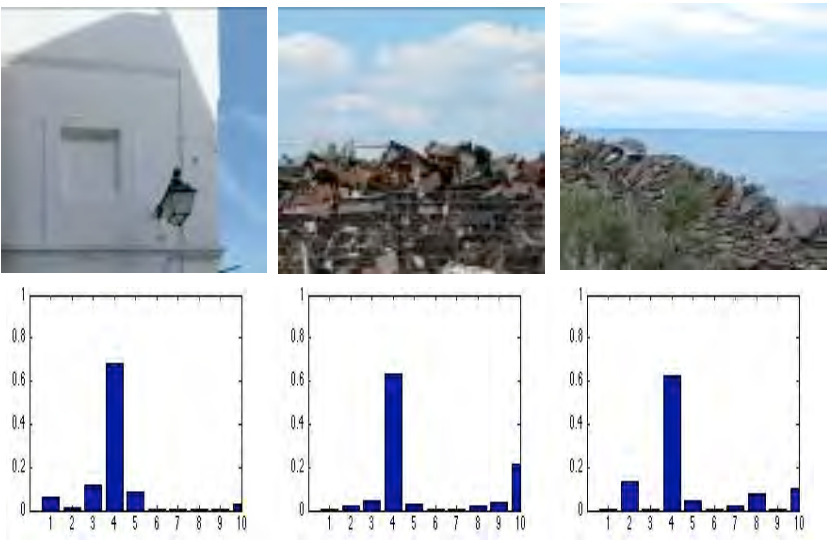

Fig. 25. Imágenes tipificadas en el Aspecto-HE4 con mayor probabilidad y los histogramas de aspectos correspondientes.

Nótese en la primera imagen las componentes de aspecto-HE3 Estructuras Verticales y aspecto-HE5 Cuadrícula.

5. Aspecto-HE5: Cuadrícula. Aspecto claramente perceptible en el que se puede visualizar perfectamente la estructura cuadricular de la composición (Fig. 26).

Cabe destacar cómo a medida que disminuye la probabilidad del aspecto-HE5 Cuadrícula, los cuadraditos son menos perfectos y a la vez aumenta la probabilidad del aspecto-HE7 Agrupaciones Rocosas. 

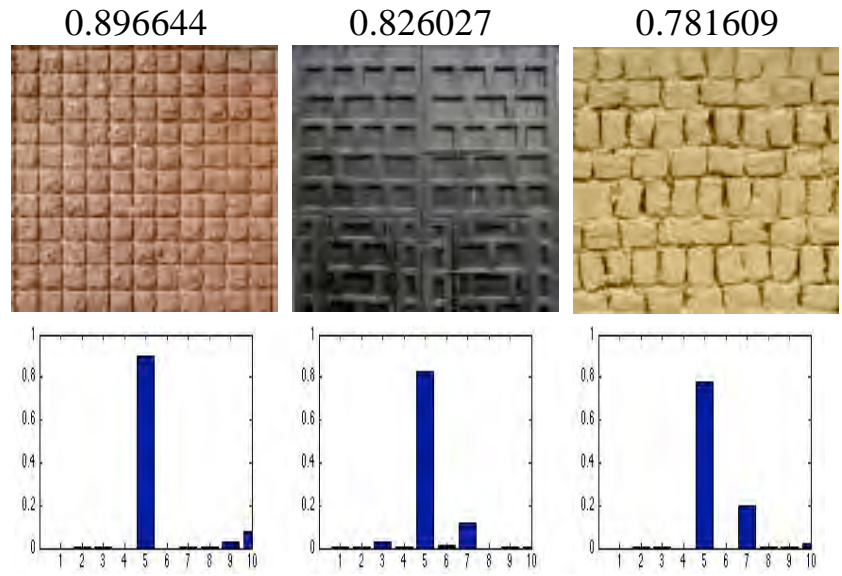

Figura 26. Imágenes tipificadas en el Aspecto-HE5 con mayor probabilidad y los histogramas de aspectos correspondientes.

6. Aspecto-HE6: Estructuras Horizontales. Este aspecto agrupa imágenes con una marcada tendencia a la horizontalidad en las estructuras predominantes. A diferencia del aspecto-LE3 Horizontal Amplia definido en las imágenes de baja entropía, éste no presenta únicamente líneas, sino más bien estructuras en forma de bandas (Fig. 27).

Es destacable la presencia en las 3 imágenes del aspecto-HE2 Textura Homogénea Bipolar (las 3 imágenes están compuestas básicamente por 2 texturas distintas) y la aparición en la segunda y tercera imágenes del aspecto-HE3 Estructuras Verticales debido a la componente vertical de los ladrillos. 

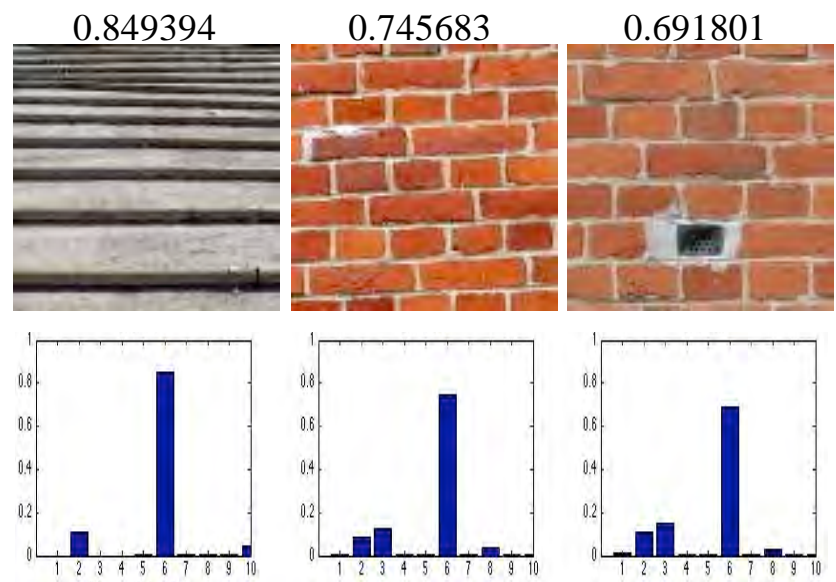

Figura 27. Imágenes tipificadas en el Aspecto-HE6 con mayor probabilidad y los histogramas de aspectos correspondientes.

7. Aspectos-HE7: Agrupaciones Rocosas. Bajo este aspecto percibimos como elemento común, en la mayoría de las imágenes, la piedra. Algunas presentan guijarros y otras restos de muros. Muchas de ellas están dispuestas por la mano del hombre en forma de muro o presentan un cierto orden natural que las caracteriza (Fig. 28).
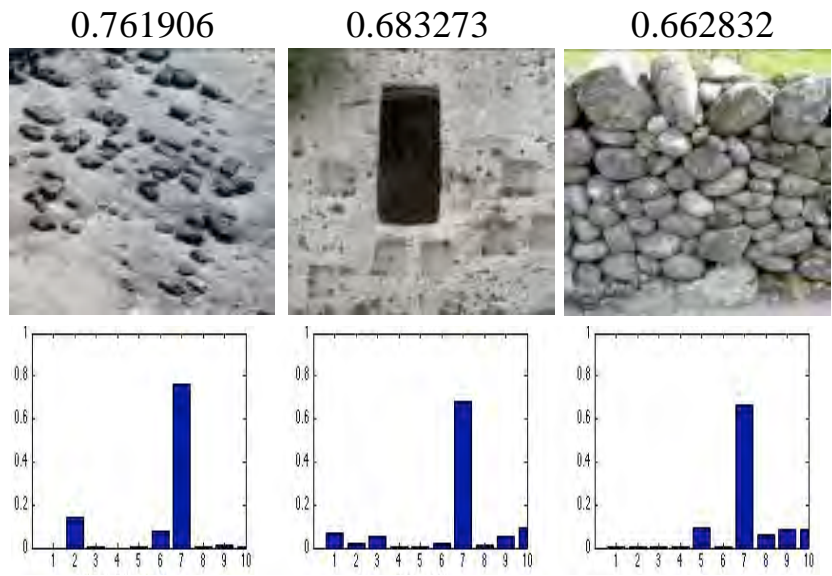

Figura 28. Imágenes tipificadas en el aspecto-HE7 con mayor probabilidad y los histogramas de aspectos correspondientes. 
En la segunda imagen aparece el aspecto-HE1 Figura-Fondo, causado por la ventana en el primer término. Es interesante comparar la distribución de los aspectos HE5 Cuadrícula y HE7 Agrupaciones Rocosas de la tercera imagen de este aspecto con respecto a la tercera imagen del aspecto HE5 Cuadrícula. Tratándose en las dos imágenes de una agrupación de piedras, el sistema detecta la sutileza del distinto tipo de ordenamiento, más cuadriculado en el primer caso (Fig. 29).
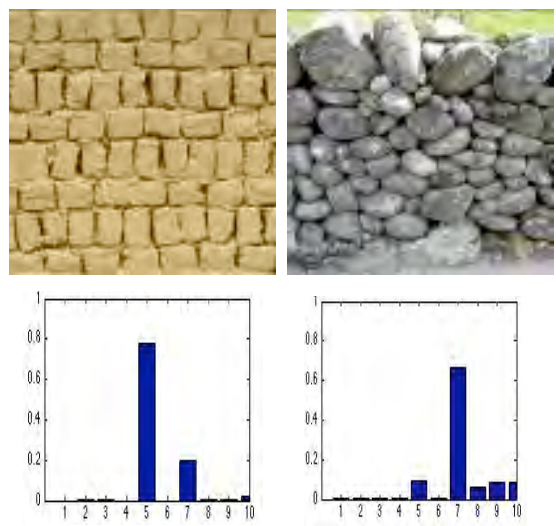

Figura 29. Primera imagen tipificada en el aspecto-HE5 y segunda imagen tipificada en el aspecto-HE7 y sus histogramas de aspectos correspondientes.

8. Aspectos-HE8: Líneas y Planos Inter-seccionados. En el aspecto-HE Líneas y Planos Inter-seccionados se recogen un conjunto de imágenes en las que predominan diferentes direccionalidades superpuestas en un mismo plano, que generalmente llenan todo el espacio (Fig. 30).

Destacable la componente de aspecto-HE6 Estructuras Horizontales de la imagen tercera, que puede explicarse si nos fijamos en las zonas sombreadas que crean unas bandas con tendencia horizontal. 

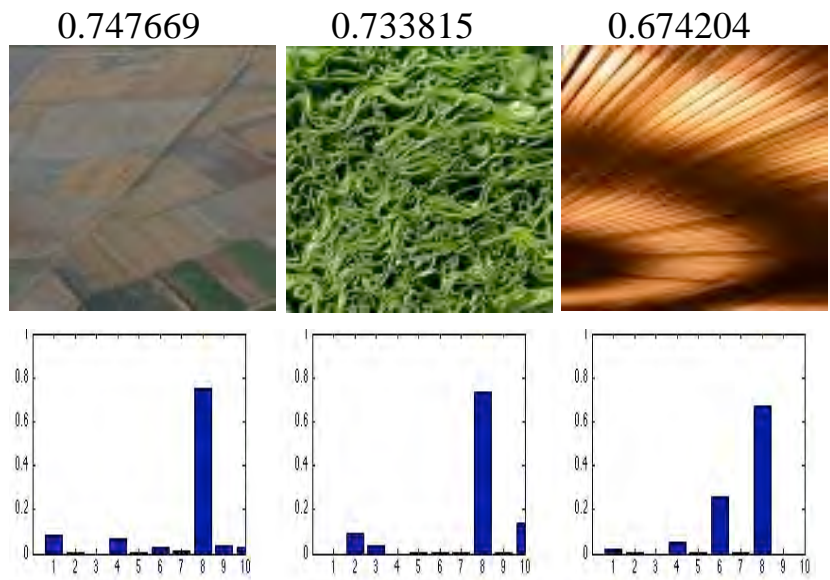

Figura 30. Imágenes tipificadas en el aspecto-HE8 con mayor probabilidad y los histogramas de aspectos correspondientes.

9. Aspecto-HE9: Estructura Heterogénea Contrastada. Este aspecto es muy compacto y aglutina un conjunto de imágenes en las que predominan estructuras volumétricas conseguidas por un claroscuro muy contrastado (Fig. 31).
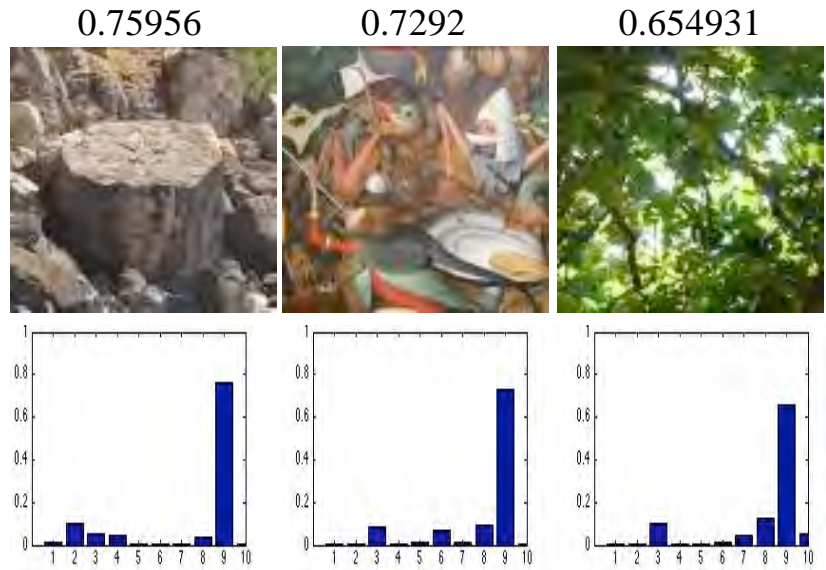

Figura 31. Imágenes tipificadas en el aspecto-HE9 con mayor probabilidad y los histogramas de aspectos correspondientes. 
10. Aspecto-HE10: Figura Con Fondo Texturado. Este conjunto de imágenes presenta recuerda mucho al aspecto-HE1 Figura-Fondo, con la variante de que el fondo no es liso, sino texturado (Fig. 32).
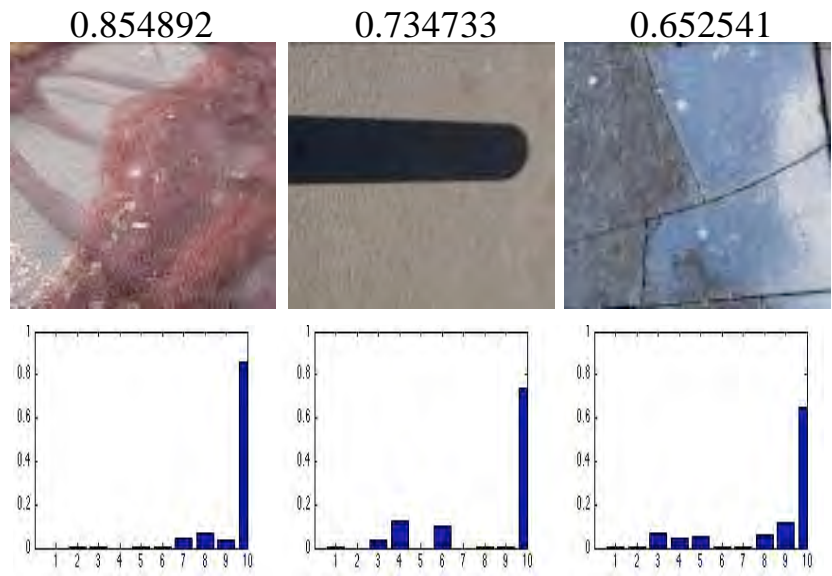

Figura 32. Imágenes tipificadas en el aspecto-HE10 con mayor probabilidad y los histogramas correspondientes.

Destacamos el componente de aspecto-HE4 Imagen Bipartita en la segunda imagen. Tampoco es un aspecto fácil de interpretar.

\section{Conclusiones y comentarios}

Es posible que algunos de los resultados expuestos anteriormente puedan parecer poco concluyentes para el lector no familiarizado con la visión artificial. Disponemos de la función HOG (histogram of oriented gradients) (Vedaldi \& Fulkerson, 2008) que descompone una imagen en pequeñas celdas cuadradas y calcula un histograma de orientación en cada celda. La utilizamos a continuación en (Fig. 33) para generar una versión pictórica de las imágenes y así poder tener una aproximación visual de cómo vería el sistema computacional estas imágenes, en escala de grises y con vectores de gradiente, de cara a facilitar la comprensión de los resultados. 

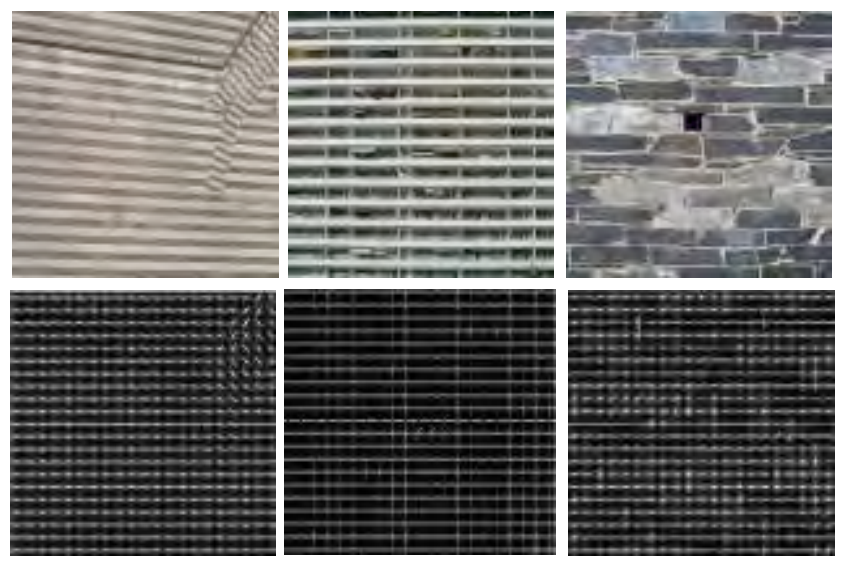

Figura 33. En la fila superior las 3 imágenes tipificadas en el aspecto-LE7 con mayor probabilidad y en la fila inferior las mismas imágenes procesadas con la función HOG.

En vista de las categorizaciones obtenidas podemos concluir que el sistema permitiría, dada una colección con gran cantidad de imágenes, realizar una importante preselección formal agrupándolas de forma más objetiva dado que la mirada artificial no está tan sujeta y condicionada como la percepción conceptual humana. El método de catalogación expuesto presentaría al autor nuevas relaciones, nuevos conjuntos difíciles de obviar, que podrían proporcionarle puntos de vista complementarios para futuros trabajos, en este sentido, el vocabulario personal del artista se vería enriquecido y más, conforme se vaya alimentando el sistema con nuevas imágenes. Todo esto será de gran ayuda en el proceso creativo, analítico, taxonómico y pedagógico de la obra.

Desde el punto de vista del espectador o del estudioso de la imagen, este tipo de sistemas puede ayudar a clarificar e interpretar, a hacer visibles matices de la imagen que de otra forma pasarían desapercibidos, y más en estos tiempos caracterizados por una saturación de imágenes, como nos apunta el artista visual Àlex Nogué (2013):

"L'omnipresència de les imatges a la vida moderna ens ha fet desenvolupar uns mecanismes perceptius capaços d'actuar amb gran 
rapidesa. Hem aprés a captar les imatges immediatament i, emprant un sistema que fa intervenir la nostra potent memòria visual, en poques fraccions de segon som capaços de discernir-ne algun significat. Això només indica que el que s'ha vist encaixa amb el que ja havia estat vist i que encara persisteix en l'arxiu visual personal, però no vol dir que realment hàgim vist la imatge"

No es la intención del presente trabajo abarcar la riqueza comunicacional de las obras del artista, tema muy complejo que estaría condicionado por múltiples factores como la psicología de la percepción estética y la relación que se establece entre la obra y el espectador, entre el que mira y el que es mirado (Hildebrand, 1988). Pero estamos convencidos de que estos sofisticados sistemas informáticos nos pueden ayudar a vislumbrar la cantidad y complejidad de procesos que lleva a cabo la mente del creador visual que persigue un objetivo estético, a la hora de decidir si una imagen pertenece o no a su vocabulario visual. Todo lo que pasa por su mente, la mayor parte procesos inconscientes, y le llevan a la decisión de capturar o no una instantánea.

Para concluir, citaremos a Joan Fontcuberta (2010), esperando haber contribuido modestamente a responder en parte a su pregunta:

"Tanto desde la filosofía del arte como desde la semiótica se ha producido un esfuerzo para diagnosticar los rasgos que en una imagen permiten identificar al objeto representado. ¿Se trata de patrones basados en una mímesis gráfica objetiva y universal o por el contrario dependen de sistemas de representación culturales y objetivos? Una multiplicidad de hipótesis ha dado respuesta a estas cuestiones que en el fondo vienen impregnadas de una incertidumbre más profunda: la que atañe a nuestros modelos de construcción de la realidad... ¿Seria hoy posible diseccionar el concepto de semejanza según un criterio de lógica matemática?"1

Consideramos que la metodología de visión artificial tiene la potencialidad necesaria para detectar algunos de los trazos semánticos subyacentes en un gran conjunto de imágenes, incluso con significados muy abstractos como las mostradas en este trabajo, y sería capaz así de ayudar al artista a organizar su trabajo. Claro está que él siempre tendrá la última 
palabra a la hora de decidir cuales de estos significados y sus combinaciones tienen el suficiente interés para materializarse en una obra de arte.

También en el ámbito académico este sistema puede ser de gran utilidad como recurso pedagógico para la mejora de la enseñanza artística. El docente y el discente pueden disponer de una herramienta de trabajo que les permita establecer unos criterios de análisis formales, planteados de manera objetiva, en un conjunto de imágenes o de obras. Este recurso aumentaría la posibilidad de conectar y de establecer relaciones entre imágenes de distintos estilos, épocas, temáticas, etc., ya que se convierte en un mecanismo autónomo y no dependiente de los hechos habitualmente tratados de carácter más historicista.

\section{Agradecimientos}

Mostramos nuestro profundo agradecimiento al Dr. M. Planas ya que sin su colaboración este trabajo no podría haberse realizado, al facilitarnos el acceso a su colección de imágenes y mostrarse en todo momento abierto y generoso en sus comentarios sobre los resultados, aportando valiosas sugerencias.

También agradecemos al Vicerrectorado de Política Docente y Científica de la Universidad de Barcelona 2011 - 2012, el soporte que nos ha prestado con la Ayuda para la realización de proyectos de investigación pre competitivos en Ciencias Sociales y Humanas (APPCSHUM).

\section{Notas}

${ }^{1}$ Fontcuberta, J. (2010). p. 83.

${ }^{2}$ Nogué, A. ((2013). p.158.

\section{Referencias}

Arnheim, R. (1983). Arte y percepción visual. Madrid: Alianza forma. 
Bosch, A., Zisserman, A. \& Muñoz, X. (2006). Scene classification via PLSA. In Proceedings of the European Conference on Computer Vision. Graz, Austria.

Cover, T.M. \& Thomas, J.A. (2006). Elements of Information Theory $\left(2^{\text {on }}\right.$ ed.). New Jersey: John Wiley \& Sons.

Dempster, A. P., Laird, N. M., \& Rubin, D. B. (1977). Maximum likelihood from incomplete data via the EM algorithm. J. Royal Statist. Soc. B, 39, $1-38$.

Enebral, J. (2009). Detección y asociación automática de puntos característicos para diferentes aplicaciones. Trabajo Final de Carrera. Escola Politècnica Superior de Castelldefels. Universitat Politècnica de Catalunya.

Fei-Fei, L. \& Perona, P. (2005). A Bayesian hierarchical model for learning natural scene categories. In Proc. CVPR. San Diego, CA, USA.

Fontcuberta, J. (2010). La cámara de pandora. La fotografi@ después de la fotografía. Barcelona: Gustavo Gili.

Grauman, K. \& Darrel, T. (2005). The pyramid match kernel: Discriminative classification with sets of image features. In Proceedings of IEEE International Conference on Computer Vision (ICCV). Beijing. Hildebrand, A. von (1988). El problema de la forma en la obra de arte. Madrid: Visor.

Hofmann, T. (2001). Unsupervised learning by probabilistic latent semantic analysis.. Machine Learning, 42,177-196.

Joachims, T. (1998). Text categorization with support vector machines: Learning with many relevant features. In Proceedings of the European Conference on Machine Learning. Springer-Verlag.

Lazebnik, S., Schmid, C. \& Ponce, J. (2006). Beyond Bags of Features: Spatial Pyramid Matching for Recognizing Natural Scene Categories. Computer Vision and Pattern Recognition, IEEE Computer Society Conference on Computer Vision and Pattern Recognition, 2, 2169-2178. doi.ieeecomputersociety.org/10.1109/CVPR.2006.68.

Lowe, D. G. (2004). Distinctive Image Features from Scale Invariant Keypoints. Int. Journal of Computer Vision, 60, 2, 91-110.

Nogué, A. (2013). Dibuixar un arbre / Drawing a tree. Barcelona: Comanegra. 
Planas, M. A. (2014). Miquel Planas. Recuperado de http://www.miquelplanas.eu

Quelhas, P., Monay, F., Odobez, J.-M., Gatica-Perez, D., Tuytelaars \& Van Gool, L. (2005). Modeling scenes with local descriptors and latent aspects. Proceedings of the Tenth IEEE International Conference on Computer Vision (ICCV'05), 1, 883-890. doi: 10.1109/ICCV.2005.152.

Vedaldi, A \& Fulkerson, B. (2008). VLFeat - An open and portable library of computer vision algorithms. Retrieved from http://www.vlfeat.org Willamowski, J., Arregui, D., Csurka, G., Dance, C., \& Fan, L. (2004). Categorizing nine visual classes using local appearance descriptors. In Proceedings of LAVS Workshop, in ICPR'04, Cambridge.

Pilar Rosado: Estudiante de doctorado y becaria de Investigación del Departamento de Escultura de la Universidad de Barcelona.

Contact Address: Pau Gargallo 4, 08028 Barcelona (España). E-mail address: pilarrosado@ub.edu

Eva Figueras: Profesora Titular del Departamento de Pintura de la Universidad de Barcelona.

Contact Address: Pau Gargallo 4, 08028 Barcelona (España). de la E-mail address: efigueras@ub.edu

Ferran Reverter: Profesor Lector del Departamento de Estadística de la Universidad de Barcelona e Investigador Postdoc del Centre de Regulació Genòmica del Parc de Recerca Biomèdica de Barcelona.

Contact Address: Avda. Diagonal 643, 08028 Barcelona (España). E-mail address: freverter@ub.edu 


\section{Anexos}

Anexo A

\section{Obtención de descriptores locales}

\section{a. Extracción de características locales (SIFT Descriptors)}

El descriptor Scale Invariant Feature Transform (SIFT) fue desarrollado por (Lowe, 2004) como un algoritmo capaz de detectar puntos característicos (keypoints) estables en una imagen. Estos puntos son invariantes frente a diferentes transformaciones como traslación, escala, rotación, iluminación y transformaciones afines. Originalmente fue desarrollado para el reconocimiento de objetos en general y para realizar la alineación de imágenes. El algoritmo SIFT se compone principalmente de cuatro etapas que se describen siguiendo la implementación de (Lowe, 2004):

a. Detección de extremos en el Espacio de Escala: La primera etapa del algoritmo realiza una búsqueda sobre las diferentes escalas $\mathrm{y}$ dimensiones de la imagen identificando los candidatos a keypoints. Esto se lleva a cabo mediante la función DoG (Difference-ofGaussian).

b. Localización de los keypoints: Se seleccionan los keypoints a partir del conjunto de candidatos encontrados, aplicando una medida de estabilidad sobre todos ellos para descartar los que no sean adecuados.

c. Asignación de la orientación: Se asignan una o más orientaciones a cada keypoint basándose en las direcciones locales presentes en la imagen gradiente. Todas las operaciones posteriores serán realizadas sobre los datos transformados según la orientación, escala y localización dentro de la imagen, lo que nos proporcionará la invariancia parcial a distorsiones de forma así como a cambios de iluminación.

d. Descriptor del keypoint: La última etapa hace referencia a la representación de los keypoints como una medida de los gradientes locales de la imagen en las proximidades de dichos puntos clave y 
respecto de una determinada escala. Cada punto de interés corresponde a un vector de características compuesto por 128 elementos.

A continuación detallaremos las etapas anteriores (Enebral, 2009)

\section{b. Detección de extremos en el Espacio de Escala}

La primera fase del algoritmo es la encargada de buscar un primer conjunto de keypoints de la imagen candidatos a poder ser identificados de forma repetida bajo diferentes vistas del mismo objeto. La detección de ubicaciones que son invariantes frente cambios de escala de la imagen se puede lograr mediante la búsqueda de características estables en todas las escalas posibles, utilizando una función continua de escala conocida como función Espacio de Escala.

La función Espacio de Escala de una imagen se define como la función, $L(x, y, \sigma)$, que resulta de la convolución de una función Gausiana, $G(x, y, \sigma)$, con la imagen original $I(x, y)$ :

$$
L(x, y, \sigma)=G(x, y, \sigma) * I(x, y)
$$

donde * denota el operador convolución en $x$ y $y, y$

$$
G(x, y, \sigma)=\frac{1}{2 \pi \sigma^{2}} \exp \left(-\frac{x^{2}+y^{2}}{2 \sigma^{2}}\right)
$$

El cálculo de todo el espacio $L(x, y, \sigma)$ se lleva a cabo construyendo una pirámide gausiana (Fig. 34), convolucionando con diferentes filtros $G(x, y, \sigma)$ al variar el parámetro $\sigma$. Las imágenes de la pirámide gausiana se distribuyen según los términos siguientes:

- Octava: Imágenes del espacio $L(x, y, \sigma)$ de igual tamaño que difieren en el parámetro de filtrado $\sigma$ con el que han sido obtenidas.

- Escala: Imágenes del espacio $L(x, y, \sigma)$ filtradas con el mismo parámetro $\sigma$ pero con diferentes tamaños.

Para mejorar la estabilidad de los puntos de interés que se obtendrán más adelante, es conveniente realizar un pre-procesado. La imagen original $I(x, y)$ se suaviza mediante un filtrado gausiano con $\sigma_{0}=0.5 \mathrm{y}$ 
posteriormente se re-escala con un factor 2 usando interpolación lineal. La imagen resultante, al doblar su tamaño, le corresponderá un valor $\sigma_{1}=1 \mathrm{y}$ es ésta la que se utilizará como imagen inicial para construir la pirámide.

Los diferentes valores del parámetro $\sigma$ con los que se configura la pirámide tienen que verificar en cada octava la siguiente condición: el penúltimo, $\sigma_{4}$ en este caso, ha de ser el doble que el primero, $\sigma_{1}=1$. Por consiguiente, dividiremos cada octava en intervalos múltiplos de $k$

$$
k=2^{\frac{1}{\text { (num.escalas)-2 }}}=2^{\frac{1}{3}}
$$

entonces

$$
\sigma_{i}=k^{i-1}=2^{\frac{i-1}{3}} \quad i=1, \ldots, 5
$$

Una vez terminada la primera octava, se elige la imagen con $\sigma_{4}=2$ como imagen inicial de la siguiente octava, de esta manera, al re-escalarla a la mitad su factor de filtrado vuelve a ser $\sigma_{1}=1$. Este proceso se va repitiendo hasta completar toda la pirámide (Fig. 34).

\section{Escalas}
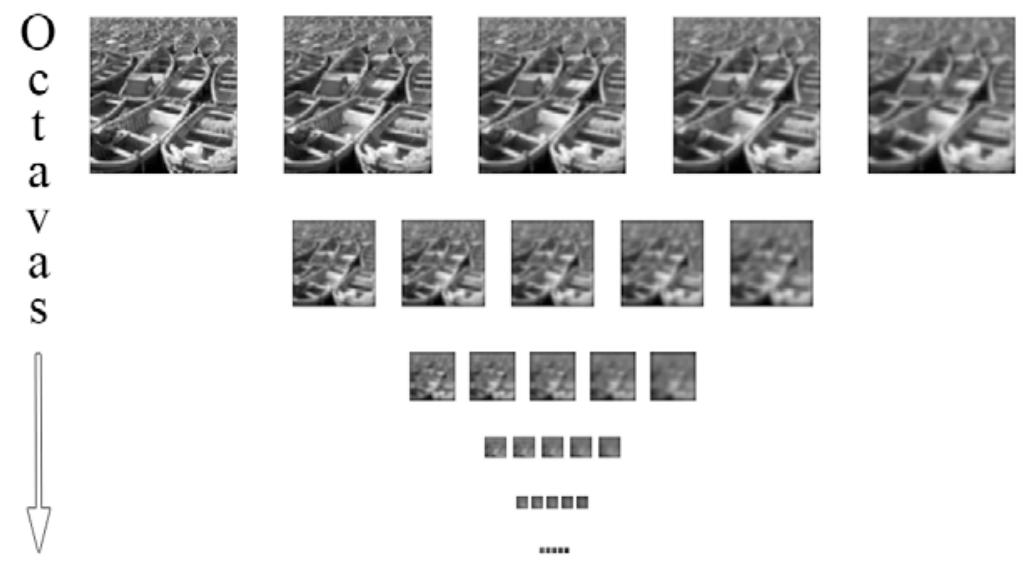

$\mathrm{V}$

a
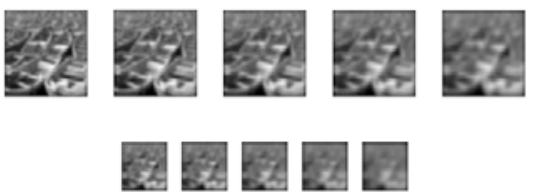

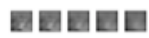

घana

Figura 34. Pirámide gausiana. 


\section{c. Localización de los keypoints}

Para detectar puntos de interés estables en el Espacio de Escala utilizamos la función DoG (Difference-of-Gaussian), definida por:

$$
\begin{aligned}
D(x, y, \sigma) & =(G(x, y, k \sigma)-G(x, y, \sigma)) * I(x, y) \\
& =L(x, y, k \sigma)-L(x, y, \sigma)
\end{aligned}
$$

Obsérvese que la función DoG resulta de la función $L(x, y, \sigma)$ calculada en la etapa anterior. La obtención de la función DoG no comporta un incremento considerable del coste computacional total, ya que se calcula simplemente restando imágenes vecinas de una misma octava. En la pirámide DoG tendremos cuatro imágenes-resta por octava (Fig. 35).
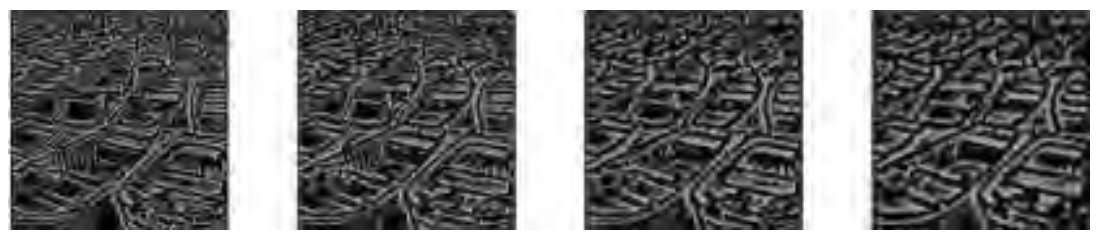

Figura 35. Imágenes-resta de una primera octava. La pirámide DoG se completa obteniendo las imágenes-resta de las sucesivas octavas.

A partir de los cálculos anteriores, se hallarán los máximos y mínimos locales del espacio $D(x, y, \sigma)$. En esta etapa cada uno de los píxeles de cada imagen de la pirámide se compararán con sus ocho vecinos de la propia imagen y con los nueve vecinos anteriores y posteriores de escala (Fig. 36). 

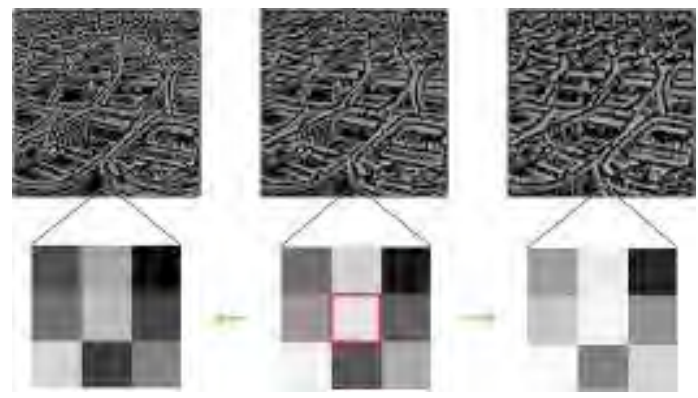

Figura 36. Vecinos anterior y posterior de escala

Un punto quedará seleccionado como keypoint sólo si es mayor que sus 26 vecinos o menor que todos ellos. Observamos que sólo se podrán detectar keypoints en escalas centrales de $D(x, y, \sigma)$ pues no existen imágenes vecinas en las escalas laterales.

En esta fase del método SIFT se centra en almacenar toda la información disponible de cada keypoint. Es decir, para cada punto de interés encontrado se guardará a qué escala y octava de la pirámide pertenece, y su posición, es decir la fila y la columna, dentro de la imagen correspondiente.

\section{d. Asignación de la orientación}

En esta etapa calcularemos las orientaciones de cada punto de interés. Una vez las tengamos podremos construir descriptores invariantes a la rotación, ya que éstos serán referenciados a sus respectivas orientaciones.

Alrededor del punto donde vamos a determinar la orientación definimos una región de 16x16 píxeles y a cada uno de los píxeles se le calcula su gradiente (Fig. 37a y Fig. 37b). El gradiente viene determinado por su módulo $m(x, y)$ e inclinación $\theta(x, y)$, ambos se calculan utilizando deferencias entre pixeles:

$$
m(x, y)=\sqrt{(L(x+1, y)-L(x-1, y))^{2}+(L(x, y+1)-L(x, y-1))^{2}}
$$




$$
\theta(x, y)=\tan ^{-1}\left(\frac{L(x, y+1)-L(x, y-1}{L(x+1, y)-L(x-1, y)}\right)
$$

La imagen empleada para obtener $m(x, y)$ y $\theta(x, y)$ será la imagen de la pirámide $L(x, y, \sigma)$ (Fig. 34) donde se detectó el punto de interés que está siendo analizado.

Después de realizar el proceso anterior, se agrupará la información en forma de histograma, uno para cada punto de interés. De esta manera cada histograma de orientaciones estará formado por 36 bins o clases para completar el rango total de $360^{\circ}$ (Fig. $37 \mathrm{c}$ ). A medida que se añade al histograma cada orientación $\theta(x, y)$, dicho valor se pondera por su módulo $m(x, y)$ y por una ventana circular gausiana con valor $\sigma$ igual a 1.5 veces la escala del punto de interés. Los motivos principales para realizar estas dos ponderaciones son: dar mayor peso a las orientaciones con módulos elevados y mayor importancia a los puntos cercanos al punto de interés.

El bin modal de cada histograma corresponderá la dirección dominante de los gradientes locales, y por lo tanto la orientación final del punto de interés.

a)

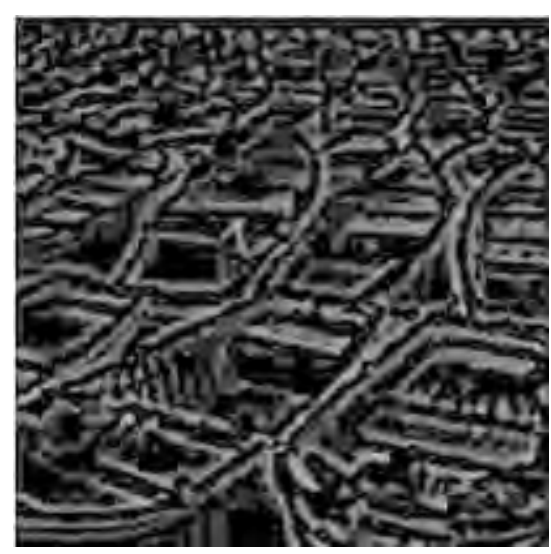

b)

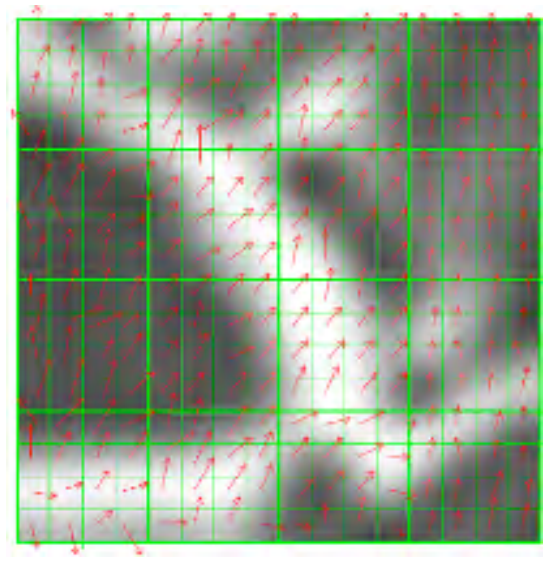


c)

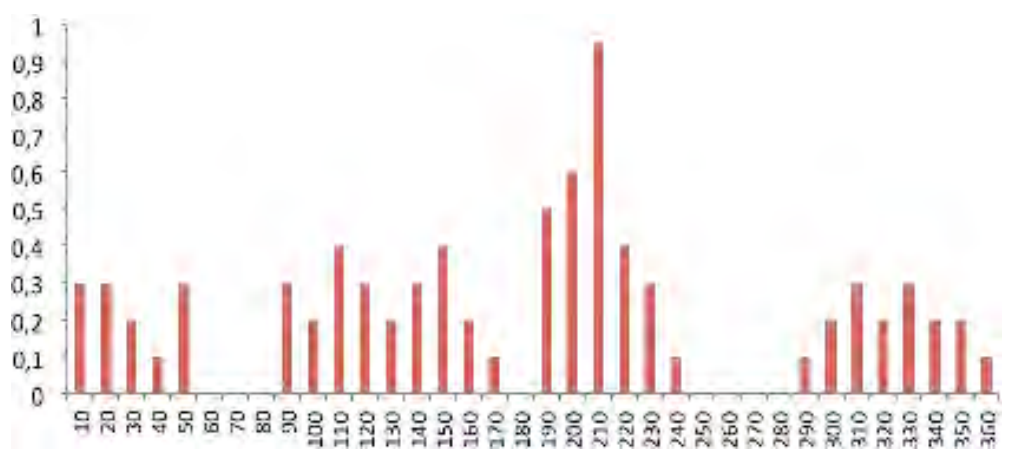

Figura 37. a) Keypoint. b) Región de 16x16 píxeles alrededor del keypoint y gradiente. c) Histograma de orientaciones. La orientación del keypoint corresponde al valor máximo.

\section{e. Descriptores de los keypoints}

Las etapas anteriores han dotado a los puntos de interés seleccionados de invariancia respecto de la orientación, escala y localización respecto de la imagen. En esta última etapa se crea un vector de características para cada uno de los puntos de interés que contiene una estadística local de las orientaciones del gradiente.

El proceso parte de las regiones 16x16 del apartado anterior ya multiplicadas por la ventana gausiana con $\sigma$ igual a 1.5 veces la escala del punto de interés (Fig. 38a). Cada una de estas regiones se divide en subregiones de $4 \times 4$ píxeles con el objetivo de resumir toda esa información en pequeños histogramas de sólo 8 bins, es decir, 8 orientaciones. Previamente a la realización de esta reconfiguración, cada gradiente de la ventana $16 \times 16$ se rota tantos grados como especifique la orientación del punto de interés (calculada en la etapa anterior, Fig. 38c), y así será independiente a la inclinación de la imagen.

Para cada punto de interés ahora pasaremos a tener 16 pequeños histogramas de 8 bins cada uno de ellos. Para evitar cambios abruptos entre las fronteras de las subregiones, cada una es filtrada de nuevo por una ventana circular gausiana (en esta ocasión de tamaño 4x4) con un factor $\sigma$ $=0.5 \mathrm{x}$ escala del punto de interés (Fig. $38 \mathrm{~b}$ ). 
Cada uno de los histogramas se compone de 8 bins, que almacenan las orientaciones posibles proporcionales a 45 grados donde la magnitud de cada flecha representa el valor acumulado para cada bin. Por lo tanto se obtienen 16 histogramas respecto de las orientaciones de los puntos de cada región para cada uno de los puntos de interés.

Finalmente el descriptor de cada punto de interés está formado por un vector que contiene los valores de las 8 orientaciones de los $4 \times 4$ histogramas componiendo un vector de características de 4 × 4 × $8=128$ elementos (Fig. 38c).

a)

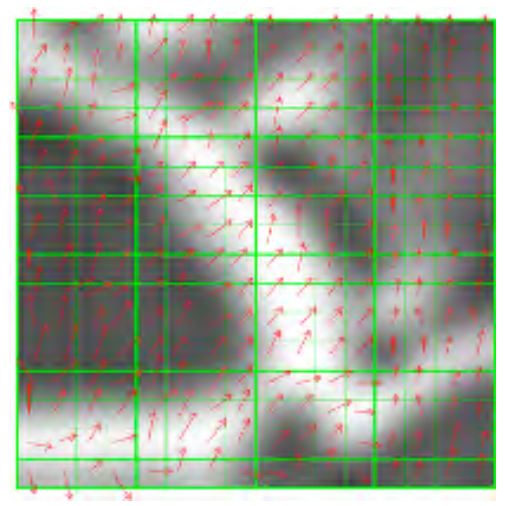

b)

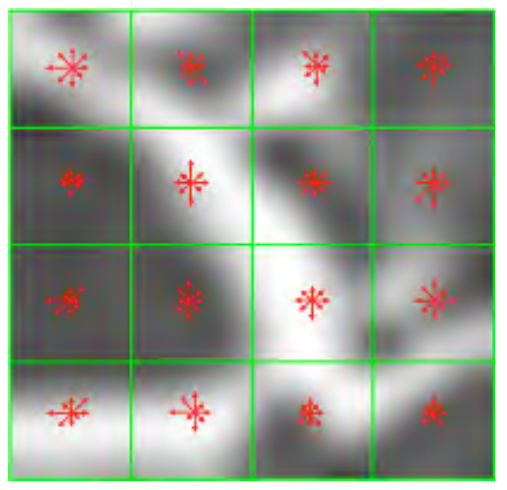

c)

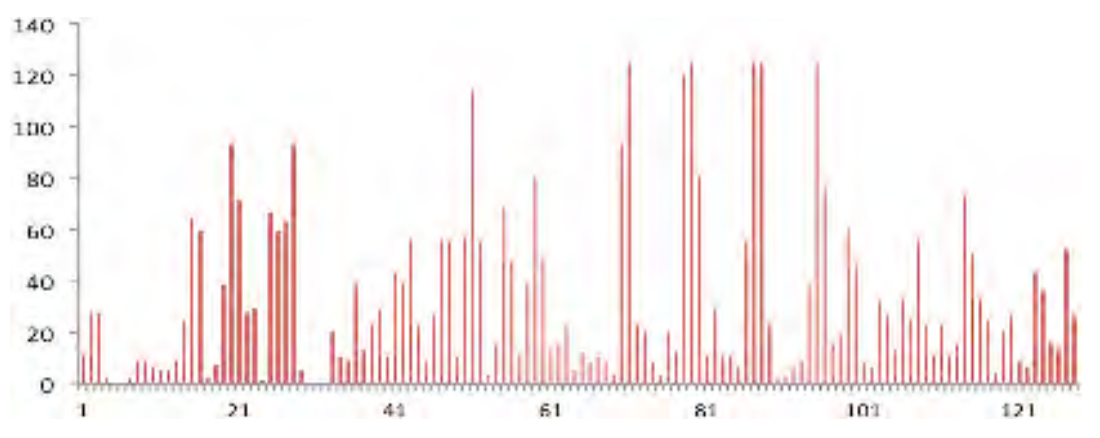

Figura 38. a) Región de 16x16 píxeles alrededor del keypoint y gradiente. b) Subregiones de 4x4 píxeles con histogramas de sólo 8 orientaciones c) Descriptor. 
Las etapas anteriores aseguran que los descriptores obtenidos sean invariantes frente a la luminosidad. Esto es consecuencia de que los gradientes están calculados mediante diferencias entre píxeles vecinos. De esta manera sumar una constante de luz a la imagen no influirá en el resultado final.

Para lograr invariancia frente a cambios de contraste hay que normalizar a la unidad cada uno de los 'sub-histogramas' del total de 16 que tiene cada descriptor.

Por la saturación de la cámara o por cambios de iluminación sobre superficies puede producirse una variación no lineal de luz.

Ante esta variación para reducir sus efectos impondremos un umbral superior de 0.2 a los histogramas normalizados y posteriormente se renormalizará de nuevo a la unidad. Efectuadas estas modificaciones, el proceso de construcción de los descriptores queda completado.

En algunos estudios (Lazebnik, Schmid \& Ponce, 2006; Fei-Fei \& Perona, 2005) el cálculo de los descriptores locales SIFT, en vez de realizarse en los puntos de interés, se efectúa en los nodos de una malla regular sobreimpuesta en la imagen (Fig. 39). Este enfoque es preferible con el fin de mejorar la capacidad de discriminación en implementaciones orientadas a la clasificación de escenas.

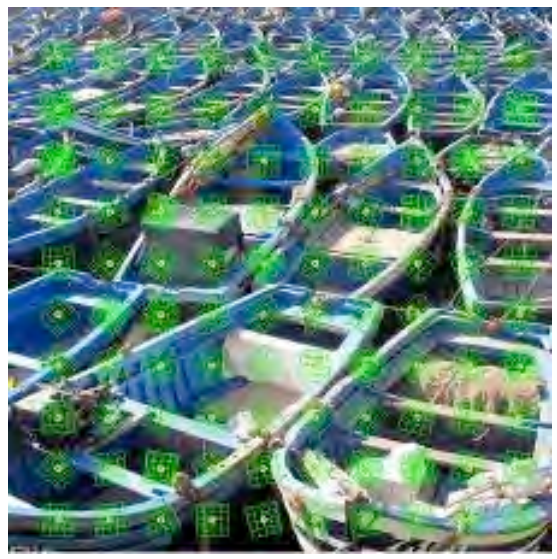

Figura 39. Imagen con una malla de $10 \times 10$. Los nodos contienen los valores de las 8 orientaciones de los histogramas $4 \times 4$. Para cada nodo resulta un vector de características, con $4 \times 4 \times 8=128$ elementos 
Anexo B

\section{Vocabulario visual}

a. Construcción del vocabulario visual

El punto de partida para la construcción de un vocabulario visual es el conjunto de descriptores $F=\left\{f_{i}: i=1, \ldots, N_{F}\right\}$ de la colección de imágenes $D=\left\{d_{1}, \ldots, d_{N}\right\}$ y el punto al cual queremos llegar es un vocabulario de "visual terms" $V=\left\{v_{1}, \ldots, v_{M}\right\}$. Utilizaremos la expresión: palabra visual como equivalente a la expresión inglesa "visual term". Cada imagen $d_{i}$ ha quedado descrita mediante los descriptores SIFT, denotemos genéricamente por $f$ un descriptor. Considerando toda la colección de imágenes tenemos por tanto una gran colección de descriptores. La construcción del vocabulario requiere la cuantización de cada descriptor local $f$ en su respectiva palabra visual $v_{i}$ de acuerdo con la siguiente regla de asignación:

$f \rightarrow Q(f)=v_{i} \Leftrightarrow \operatorname{dist}\left(f, v_{i}\right) \leq \operatorname{dist}\left(f, v_{j}\right), \quad j=1, \ldots, M$

donde $\operatorname{dist}(\cdot ;)$ es una función distancia.

Si indicamos con $S$ el espacio de los descriptores, en nuestro caso al tener descriptores 128 dimensionales podemos asumir que $S \equiv \mathrm{R}^{128}$. Una vez fijado el vocabulario $V=\left\{v_{1}, \ldots, v_{M}\right\}, S$ queda dividido en $M$ regiones $S=\left\{S_{1}, \ldots, S_{M}\right\}$ de acuerdo con:

$S_{i}=\left\{f \in S: Q(f)=v_{i}\right\}$

La construcción del vocabulario se realiza mediante agrupación (clustering). Más específicamente, aplicamos el algoritmo k-means a un conjunto representativo de descriptores locales extraídos de la colección de imágenes y tomaremos como palabras visuales los vectores de medias de cada clúster. Usamos la distancia euclidiana en los procesos de agrupación 
y cuantización y elegimos el número de clústeres dependiendo del tamaño deseado de vocabulario.

El algoritmo k-means establece una partición o agrupación del conjunto de descriptores

$$
F=\left\{f_{i}: i=1, \ldots, N_{F}\right\}
$$

En $M$ subconjuntos disjuntos $S_{i}$ que contienen los descriptores que minimizan la función de error cuadrático:

$$
J(F)=\sum_{i=1}^{M} \sum_{j \in S_{i}}\left(f_{j}-\mu_{i}\right)^{2}
$$

Donde $\mu_{i}$ denota el vector de medias (centroide) del subconjunto de descriptores $S_{i}$.

El algoritmo busca la partición mediante la iteración de dos etapas. La primera etapa consiste en asignar cada descriptor al centroide más cercano. En la segunda atapa se recalculan los centroides de cada región, calculando el vector de medias de los descriptores que han sido asignados a cada región (Fig. 40).

\section{b. Algoritmo K-means}

- Establecer al azar $M$ centroides iniciales.

- Asignar cada descriptor al subconjunto $S_{i}$ que tenga el centroide $\mu_{i}$ más cercano, de acuerdo con la fórmula 1.

- Recalcular el valor del centroide $\mu_{i}$ mediante el vector de medias de los descriptores asignados a $S_{i}$.

- Repetir los pasos 2 y 3 hasta que los valores de los centroides $\mu_{i}$ no se modifiquen. 
a)

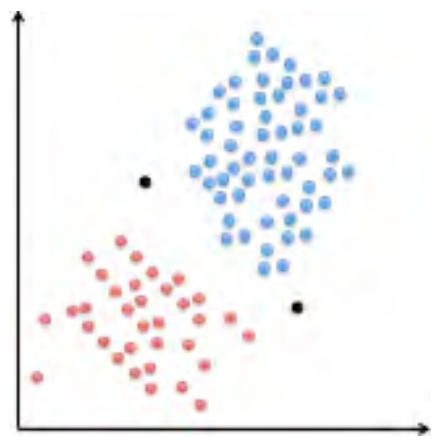

b)

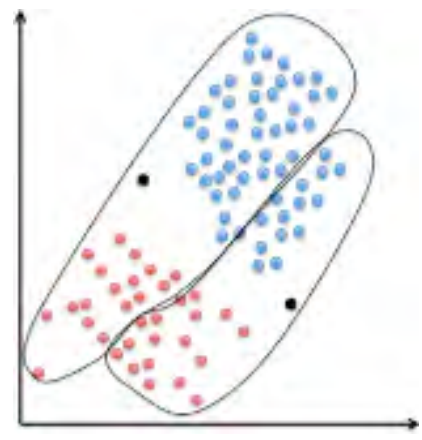

c)

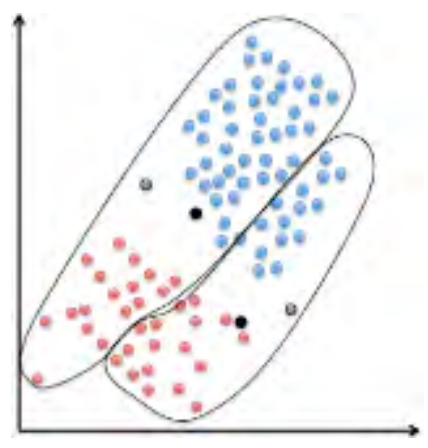

e)

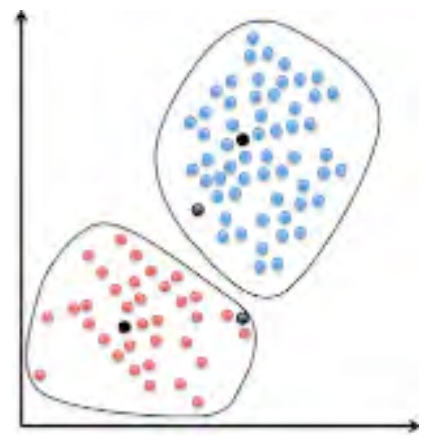

d)

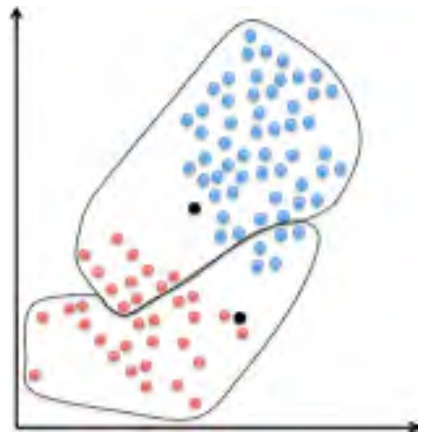

f)

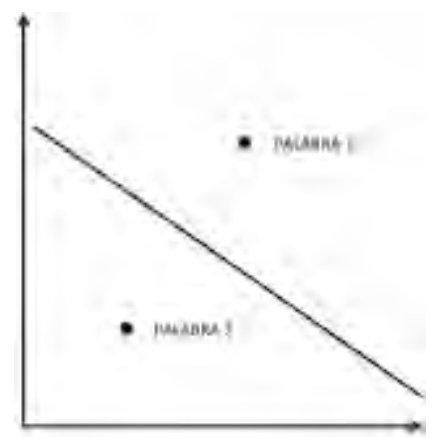


g)

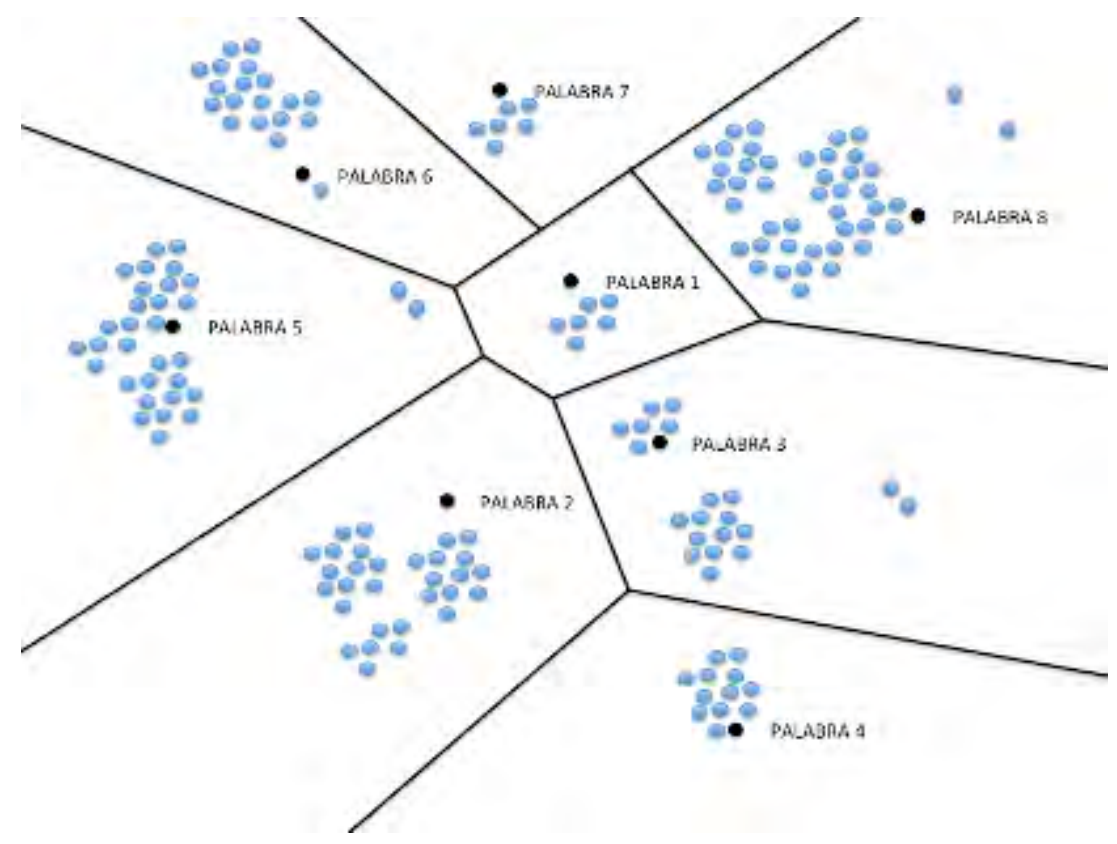

Figura 40. A modo de ejemplo, supongamos el caso de descriptores bidimensionales y de dos palabras visuales. El algoritmo k-means establecerá una partición del espacio en dos regiones cada una asociada a una palabra. a) Supongamos que los descriptores de la colección de imágenes configuran dos grupos separados (azul y rojo). El algoritmo empieza estableciendo dos centroides al azar (negro), b) Asignamos cada descriptor al centroide más cercano. c) Recalculamos los nuevos centroides de los grupos formados en la etapa anterior. d) Repetimos la asignación de los descriptores al centroide más cercano. e) El procedimiento prosigue recalculando los nuevos centroides. f) El proceso iterativo se detiene cuando no se produce cambio en los centroides. g). Ilustra la partición del espacio de descriptores en el caso de una vocabulario de más palabras. Dado un descriptor $f$ calcularemos el centroide más cercano, y le corresponderá la palabra representada por dicho centroide. 
Dada una imagen $d$ con un conjunto de descriptores

$$
F(d)=\left\{f_{j}: j=1, \ldots, N_{F(d)}\right\}
$$

podemos usar los centroides obtenidos en el algoritmo k-means para atribuir la palabra visual $v_{i}$ a todo descriptor $f_{j}$ para el que el centroide más cercano sea $\mu_{i}$. Una vez completada la atribución obtenemos la representación $\mathrm{BOV}$ de la imagen:

$h(d)=\left(h_{1}(d), \ldots, h_{M}(d)\right), h_{i}(d)=n\left(d, v_{i}\right)$

donde $n\left(d, v_{i}\right)$ indica la frecuencia de la palabra visual $v_{i}$ en la imagen $d$. 
Anexo C

\section{Representación de aspectos latentes}

Vamos a explicar el modelo en términos de imágenes, palabras visuales y aspectos. Disponemos de una colección de imágenes $D=\left\{d_{1}, \ldots, d_{N}\right\}$ y un vocabulario de palabras visuales $V=\left\{v_{1}, \ldots, v_{M}\right\}$. Podemos resumir las observaciones en una tabla $N \times M$ de frecuencias $n\left(d_{i}, v_{j}\right)$, donde $n\left(d_{i}, v_{j}\right)$ indica la frecuencia con que la palabra visual $v_{j}$ ocurre en la imagen $d_{i}$. PLSA es un modelo estadístico generativo que asocia una variable latente $z_{l} \in\left\{z_{1}, \ldots, z_{K}\right\}$ con cada observación, entendiendo por observación la ocurrencia de una palabra visual en una imagen dada. Estas variables, normalmente llamadas aspectos, se utilizan para construir un modelo de probabilidad conjunta sobre las imágenes y las palabras visuales, definido por:

$$
P\left(d_{i}, v_{j}\right)=P\left(d_{i}\right) \sum_{k=1}^{K} P\left(v_{j} \mid z_{k}\right) P\left(z_{k} \mid d_{i}\right)
$$

donde $P\left(d_{i}\right)$ indica la probabilidad de $\quad d_{i} P\left(v_{j} \mid z_{k}\right)$ indica la probabilidad condicionada de una palabra visual específica condicionada al aspecto latente $z_{k}, \mathrm{y} P\left(z_{k} \mid d_{i}\right)$ indica la probabilidad condicional específica de cada imagen. El PLSA introduce un principio de independencia condicional: asume que la ocurrencia de una palabra visual $v_{j}$ es independiente de la imagen $d_{i}$ en la que esta, dado un aspecto $z_{k}$.

La estimación de las probabilidades del modelo PLSA se llevan a cabo mediante el máximo de la verosimilitud utilizando la colección de imágenes $D=\left\{d_{1}, \ldots, d_{N}\right\}$. La optimización se resuelve mediante el algoritmo EM (Dempster, Laird, \& Rubin, 1977). El algoritmo EM alterna dos etapas. En la etapa E se calculan las probabilidades a posteriori para los aspectos latentes basándonos en las estimaciones actuales de las probabilidades del modelo, en la etapa $\mathrm{M}$ las probabilidades del modelo se actualizan maximizando la llamada "expected complete data log-likelihood": 
Etapa E

$$
P\left(z_{k} \mid d_{i}, v_{j}\right)=\frac{P\left(v_{j} \mid z_{k}\right) P\left(z_{k} \mid d_{i}\right)}{\sum_{i=1}^{K} P\left(v_{j} \mid z_{l}\right) P\left(z_{l} \mid d_{i}\right)}
$$

Etapa M

$$
\begin{aligned}
& P\left(v_{j} \mid z_{k}\right)=\frac{\sum_{i=1}^{N} n\left(d_{i}, v_{j}\right) P\left(z_{k} \mid d_{i}, v_{j}\right)}{\sum_{m=1}^{M} \sum_{i=1}^{N} n\left(d_{i}, v_{m}\right) P\left(z_{k} \mid d_{i}, v_{m}\right)} \\
& P\left(z_{k} \mid d_{i}\right)=\frac{\sum_{j=1}^{M} n\left(d_{i}, v_{j}\right) P\left(z_{k} \mid d_{i}, v_{j}\right)}{n\left(d_{i}\right)}, n\left(d_{i}\right)=\sum_{j=1}^{M} n\left(d_{i}, v_{j}\right)
\end{aligned}
$$

Las etapas E y M se alternan hasta que se alcanza una cierta condición de terminación. El proceso iterativo se inicia asignando valores aleatorios al conjunto de probabilidades $P\left(z_{k} \mid d_{i}\right)$ y $P\left(v_{j} \mid z_{k}\right)$.

Como consecuencia del proceso anterior obtenemos una nueva representación para las imágenes de la colección basada en la distribución de aspectos,

$$
a\left(d_{i}\right)=\left(P\left(z_{1} \mid d_{i}\right), \ldots, P\left(z_{K} \mid d_{i}\right)\right)
$$

De hecho, también es posible hallar la distribución de aspectos para una imagen cualquiera que no forme parte de la colección inicial (Quelhas, Monay, Odobez, Gatica-Perez, Tuytelaars \& Van Gool, 2005; Bosch, 
Zisserman \& Muñoz, 2006). Basta recurrir de nuevo al algoritmo EM antes descrito pero en este caso en la etapa $M$ sólo se actualizan las probabilidades $P\left(z_{k} \mid d\right)$ y las probabilidades $P\left(v_{j} \mid z_{k}\right)$, independientes de la imagen, estimadas a partir de la colección en la fase de aprendizaje, se mantienen fijas.

Si bien la representación de imágenes basada en aspectos se puede usar como punto de entrada para alimentar un clasificador de escenas, nosotros vamos a centrarnos en la utilización de dicha representación para la ordenación o ranking de imágenes basada en la distribución de aspectos subyacentes. Dado un aspecto $z$, las imágenes pueden ordenarse según los valores:

$$
P(d \mid z)=\frac{P(z \mid d) P(d)}{P(z)} \propto P(z \mid d)
$$

de esta manera, una vez estimados los valores de $P\left(z_{k} \mid d\right), k=1, \ldots, K$, para una imagen dada $d$, podemos ordenarlos y tener una medida objetiva de la asociación entre la imagen y cada uno de los aspectos. En consecuencia, asociaremos la imagen al aspecto con mayor probabilidad. 
Instructions for authors, subscriptions and further details:

http://brac.hipatiapress.com

\section{Der Baum in der Gegenwartskunst: Nachhaltigkeitsindikator}

Àngels Viladomiu ${ }^{1}$

1) University of Barcelona. Spain

Date of publication: February $3^{\text {th }}, 2014$

Edition period: October 2013-February 2014

To cite this article: Viladomiu, À., (2013). Der Baum in der Gegenwartskunst: Nachhaltigkeitsindikator. Barcelona, Research, Art, Creation, Vol 2(1), 55-80. doi: 10.4471/brac.2014.02

To link this article: http://dx.doi.org/10.4471/brac.2014.02

The terms and conditions of use are related to the Open Journal System and to Creative Commons Attribution License (CC-BY). 
BRAC - Barcelona Research Art Creation. Vol. 2 No. 1, February

2014, pp. 55-80

\title{
Der Baum in der \\ Gegenwartskunst: \\ Nachhaltigkeitsindikator
}

\author{
Àngels Viladomiu \\ University of Barcelona. Spain
}

(Received: 31 October 2013; Accepted: 19 December 2013; Published: 3 February 2014)

\section{Zusammenfassung:}

Dieser Artikel analysiert wie der Baum, hauptsächlich als lebendiges Wesen, im Bereich der zeitgenössischen Kunst verwendet wird. Der Baum wird als Objekt und als Subjekt behandelt, wird jedoch auch zum Experimentier- und Forschungsfeld der Kunst. Abgesehen von seinem Wesen als Objekt und Pflanze, erlangt er gleichzeitig als Standort eine räumliche Bedeutung. Anhand ausgewählter Beispiele wird aufgezeigt wie der Baum als weltweite Ikone sowohl auf die Zerstörung der Umwelt als auch auf die Ökologische Erhaltung und Zerstörung des Planeten in der zeitgenössischen Kunst hinweist.

Schlüisselworte: Baum Kunst, Gegenwartskunst, Interdisziplinarität, zeitgenössische Baumkultur. 


\section{The Tree in Present-Day Art: an Indicator of Sustainability}

Àngels Viladomiu

University of Barcelona. Spain

(Received: 31 October 2013; Accepted: 19 December 2013; Published: 3 February 2014)

\section{Abstract}

This paper analyses how the tree, mainly as a living being, is used in contemporary art. The tree is approached as object and subject, but also becomes a territory-space of experimentation and research. But beyond its plant and objectual character, the tree itself adopts a territorial sense as place. The diverse examples selected corroborate the use of the tree in contemporary art as a universal global icon of conservation and the environmental destruction of the planet.

Keywords: Arboreal art, contemporary art, interdisciplinarity, contemporary arboreal culture. 
BRAC - Barcelona Research Art Creation. Vol. 2 No. 1, February 2014, pp. 55-80

\section{El Árbol en el Arte Actual: Indicador de Sostenibilidad}

Àngels Viladomiu

Universidad de Barcelona. España

(Recibido: 31 Octubre 2013; Aceptado: 19 Diciembre 2013; Publicado: 3 Febrero 2014)

\section{Resumen}

El artículo analiza como el árbol, principalmente como ser vivo, es utilizado en el arte contemporáneo. El árbol es abordado como objeto y sujeto, pero también se convierte en un territorio-espacio de experimentación e investigación. Pero más allá de su carácter vegetal y objetual, el árbol en sí mismo adopta un sentido territorial como lugar. Los diversos ejemplos seleccionados corroboran el uso del árbol en el arte actual como icono global universal de la conservación y destrucción medioambiental del planeta.

Palabras clave: Arte arbóreo, arte actual, interdisciplinariedad, cultura arbórea contemporánea. 
D ie Analyse in diesem Text ist vorwiegend aus einem aktuellen Blickwinkel der objektbezogenen Welt unserer Zeit zu betrachten. Allerdings ist diese Annäherung an das Naturelement Baum nicht aus einer beschaulichen Haltung gegenüber dem Naturraum entstanden, sondern sie entstand vorrangig aus einer urbanen Gesellschaftsperspektive. Der Bezug zwischen Kunst und Natur im Heute kann nicht nur in Bezug auf Konzepte wie Betrachtung, Ausdruck und Verarbeitung verstanden werden, sondern muss unter den Aspekten von Kreuzungsstrategien und Vermischung der Fachzweige, Frucht der komplexen Struktur einer Welt in permanenter und beweglicher Veränderung, begriffen werden. Auch die Kunst wird zum Spiegelbild dieser Welt. Eine Welt, die durch atemberaubend schnelle Wechsel, hervorgerufen durch das Schwinden ihrer natürlichen Vorkommen und die Migrationsströme der Menschen, gekennzeichnet ist.

Die verschiedenen künstlerischen Arbeiten gliedern sich in thematische Blöcke, die den Baum lebend oder tot als ready-made behandeln. Der Baum und die Dinge, der Baum und das Buch, der Baum als Subjekt, Aktion und Artefakt der Wahrnehmung, und schließlich der Baum als Säule, als Lebensraum, als Bühne, oder Baumpflanzungen. In den folgenden Bespielen kommt die Bearbeitung des Baumes als Wesen, Objekt, wie auch implizit seine räumliche Bedeutung vor.

\section{Der Baum: Kunst, Kultur und Leben}

Vorausgehend werden in einer allgemeinen Einführung die Verknüpfung und Bezüge zwischen dem Baum und Kunst, Kultur und Leben erläutert, um die kulturellen und künstlerischen Zusammenhänge der analysierten, zeitgenössischen Kunstwerke verstehen und einordnen zu können.

Der Baum ist schon immer ein Bestandteil der Kultur und der Zivilisation des Menschen gewesen und ist von ihm seit jeher katalogisiert worden. Nur mit großer Schwierigkeit können wir deswegen uns den Baum abgelöst von den menschlichen Prozessen und dem menschlichen Tun vorstellen, nicht nur auf Grund seiner vielseitigen Nutzung seitens des Menschen, sondern auch wegen des symbolischen Wertes, den die verschiedenen Kulturen dem Baum übertragen haben (Brosse, 2001). 
Die eindrucksvolle Morphologie des Baumes verleiht dem Menschen die Intuition, dass der Kosmos voller Sinn steckt. Innerhalb der bemerkenswerten räumlichen Struktur des Baumes, dürfen wir nicht die Präsenz der Lebenszyklen außer Acht lassen, die den Baum verändern; in seinem Inneren materialisiert er die Zeit durch die konzentrischen Jahresringe seines Stammes.

Der Kunstwissenschaftler Karl Schawelka (2004) hinterfragt die Bedeutung der Bäume von der Vergangenheit bis heute in der von ihm so benannten „Renaissance des zeitgenössischen Baumkult“, in der die Bäume für jeglichen Symbolismus weiterhin enorm wichtig und passend erscheinen:

Wenn wir in unserer gegenwärtigen westlichen Kultur eine Renaissance der Baumkulte erleben, die gerade auch innerhalb und mittels der Kunst eigene Sichtweisen und Sinnwelten zu generieren vermögen, so sollten die Natur menschlicher kognitiver Fähigkeiten ebenso wie deren Ausprägung durch zeittypische Faktoren einer Analyse zugrunde gelegt werden. Denn es sind gerade die Phantasmen und Ängste unsere Zeit, die in den wieder entdeckten Baumkulten bearbeiten werden, wobei aber ein ironisches, spielerisches Element des „Als-Ob“ nicht übersehen werden kann. ${ }^{1}$

Jener althergebrachte Glaube, nach dem bestimmte menschliche Leben mit dem eines bestimmten Baumes verknüpft sind, ist immer wieder seit jeher von Schriftstellern, Dichtern und Künstlern aufgegriffen und dokumentiert worden. Warum sind Bäume so passende Stellvertreter der Menschen? Diese Frage ist sicher nicht weit von der erlösenden Idee Joseph Beuys entfernt, der den Bäumen seine Dankbarkeit für ihr Leiden an Stelle des Menschen ausspricht.

Der Artikel sammelt und stößt uns auf jene Ansichten, die die Künstler mit den Bäumen, an den Bäumen und durch die Bäume entwickelt haben. Dieser Zusammenhang umfasst jede Art von künstlerischen Interventionen, Installationen, Aktionen, Werken oder Arbeiten, die das Vorhandensein des Baumes auf verschiedenen Ebenen und mit unterschiedlicher Intensität als Wesen als Objekt wie auch als Konzept aufweisen. Diese Herangehensweise ermöglicht einen Dialog und eine Analyse der Kontraste, Ähnlichkeiten und Unterschiede des Forschungsthemas Baum und Kunst seit ihrem Entstehen. Weiterhin umfasst es verschiedene Gebiete 
der Plastik, der Architektur, der Landschaftsplanung und des Designs, wie auch der Ausdehnung der Arte Arboreo auf andere Gebiete der Wissenschaft wie der Biologie, Botanik, Landwirtschaft, Dendrologie, etc.

Die aktuelle Kunst benutzt den Baum lebend oder tot, verwurzelt oder entwurzelt, aus dem Gewächshaus oder in situ, in seiner Vollständigkeit oder einer Fragmentation unterworfen, auf einheitliche oder partielle Weise, als Einzelstück oder in einer Gruppe, in Anpflanzungen oder in Waldstücken. Der lebendige Baum in situ wird wegen seiner botanischen, räumlichen (Örtlichkeit) (Jones\&Cloke, 2002) und formalen Besonderheiten und Eigenschaften ausgesucht. Andererseits, der lebendige Baum aus der Baumschule erlaubt es, Kunstwerke unabhängig von jedem Zusammenhang und jeder Örtlichkeit zu erschaffen. Auch durch seine Abwesenheit kann der Baum schließlich dargestellt werden.

In den folgenden Beispielen entsteht ein Dialog zwischen den Bäumen und den Elementen unserer Umwelt, den Objekten, den Sachen, den Büchern, dem eigenen Körper des Künstlers und sogar dem Körper des Betrachters. Der Baum wird so zu einer Basis oder Bühne um einen Zustand zu erklären oder etwas festzustellen. Schließlich, der Baum wird als Indikator eines Ortes mit einer bestimmten Identität und Geschichte behandelt und wegen seiner konstruktiven Eigenschaften verdient er einen Ort an dem Künstler utopische und politische Wohnräume projizieren. Der Baum und der Wald werden in Folge dessen zu einem von künstlerischen Akten besiedelten Raum.

\section{Lebendige Bäume in der Gegenwartskunst: Eine Auswahl}

Im Folgenden werde ich das ausgearbeitete Forschungsthema an Hand einiger ausgesuchter Kunstwerke vorstellen. Einige der Beispiele entstammen den letzten wichtigsten Kunstveranstaltungen (Biennale Venedig, 2013; Documenta Kassel, 2012). Die folgenden Interventionen spielen sich um den Baum herum ab, und er (der Baum) nimmt dabei die Rolle des Hauptdarstellers ein, herausragend durch seine eigene Präsenz und seine Identität, ausgedrückt mittels seiner physischen Körperlichkeit sowie seines konzeptuellen und symbolischen Gewichtes. 


\section{Von Lebendiger Objektkunst und Bäumen}

Der Olivenbaum von Maurizio Cattelan - Ohne Titel (Castello di Rivoli, Torino, Italien, 1999) vertritt eine Definition von Kunst, bei der Kunst das ist, worüber der Künstler verfügt. Wie auf einer Bühne, will diese Arbeit Cattelans einfach das Leben eines Olivenbaums darstellen, ein lebendiges Element der Realität, welches für drei Monate in den Kunstraum des Museums eindringt. Seine imposante kubische Plinthe aus Erde verwandelt den Olivenbaum in eine lebendige Skulptur. Hierbei interessiert sich Cattelan mehr für die Ausstellungsstrategien, die in den zynischen Zwischenräumen der Kommunikation operieren und durch Gerüchte und Provokation ausgelöst werden, als für das lebendige Kunstwerk an sich. Der lebende Baum selbst wird zum Kunstobjekt und der Künstler verleiht ihm so den Status eines Kunstwerkes in seiner ganzen Exklusivität.

Der Architekt Dominique Perrault in Kolonihavehus Installation (Copenhague, Denmark, 1996) stellt uns einen kubischen Raum aus Glas vor, der den Raum um den Baum begrenzt und schließt. Dieser hermetisch abgeschlossene Würfel zeigt uns die wechselnden Faktoren der Natur, die von den Klimabedingungen abhängig sind. Innerhalb dieser Vitrine wird der Baum zum Wertobjekt, er benutzt die allen Kunstobjekten eigene Distanz, aber gleichzeitig handelt es sich auch um eine Art schützende Aufbewahrungskammer, deren Unberührbarkeit uns zwingt, unsere Art die Natur zu betrachten und wahrzunehmen zu überprüfen. Ganz im Sinne Perraults: „Müssen wir etwa die echte Natur in einer künstlichen wiederfinden?“. Perrault nimmt eine Umgestaltung des Friedrich-EbertPlatzes, dem wichtigsten Kreisverkehrs in Düren, vor. Er umgibt die vorhandenen zwölf Kiefern jeweils mit einem Teppich aus Metallgewebe und macht sie zu Protagonisten der Stadteinfahrt von Düren (Düren, Deutschland, 2004). Nachts werden die Bäume von Halogenlicht künstlich beleuchtet, was das metallische Gewebe zum Schimmern bringt. Dies und das unregelmässige Scheinwerferlicht der Autos kreiert eine bewegliche und changierende Vision des Platzes.

Mit seinem Werk Public Toilets (Temse, Belgien, 1990) schlägt uns der Künstler afroamerikanischer Herkunft David Hammons, eine neuerliche Betrachtung der historischen Ikonographie des "ready-made" vor. In einem heimeligen Waldstück installiert, provozieren, die aus ihrem Kontext 
gerissenen Pissoirs, eine Verschiebung von Orten, die gleichzeitig die Aktivitäten an diesen Orten und ihren Gebrauch assoziieren lassen. Public Toilets entwirft ein Bild in uns von dieser ganzen Verschmutzung, die wir im Wald hinterlassen und wird zum reflektierenden Spiegel der dunkelsten, niedrigsten und von Exkrementen handelnden menschlichen Aktivitäten. Indem er sich des Begriffs Duchamps bezüglich des immanenten Wertes eines Objektes als Skulptur bemächtigt, beabsichtigt der Künstler mit einer kritischen Haltung und voller Ironie die Überraschung des Waldbesuchers zu provozieren, der nicht auf so etwas Unangemesses, Groteskes und Pietätsloses gefasst ist. Der Baum, und in einem größeren Ausmaß der Wald, werden $\mathrm{zu}$ einem Experimentierfeld und Forschungsgebiet für Künstler, zu einem Raum wo ein Assoziationsfeld beschrieben wird, welches offen ist für alle Interpretationen.

Die Künstler Christo \& Jeanne Claude benutzen für ihre komplexen, spektakulären und vergänglichen Interventionen die von ihnen üblicherweise angewandte Verwandlungsstrategie. In Verhüllte Bäume (Fondation Beyeler, Berower Park, Riehen, Schweiz, 1998) haben sie 178 Bäume in einen grausilbernen metallischen Stoff eingepackt. Der Stoff, der zur Umhüllung der Bäume benutzt wurde wird in Japan zum Schutz der Bäume vor Frost und Schnee benutzt. Dieses zitternde Netz wechselt sein Aussehen je nach Lichteinfall und Sonnenstrahlung und bewirkt auf diese Weise eine wechselhafte Wahrnehmung dieser eingepackten Baumvolumen. Das beeindruckende Schauspiel, das dieses Künstlerpaar darbot, nicht unüblich für ihre Projekte, bekam dieses Mal einen unüblichen sehr organischen Charakter. Die Baumverhüllungen unterschieden sich eine von der anderen und bekamen auf diese Weise eine überwältigend eigene Identität, die einen tiefen Eindruck auf Grund ihres figurativen Potenzials hinterließ. Gigantische Baumriesen die trotz ihrer Verwurzelung ihre Beweglichkeit zu Gunsten des Windes behielten.

Die unterschiedliche Behandlung, die die Künstler dem Baum zuteil werden lassen, ist hauptsächlich ausgelöst durch eine zeitgenössische Betrachtung, die sich das Element Baum mittels seiner Objektualisierung, Verfremdung und Kreuzung seiner Arten zu eigen macht. Salvador Juanpere zeigt uns eine zauberhafte Würfelsammlung in wunderbaren Exemplaren von Zedern in Alea Iacta Est (Art Public i Ecologia, Montornès del Valles, Barcelona, Spanien, 1993). Alea Iacta Est (Gaius Julius Caesar) 
ist ein Ausspruch Caesars auf deutsch: der Würfel ist geworfen. Seine metaphorisch-räumliche Darstellung, bezieht sich auf den nicht rückgängig zu machenden Spielzug, wie der Titel schon zeigt. Die Würfel sind geworfen, aber das Spiel ist nicht freiwillig beendet worden. Ist jetzt also die Natur selbst an der Reihe? Der Künstler will uns unter Zuhilfenahme des Zufallsaspekts den Zustand der Natur offenkundig machen. Der Betrachter stößt hier auf eine kritische und skeptische Anschauungsweise. Der Künstler zweifelt hier doppelt, einerseits an der Fähigkeit des Menschen sich mittels seiner Intelligenz das Überleben seiner Art zu sichern und andererseits die zweifelhafte Fähigkeit der Kunst soziale Umwandlung zu bewirken und Ideen und Ursachen zu beeinflussen.

Die Intervention Natural de Naturals (Zyklus Skulptur im Garten, Caixa Sabadell Stiftung Garten, Sabadell, Spanien, 1997) von Àngels Viladomiu an einer mächtigen Pinie und einem herrschaftlichen Exemplar einer Zeder, zeigt uns eine absurde Identifikation und eine Empathie zwischen dem Werkzeug des Bäumefällens und dem Baum, bis zu dem Punkt, dass der Henker sich in die Natur seines Opfers einfügt. Das Ergebnis ist ein Baumhybride, der durch das Infrage stellen eines Kunstgriffs verwirrt. Der hybride Baum ist das Ergebnis einer plötzlich eintretenden Situation, in der sich das Organische und Mechanische vermischt und dadurch einen ironisch und gleichzeitig kritischen Dialog provoziert. Seine Verwandlung bringt den Zweifel an der angeblichen Selbstverständlichkeit der Realität auf, indem sie Verwirrung und Unordnung stiftet und so versucht das unveränderliche Naturell der Bäume umzustürzen. Wie schon Jean Baudrillard (1978) uns erzählt, handelt es sich bei der visuellen Vortäuschung nicht darum, sie mit der Wirklichkeit zu verwechseln, sondern ein Trugbild im vollen Wissen dass es sich um ein Spiel und ein Kunststück handelt, zu erzeugen.

Der lebende verwurzelte Baum wird zum Träger von Objektinterventionen. Fremde Elemente werden in seine Struktur eingefügt. Die Motivation, die diese Interventionen antreibt, ist im Allgemeinen von einer expressiven, metaphorischen und poetischen Intention bestimmt, seine Absicht ist deswegen mehr erzählerischer Art als ein Verfahrensablauf. 


\section{Von Büchern und Bäumen}

Die Bäume und die Bücher haben immer diese paradoxe Beziehung geführt, in der die Natur des einen die Konsequenz des anderen darstellt. Allerdings, über diese Beziehung hinaus, enthalten Bücher Geschichten, Dichtkunst, Wissen, Worte... die der Baum auf geheimnisvolle Weise wiederaufnimmt in der Erfahrung seines Standorts. Wenn der Rohstoff, die Basis eines jeden Buches, von den Bäumen stammt, so existiert ein rückwirkender Kreislauf, in dem das, was die Bücher enthalten, wieder zu seiner bäumlichen Herkunft zurückkehrt.

Die Bäume sind nicht nur Bäume, sondern das, was sie uns bieten und nicht nur in materieller Art auf Grund ihrer botanischen Eigenschaften, sondern sie übermitteln auch durch ihren Standort Botschaften oder lösen Prozesse aus. Deswegen bieten die Bäume diesen Bühnenort, an dem ihr sozialer und kultureller Gebrauch, den eine bestimmte Gruppe ihnen zugewiesen hat, sichtbar gemacht werden kann. Verliebte Pärchen ritzen ihre Namen in seine Rinde ein und lassen so ihre Gefühle der Liebe offenkundig werden, dennoch handelt es sich hier nicht nur um einen Akt des Bekanntmachens, sondern diese Verletzung in den Bäumen stellt einen Weg der Verbindung zwischen dem Leben des Baumes und jenem Gefühl dar. Ian Hamilton Finlay knüpft an diese Thematik an, indem er fünf Steinplatten mit den Namen von bekannten Liebespärchen auf der Rinde anbringen lässt. Daneben wird den Bäumen mit einer Tafel, auf der ihr botanischer Name in Latein eingraviert ist, gedacht.

Finlays Intervention Domaine de Kerguehennec (Bretagne, Frankreich, 1986) lässt den Ort zu einem Sprachrohr poetischen Nutzens werden. Der Künstler erreicht so, dass der Garten als lebendiger Ort, voller Paradoxen in sich erhalten bleibt. In dieser Hinsicht ist sein gedanklicher Ansatz globalisierend, da er ein Freizeitgebiet errichtet, in dem Verbales und Visuelles, Poetisches Philosophisches und Botanisches zusammenfließt. Er führt uns seine Baumwelten als Bewahrungsstätte der Werte, Ideen, Kultur und Zivilisation vor.

Die Waldbibliothek von Miguel Ángel Blanco, begonnen im Jahr 1985, ist mittlerweile im Besitz von mehr als 1000 Holzbuchschachteln. Diese Bibliothek besteht allein aus dem Material, der Wälder des Fuenfria Tals (Guadarrama Gebirge), wo der Künstler seit über 20 Jahren wohnt. 
Ausgehend von der Philosophie eines Natursammlers, beansprucht dieses Werk eine methodische Herangehensweise zur Einordnung und Archivierung des gesamten im Wald gesammelten Materials, welches der Künstler in seinem eigenen künstlerischen Prozess über die Jahre gefunden und aussortiert hat. In dieser speziellen Bibliothek haben die Bücher die Worte hinter sich gelassen, um ein Wissen mittels Materie und Elementen des Waldes zu überliefern.

Dasselbe Procedere finden wir bei der sogenannten "Xylothek" aus der Epoche der Aufklärung, bei der die Buchbände die Taxonomie der Bäume veranschaulichen und jeder Buchband aus der Materie gemacht wurde, über die er auch berichtet. Die "Holzbibliothek" von Carl Schildbach in den Beständen des Kasseler Naturkundemuseums im Ottoneum ist die erste Sammlung ihrer Art (Feuchter-Schawelka, 2001b), sie umfasst heute noch 530 einzelne Bücher die aus 441 einheimischen Bäumen und Straucharten hergestellt wurden und in Form einer Enzyklopädie angeordnet sind. Wie die Wissenschaftlerin Anne Feuchter-Schawelka (2001a) beschreibt:
(...) aus jeder einzelnen Baum- oder Strauch-art eine Art Scheinbuch gebildet, dessen Äußeres aus Holz und Rinde besteht, während im Inneren die jeweiligen Blätter, Blüten und Früchte dreidimensional vorgestellt sind. Eingeklebte Legenden enthalten das damalige forstbotanische Wissen zur jeweiligen Art.
(...) Mit und im Holzkasten kombiniert und komponierte Schildbach somit Holzsammlung und Herbarium: Außen das Holz und innen dreidimensional die Pflanze. Ergänzt wurden die Naturalien durch auf den Kasten aufgeklebte schriftliche Informationen. ${ }^{2}$

Der amerikanische Künstler Mark Dion hat anlässlich der dOCUMENTA (13) eine neue Prasentationsarchitektur für diese außergewöhnlichen Artefakte entworfen, die ihre Bedeutung unterstreichen und ihre visuelle Präsenz dauerhaft verbessern soll. Diese heutige Bibliothek besteht aus einem sechseckigen Eichenholzkabinett - ein Verweis auf die kunsthistorische Bedeutung, die der Baum durch Joseph Beuys' Anpflanzung von 7.000 Eichen für die Documentas 7 und 8 in den Jahren 1982 bis 1987 für Kassel gewann -, in das eigens dafür angefertigte Regale eingebaut sind. Auf den Außenseiten befinden sich fünf Intarsientafeln, die jeweils das Bild eines Baumes zeigen; heraldischen 
Emblemen gleich stehen sie für Afrika, Asien, Ozeanien und Nord- und Südamerika, während Europa, Ursprungsort und Heimat der Sammlung, den Eingang bildet. Dion übernimmt die Xylothek als eine Art Readymade in seine eigene Installation, wobei er sechs neue Bücher hinzufügt. Fünf von ihnen zeigen ein besonderes Holz von je einem der fünf in Schildbachs Sammlung fehlenden Kontinente und bringen so deren enzyklopädisches Unterfangen zu einem symbolischen Abschluss, worauf das Documenta Begleitbuch verweist (Christov-Bakargiev \& Funcke, 2012).

Innerhalb dieser Tradition, in der Bäume Wissen und Information überliefern, finden wir auch die Dendogramme und Stammbäume. Ihre verzweigte Struktur vermag in ihrer Einheit Informationen über einen weiten Zeitraum verteilt darzustellen. In der Installation The Library for the birds of Antwerp (Museum für Zeitgenössischen Kunst, Antwerp, Holland, 1993) ist der Stammbaum hier durch das leblose und kranke Skelett eines Baumes dargestellt, auf dem Gegenstände, Bilder und Bücher ausgestellt sind, die den Vogelhandel, wie er in der Vergangenheit praktiziert wurde, dokumentieren und belegen. Der lukrative Handel in dieser Zeit mit exotischen Vögeln, der sich im 16. Jahrhundert ausbreitete und auf dem bekannten Vogelmarkt von Antwerpen stattfand, rottete bedauerlicherweise die Arten aus, die auf den Kacheln der Installation dargestellt sind. Der Künstler Mark Dion hatte den Museumsraum als temporäre Bleibe für 18 afrikanische Finken herrichten lassen, die vielleicht weniger süß gesungen hätten, wenn sie sich des Inhalts ihres derzeitigen Aufenthaltsortes ihrer Gefangenschaft bewusst gewesen wären. Der Künstler evoziert eine reale Erfahrung des Zuschauers, indem er einen Ausstellungsraum ohne die herkömmlichen Barrieren zwischen den Vögeln und dem Betrachter schafft (Corrin, Bryson, Kwon, Berger, 1997).

Die Video-Installation Assaig de mimologia forestal (Essay über die Mimologie der Bäume) (2005) von Perejaume knüpft an die antike Tradition der sprechenden Steineichen, Überbringer von Nachrichten der Götter des antiken Griechenlandes, an. In diesem Fall handelt es sich um Korkeichen, die mit Mikrophonen ausgestattet sind, damit die Bäume das Wort erhalten. Der Künstler überlässt und übergibt den Bäumen eine demokratische Stimme. Der erste Satz, der auf der Leinwand erscheint, sagt: Ein Baum richtet sich an die Menschen. Der Künstler greift mit diesem Satz die politische Idee des Anthropologen Bruno Latour auf, der 
die Natur als lebendige Einheit versteht, die angehört werden muss und ihre demokratischen Rechte besitzt (Latour\&Weibel, 2005).

Die Installation Codi de Subsistència (Lebensunterhalts - Code) (Bòlit, Centre d'art contemporani, Girona, Spanien 2011) von Àlex Nogué lässt sich wie ein Buch betrachten. Eine geometrisch fragmentierte Zeichnung bringt das Bild einer majestätischen Eiche hervor. Die verzweigte Struktur des Baumes verdoppelt sich durch die Spiegelung auf Wasserbehältern am Boden. Die effektvolle Inszenierung dieser eindrucksvollen auf den Kopf gestellten Eiche ermöglicht es uns in eine verkapselte Zeit einzudringen. Die Betonung des Zeitlichen, die die Fragmentierung des Baumes in der Zeichnung hervorruft, wird zu einem der wichtigsten Merkmale in der Arbeit Nogués. Innerhalb der Installation koexistieren gleichzeitig zwei Zeiten: Erstens die statische Zeit des Existenzraumes des Baumes, der dem Erfahrungsraum des Künstlers entspricht, und dies aufgrund des Prozesses der Entdeckung und der sorgfältigen Beobachtung mit dem Ziel, das Wissen um das Wesen des Baumes zu erreichen. Zweitens, die tatsächliche Zeit der Ausstellung, repräsentiert durch numerische Zeitmessung unter Verwendung zweier Digitaluhren, die in entgegengesetzter Richtung laufen, sozusagen in einem Wettkampf um das zeitlich Begrenzte. Und dies erinnert uns daran, dass die Gegenwart genau der Augenblick ist, der sowie der Vergangenheit als auch der Zukunft angehört. In den letzten Jahren hat Nogué seine künstlerische Forschung rund um die Figur des Baumes konzentriert. (Viladomiu, 2013a). In etwa einem Dutzend seiner Kunstwerke erscheint immer, wenn auch auf sehr unterschiedliche Weise, der Baum als Protagonist und die Ergebnisse sind in dem Publikationsprojekt „Dibuixar un arbre/ Drawing a Tree“ ${ }^{3}$ (Einen Baum zeichnen) (Nogué, 2013) gesammelt, wobei „zeichnen“ zum Strategiethema wird. Der Künstler verbindet auf magische Weise den Raum der Bäume mit der menschlichen Zeit und erreicht dadurch in seiner Arbeit, dass Bäume stimmungsvoll wirken (Viladomiu, 2013b).

\section{Baum und Körper: Performative Aktionen und Anthropomorphische Verbindung}

Die anthropomorphe Befähigung der Bäume, Stimmen und Geräusche zu hören und zu vernehmen wie auch Laute, Botschaften und Prophezeiungen 
auszusenden, scheint absolut universell in allen Kulturen und Baumkulten zu existieren. Einige Künstler richten ihr zentrales Interesse auf die Beziehung zwischen dem Baum und dem menschlichen Körper. Sowohl der Baum als auch der menschliche Körper sind Mutationen, Kreuzungen und Metamorphosen unterworfen, durch die der menschliche Körper bäumliche Aspekte annimmt und der Baum menschliche.

Viele Künstlerinnen haben die Thematik Baum-Frau aufgegriffen und sie von der Aktionskunst aus entwickelt. Auch wenn die Kunst Ana Mendieta als eine Kunst vom, mit und für den Körper darstellt, existiert doch eine enge Beziehung zur Natur. Ein umfassender Teil ihres Schaffens ist sogar mit dem Element Baum verbunden. In den siebziger Jahren, führte sie eine Reihe von Aktionen in einer Wüstengegend durch, die die Künstlerin als Dead Tree Area (Serie Tree of Live, Old Man's Creek, Iowa, USA, 1976) definierte. Während dieser Aktionen tarnte sie ihren Körper, indem sie ihn mit organischer Materie zwischen den Wurzeln, der Rinde und den noch stehenden oder umgestürzten Baumstämmen bedeckte. Für Mendieta gehört der weibliche Körper zur Landschaft und zur Erde, in der er seinen Abdruck hinterlässt; der Körper selber formuliert sich als Landschaft und wird zum Baum. In ihrer Kreation verwandelt sich der Baum in einen vergänglichen Raum. Das wäre ohne ihn so nicht möglich.

In der Aktion sich zu verwurzeln und sich zu pflanzen schlägt Fina Miralles mit Baum-Frau (Sant Llorenç de Munt, Barcelona, Spanien, 1973) der Frau, die der urbanen Kultur angehört, eine Rückkehr zur Erde vor. Auf diese Weise arbeitet sie mit dem Aufeinanderprallen von Kontrasten, mit der deutlichen Konfrontation zwischen der natürlichen Umgebung und der urbanen Kultur. Zweifelsohne nimmt diese Aktion Bezug auf die Fruchtbarkeit der Frau und zeigt, dass dieser Aspekt in verschiedenen Epochen der Zivilisation eine Verschiebung in die Pflanzenwelt erlebt hat. Das Bild der Frau kreuzt sich mit den Bäumen, um über Macht und Kraft der Fruchtbarkeit und über den Sinn des Lebenszyklus zu reden (Viladomiu, 2011b).

Die Künstler planen mit Erfindergeist und Kunstgriffen, die Wahrnehmung des Betrachters Richtung Baum zu schärfen und zu modifizieren. Es handelt sich um Projekte, in denen eindeutig die Prozesse der Wahrnehmung den höchsten Stellenwert einnehmen und mitsamt der aktiven Beteiligung des Betrachters in das Gesamtkonzept des Werkes 
integriert werden. Die folgenden Beispiele weisen zwei vollkommen unterschiedliche Thematiken auf. Zum Einen: Aktionen mit und über den Baum und zum Anderen: Artefakte, um die Bäume wahrzunehmen. In beiden Fällen allerdings existiert als gemeinsamer Nenner, die gegenseitige Beziehung, Benutzung und Wahrnehmung mit dem Körper, sei es der des Künstlers oder der des Betrachters.

Die Aktionen über die biologische Natur des Wesen „Baum“ und seine Wachstumsprozesse erreichen einen wesentlichen Stellenwert hinsichtlich des Experimentierens und der Forschung auf dem Gebiet der Physik, der Biologie, der Wissenschaft oder der Alchemie. Es gibt sogar genetische Experimente mit Bäumen künstlerischer Art, erinnern wir uns nur an das Werk One Tree (1999) von der Künstlerin Natalie Jeremijenko, das aus dem Klonen eines Baumexemplars bestand mit 100 identischen Baumnachfahren in einer Mikrokultur.

Ein Ergebnis der Arbeit mit der lebendigen Natur der Bäume ist ausgerechnet die Unberechenbarkeit, die ganz im Gegensatz zu dem Bestreben steht, alles in der Wissenschaft, und was die Menschheit betrifft zu kontrollieren und vorherzusehen. Somit stellen sich die Künstler der Herausforderung, mit einer wechselnden Materie zu arbeiten, die sich bis in die Zukunft erstreckt. Guiseppe Penone fügt den Bäumen in seinen verschiedenartigen Baumaktionen leichte strukturelle Veränderungen zu, die das Wachstum der Bäume modifizieren. Der gemeinsame Nenner befindet sich zwischen dem Körper des Künstlers und des Baumes: kneifen, nageln, festbinden, ziehen, verkürzen in diesem Spiel der gegenseitigen Beziehung wird der Faktor Zeit unersetzbar, um die Spuren des Künstlers auf den Baumkörpern wahrzunehmen. Die Arbeit Idee di pietra (2003/2008/2010) an der Kasseler Karls-Aue, der Bronzeguss eines Baumes der einen rissigen Stein trägt, ist in der letzten Documenta Kassel ausgestellt worden. Neben der Bronzeskulptur wächst ein kleiner Busch, dessen Wurzeln ihren Weg zwischen dem Bronzeguss finden. So wie das Documenta Begleitbuch (2012) beschreibt:

Die Skulptur (...) macht die sie umgebende Naturelemente und -Kräfte sichtbar: das Licht, das der Baum ständig verwandelt und das ursprünglich das Gewicht seiner Zweige bestimmte und sein Wachstum nährte; die Schwerkraft, die ihn auf immer und unausweichlich an die Erde fesselt. All diese dynamischen Elemente sind durch die Bronze in einem ewigen 
Augenblick aufgehoben, so dass die Skulptur zu einem festen Moment im Verlauf der Naturgeschichte wird. ${ }^{4}$

\section{Baum und Lebensraum/Architektur}

Abgesehen von dem schon vorher erwähnten Bezug Baum - Buch, darf nicht eine andere fast unvermeidbare Verknüpfung des Baumes mit dem architektonischen Element Säule außer Acht gelassen werden. Die Struktur der Bäume, ihre stoffliche Beschaffenheit und die Möglichkeiten, die der Baum zur Verarbeitung bietet, haben eine konstruktive Verwendung des Baumes verursacht. In Folge dessen hat eine funktionale und konzeptuelle Verschiebung des Stammes zur architektonischen Säule stattgefunden.

Dani Karavan, mit seinem Säulengang in der Straße der Menschenrechte (Nürnberg, Deutschland, 1989-1993) bezweckt eine Promenade, einen Durchgangsbereich erzählender Art, einen Gang der uns die Geschichte des deutschen Volkes bis zu unserer jüngsten Vergangenheit erzählt. Auf den Säulen ist die Deklaration der Menschenrechte, von der UNO 1948 angenommen, geschrieben. Der Künstler hat bewusst dieselbe Stadt ausgesucht, in der die nationalsozialistische Regierung ihre Rassengesetze verabschiedete. Die Paragraphen sind auf der einen Seite in Deutsch, auf der anderen in einer Sprache zu lesen, die von einem Volk gesprochen wird, das weltweit Opfer von Diskriminierung war, oder das sich durch seinen Widerstand gegen das Naziregime hervorgetan hat. Die monotone Geradlinigkeit der weißen Säulen wird mittels Ersatz einer Säule durch einen lebenden Baum, einer 10 Meter hohen Eiche, unterbrochen. Eichen stehen in enger Verknüpfung zu den germanischen Wurzeln als Symbol nationaler Identität. Der Baum stellt hier als universales, verbindendes, bleibendes und stabiles Symbol den Unterschied und die Einheit dar.

Die Verwendung des Paradiesbaumes (Ölweide) beim Baumdach des Garten des Exils (Jüdisches Museum, Berlin, Deutschland, 1990-1999) entspricht der symbolischen Bedeutung, die ihr der Architekt Daniel Libeskind geben wollte. Dieser Garten des Exils, symbolische und metaphorische Teil des Jüdischen Museums Berlin, besteht aus einem quadratischen, abgeschlossenen und begrenzten Grundriss, der um 12 Grad geneigt ist und vollkommen von einem labyrinthischen Raster aus 49 Betonstelen ausgefüllt ist. Die 6 Meter hohen Säulen sind mit Erde gefüllt, 
aus der die von einem Bewässerungssystem am Leben gehaltenen Bäume wachsen. Halt- und Orientierungslosigkeit prägt den Durchgang durch dieses trübselige Labyrinth. Metaphorisch gesehen, befindet sich die Hoffnung, die Flucht und das Entkommen aus diesem Labyrinth in seinem Baumhimmel, halb Wald, halb Architektur. Ein Baumdach, welches auf Grund seiner botanischen Besonderheit des Paradiesbaumes (Ölweide) an Olivenbäume erinnert. Auch als olibo-zume Beschreibung bekannt, ein wichtiger Hinweis darauf, dass der Baum mediterraner Herkunft ist, und die Erde, wo er gepflanzt worden ist, Israel, repräsentiert.

Als Weiterführung der Tradition, die Gothik und die Bäume zu verbinden, entwickelt der niederländische Künstler Marinus Boezem sein Projekt De Groene Kathedraal Die Grüne Katedral) (Flevoland Polder, Almere, Niederlande, 1978-1987). Fast 10 Jahre nach der Initiierung des Projekts, wurden in einem holländischen Polder 178 italienische Silberpappeln angepflanzt, die den Umriss der Kathedrale von Reims nachzeichnen. Die Bäume, in ihrer gotischen Erscheinung, stellen die Säulen jener Kathedrale dar. Zu diesem Zweck wurden speziell diese Art von Bäumen, die Silberpappel (populus alba) ausgesucht, damit die Annäherung -das aufrechte Wachstum der Stämme- und Ähnlichkeit -ihre Höhe kann bis zu 20- 30 Meter betragen- mit den Säulen einer Gotischen Kathedrale gewährleistet ist. Das Endprojekt besteht aus zwei Kathedralen: einer "positiven” Konstruktion, aus den 178 Silberpappeln bestehend und einer "negativen”, die über die Jahre wächst und aus einer Lichtung in Form des Umrisses der Kathedrale besteht.

Die Bäume sind die Wohnplätze schlechthin für die Vögel, wo sie nisten, allerdings sind sie auch mit der Zeit zu idealen Wohnplätzen geworden und möglicherweise waren unter unseren Vorfahren die ersten Baumbewohner. Die Performance Tree Dance (1971) von Gordon MattaClark ist das klare Ergebnis dieser engen Beziehung zwischen Mensch und Baum. Der Künstler entwickelt hier eine in dem Wachstum des Baumes inspirierte Choreographie, indem er die Energie des Baumes in tänzerische Bewegung umsetzt. Die Baumkrone wird hier zur Bühne einer Tanzaktion. Tree Dance, ist gleichzeitig von Matta-Clark als alternatives urbanes Wohnmodel gedacht, wie schon der Untertitel Tree House andeutet. Diese Aktion ist in der Tat nicht so weit von den Baumhäusern der Neunziger 
entfernt, die eine Konsequenz des militanten Widerstands zum Thema "Schützt den Wald" darstellen.

Eine Ähnlichkeit zu Tree Dance weist die Lazy Climbing (2011) Aktion der finnischen Künstlerin Pia Lindman auf. Sie bietet auf der Suche nach „Entgiftung“ in Performances und Workshops den Besuchern finnische Torfbäder, Körperbehandlungen und faultierartiges, kontemplatives Baumklettern in den Bäumen des Berliner Tiergartens an. Im Rahmen des Labor Berlin6 zeigt die Künstlerin Poison and Play (Haus der Kulturen, Berlin, 2011), das sich mit der Ver- und Entgiftung von Körper, Geist und Umwelt auseinandersetzt. Projektblog (Lindman, 2011) beschreibung:

Ihr Ausgangspunkt, von dem aus sie biochemischen,neurowissenschaftlichen, psychologischen sowie philosophischen Erklärungen folgt, ist die Frage, wie der moderne Mensch sich dazu verhält täglich von einer Vielzahl von Giften umgeben zu sein. (...) Die Arbeiten Pia Lindmans eröffnen ungewohnte Perspektiven: in der Tradition von Minimal Performance und sozialer Plastik kombiniert die Finnin künstlerische, gesellschaftliche und wissenschaftliche Recherche miteinander zu einer lebendigen veränderlichen Kunst. Die Partizipation der Betrachter ist dabei notwendige Voraussetzung aber auch in Lazy climbing die Bäumen spielen eine wichtige Rolle: „Wie faul Kletterer, erkunden wir Bäume als lebende Körper, mit dem durch die Schwerkraft und unseren eigenen Körper zu verbinden. Dies bringt unseren Körper an den Rändern der anderen Dimensionen, Erfahrungen und Wahrnehmungen: Was bedeutet die Welt wie auf den Kopf schauen, während hängen von einem Ast? ${ }^{5}$

\section{Baumbewohnte Szene}

Die Künstler führen in den Ausstellungsraum das Element Baum als Teil des Bühnenbilds ein, als Vorbedingung gilt das Konzept einer Installation. Die folgenden beiden Beispiele sind eine Ausnahme der hier analysierten und weit verbreiteten Verwendung des Baum als lebendiges Wesen. Obwohl es sich um tote Baumstämme handelt, schafft es das szenische Potential der beiden Kunstinstallationen diesen leblosen Wesen Leben einzuhauchen. Die Installation von Bill Viola, The Theater of Memory (Museum of Contemporary Art, Los Angeles, USA, 1985) ist eine umfassende Inszenierung, in der er den Baum dazu benutzt um von einem Teil unserer Existenz zu reden, und zwar jener Erinnerungen, die durch das 
Gehirn aktiviert werden. Der Baum verweist auf das verzweigte System der Neuronen in unserem Gehirn, die blinkenden Lichter der Laternen werden zum Antrieb unserer Erinnerung, die unscharfen Bilder werden von dem konstanten Geräusch der Glöckchen ausgelöst, der Gegenwart der Zeit.

Die site-specific Installation von Berlinde De Bruyckere im belgischen Pavillon der diesjährigen Biennale von Venedig, Kreupelhout (Unterholz) (2013) präsentiert einen beeindruckenden Stamm als einen verwundeten, kranken, im Sterben liegenden Baum, der den gesamten Pavillon einnimmt (De Bruyckere, 2013). Die Lichtgestaltung ähnelt Lucas Cranachs Malerei und die Künstlerin setzt in einer sehr persönlichen expressiven und dramatischen Bildsprache Aspekte wie Einsamkeit, Verstümmelung, Gewalt in Szene. Für diesen Anlass hat sie mit dem Schriftsteller JM Coetzee, dem Nobelpreisträger für Literatur im 2003 zusammengearbeitet. Coetzee (2013) beschriebt die Arbeit:

Ihre Skulpturen erforschen Leben und Tod - Tod im Leben, das Leben in den Tod, das Leben vor dem Leben, den Tod vor dem Tod - in die intimsten und Most störend. Sie bringen Beleuchtung, aber die Beleuchtung ist so dunkel wie es tief ist. ${ }^{6}$

Für die Künstler Fortuyn\&O’Brien nimmt eine herrschaftliche, den Garten dominierende Linde, die Rolle des Harlekins ein. In Harlequin (1984) umgrenzt den Baum eine Balustrade, um ihm so eine neue Beschaffenheit des bäumlichen Standorts zu verleihen. Sowohl der Titel wie auch die angegliederten Elemente verstärken das Bild eines im Geiste des 17.Jahrhunderts theatralisierten Gartens. Der Baum ist die Person, ist der Darsteller, der uns von dem Balkon der Natur aus betrachtet. In ihren Installationen schaffen es Fortuyn\&O’Brien ihren Objekten, Skulpturen und sogar ihren Bäumen aus den Gartenprojekten eine Menschlichkeit und Erlebnisbereitschaft zu verleihen.

Da Wald oder Baumgruppen ausgezeichnete Bühnenplätze für grenzüberschreitende Aktionen und kulturell moralisch-ethische Randereignisse darstellen, dienen sie heutigen Künstlern auch als geeignete Szenen für ihre Installationen. The Work is dedicated to an Emperor (2012) ist der Titel einer wechselnden und mobilen Skulptur von Maria Loboda. Ein Wald in Bewegung entsteht aus dutzend in Töpfe gepflanzter Zypressen, die langsam während der 100 Tage dauernden Documenta 13 
durch die Landschaft des Karls-Auer Park von Hand bewegt werden. In Anlehnung an die Abhandlung De re militari des römischen Kriegstheoretikers Flavius Vegetius Renatus und mithilfe eines Militärstrategen lässt die Künstlerin die Zypressen immer wieder neu formieren und verschiedene militärische Praktiken nachexerzieren und lässt die Bäumliche Armee langsam bis zur Orangerie vorrücken. Ohne Zweifel lässt die expressive Kraft dieser Szenen nicht nur eine groteske Ironie, sondern auch aus uralten Baumkulten überlieferte Rituale und Heilige Handlungen erahnen.

\section{Bepflanzungen}

Schlussendlich, finden wir Aktionen unter der Kategorie Bepflanzung, die sich einen Wiederaufbau und eine Forderung zum Ziel gesetzt haben. Beiden ist die ökologische Grundhaltung in Bezug auf die Natur und die Umwelt gemein, die manchmal bis zu aktivem Umweltschutz führen kann.

7000 Eichen (Documenta 7, Kassel, Deutschland, 1982-87) von Joseph Beuys stellt als Verschmelzung von Kunst, Gesellschaft und Umweltschutz ohne Zweifel einen Meilenstein in der Kategorie dieser Aktionen dar. Seine komplexe Struktur, was Ablauf, Finanzierung, Gesellschaft, Politik, Stadtplanung angeht, sein monumentaler Aufbau, seine enormen Ausmaße und Dimensionen im Raum und in der Zeit... und viele andere Aspekte, erfordern dass diesem Werk ein besonderer Stellenwert in dieser Arbeit eingeräumt wird. Schon im Jahr 1970 hatte dieser deutsche Künstler eine Konfrontation voller Kreativität und Forderungen im Wald angeregt: Die Ballade vom Grafenberger Wald. Anlässlich des Vorschlags das Waldgebiet am Rande von Düsseldorf, den Grafenberger Wald, in einen Golfplatz zu verwandeln, fegt Beuys mit 50 Studenten den Wald und markiert mit einem Kreuz die bedrohten Bäume, so als ob es sich um ein Ritual der Waldgeister aus der althergebrachten teutonischen Religion handeln würde (Schama, 1996). Im Jahre 1979 lässt sich Beuys als Kandidat der Grünen für das Europaparlament aufstellen, aber seine besondere Persönlichkeit machten ihn genauso unbequem für den Pragmatismus politischer Prozesse wie für die Konventionen der modernen Kunst. So suchte er neue Formeln und Wege, um eine gesellschaftlichhistorische Aktion zu beginnen, die eine direkte öffentliche Bedeutung hätte 
und seine Mitbürger dazu zwingen würde, sich mit der Realität auseinanderzusetzen. Hierbei handelte es sich, nach Beuys, um eine der einfachsten, aber umso stärkeren und machtvollsten Aktivitäten. „Das Bäume pflanzen“ wird zum Hauptantrieb seiner Kunst in den letzten Jahren seines Lebens.

Mit 7000 Eichen entwickelt Beuys das neue Konzept der Stadtverwaldung. Hier verwendet der Künstler wieder die Idee des Waldes als kollektives Symbol der Hoffnung auf das Überleben. Wir pflanzen Bäume und die Bäume pflanzen uns. Im Jahr 1994 wurde von einer Gruppe Kasseler Bürger die Stiftung 7000 Eichen eingeweiht, damit die Bäume im kollektiven Bewusstsein den Status als Kunstwerk und kulturelles Vermächtnis bewahren, wie auch zum Schutz des Kunstwerks, welches eine grundlegend andersartige Pflege benötigte.

Tasting Garden (Art Transpeninne, Yorkshire, England, 1996) des Künstlers Mark Dion, besteht aus einem Projekt, wo ein Obstgarten bestehend aus Apfelbäumen in eine Gartenanlage verwandelt wird, die aus einem Wegenetz besteht, welches für sich die Form eines Baumes annimmt. Jene Pfade führen zu Orten, an denen seltene oder vom Aussterben bedrohte Obstarten wiederangepflanzt wurden. Die Bronzeskulptur mit ihren überdimensionierten Früchten und einer Beschreibung, wie die Früchte schmecken, lädt den Betrachter dazu ein, direkt vom Baum die reifen Früchte zu pflücken, zu probieren und seltengewordenen Geschmacksreichtum und Intensität zu erfahren. Tasting Garden ist in einer gemischten Kategorie anzusiedeln, halb Garten (Landschaftsplanung) halb Kunstwerk: der Obstgarten wird zum Kunstwerk. Das Kunstwerk wird zum Obstgarten. Die zentrale Metapher dieses Obstgartens ist der Baum: der Baum des Lebens, des Wissens und der Stammbaum der Bäume (Viladomiu, 2011a).

In der letzten dOCUMENTA ist auch ein Baum in der Karls-Aue gepflanzt worden, aber dieses Mal war es eine ganz bestimmte und besondere Obstart, die als KZ-3 und später als Korbiniansapfelbaum bekannt wurde. Diese Obstart züchtete Koribinian Aigner, auch genannt der Apfelpfarrer, während seiner Gefangenschaft im Konzentrationslager Dachau. Jedes Jahr seiner Gefangenschaft gelang es Ihm neues Leben in Form von vier neuen Apfelsorten zu schaffen, die er taufte $K Z-1, K Z-2, K Z$ 3 und KZ-4 (Konzentrationslager), heute wird nur noch die KZ-3 kultiviert. 
In den Ausstellungsräumen des Fridericianum findet man eine Menge der etwa 900 Zeichnungen im Postkartenformat, in denen der Pfarrer über fünfzig Jahre lang die Bio-Diversität von Apfel und Birnen Sorten dokumentiert hat. Dieser systematische und unglaubliche Prozess ähnelt derselben Prozedur eines Konzeptkünstlers. Jetzt gepflanzt in der KarlsAue, gilt er als ein informelles (Gegen-) Denkmal, das dem in Dachau entspricht, so wie die Kurator Carolyn Christov-Bakargiev (2012) erläutet:

Auf einem kleinen Platz, der von Bürogebäuden und den Geschäftsräumen eines Autohändlers umgeben ist, gleich neben dem Museum der Dachauer Gedenkstätte, hat jemand auf eine Grünfläche (...) ihm zu Ehren einen zierlichen Apfelbaum gepflanzt; eine kleine Plakette erzählt die Geschichte an der Stelle, wo einmal der Dachauer Kräutergarten war mit all den Schmerzen, die sich mit ihm verbanden, wo einmal der Salbei und der Rosmarin und die Petersilie und die Apfelbäume und die Heilkräuter wuchsen und den Menschen zusahen und sich stumm vor ihnen entsetzten. ${ }^{7}$

Im Jahr 2005 aus Anlass der Retrospektive von Robert Smithson im Whitney Museum wurde die Realisierung des Projekts Floating Island, aus dem Jahr 1970 möglich. Seine schwimmende Insel sieht aus wie eine Art pflanzliche Archäologie, eine Erinnerung an das, was die Insel Manhattan einmal gewesen ist. Smithsons Idee war es, die schwimmende Insel wie ein Freilichtmuseum um Manhattan herum auszustellen. Diese Art Arche Noahs für pflanzliche Spezies soll an den archaischen und paradiesischen Zustand Manhattens wieder erinnern. Darüber hinaus handelt es sich um eine ausgezeichnete visuelle Metapher für die Problematik der Grünzonen in der Stadt. Vom Bereich der Kunst aus werden den Bäumen paradoxerweise nomadische Eigenschaften zugesprochen. Die nomadischen Anpflanzungen, stellen einen Ort der Identifizierung dar, der mit seiner poetischen Anwendung neuerlich einen Sinn für das Territorium erweckt.

\section{Schlussfolgerungen}

Dieser Artikel dokumentiert einen breiten thematischen Ausschnitt, wie auch die Vielzahl der von den Künstlern behandelten aktuellen Thematiken. Aus der gesamten Arbeit lassen sich folgende Schlussfolgerungen ableiten: 
Die vielfachen, wechselnden, zeitlich bedingten und vergänglichen Eigenschaften der Bäume machen sie zu einem idealen Objekt und geeigneten Vorwand für die geltende Heterogenität, die die zeitgenössische hybride Kunst erfordert. Diese künstlerischen Anwendungen der Bäume untermauern die Universalität und UN-Zeitlichkeit des Elements Baum (Jones\&Cloke, 2002).

Die Baumarten sind auf Grund ihrer botanischen, physischen, materiellen und räumlichen Eigenschaften ausgesucht worden, aber auch wegen ihrer kulturellen und symbolischen Bedeutung. Gleichzeitig zeigen uns diese verschiedenen Beispiele, warum nur allzu häufig Bäume dazu auserwählt wurden, als weltweit meistbenutzte Ikone für die Erhaltung und Zerstörung der Natur zu stehen. Angesichts des klar erkenntlich ökologischen Bewusstseins, haben die Künstler und Gestalter ihren Blick auf die Zerstörung der Umwelt, die Entwaldung, die Verschmutzung, die Entropie der Gebiete, den klimatischen Wandel und die Katastrophen gerichtet (Zybok\&Stange, 2009). In Folge dessen, legt ein Teil der Künstler, die ihre Werke innerhalb der Natur ansiedeln und dabei die Bäume zu Hilfe nehmen, den Akzent auf die Zerstörbarkeit der Umwelt und das bedrohte Gleichgewicht einiger Ökosysteme angesichts der konstanten Auswirkung des menschlichen Tuns.

Die zeitgenössische Kunst, die sich mit den Bäumen und Naturmythen beschäftigt, hat in diesem Medium ein Mittel gefunden, mit dem sie Integrität, Herkunft und Authentizität an die Oberfläche bringt. Zweifelsohne haben die Künstler im Baum einen geeigneten Mittler gefunden, der bestimmte Fragestellungen und Aspekte wie Identität und Ortansässigkeit, Zugehörigkeit, Gebiethaftigkeit aufwirft. Jeff Wall (2004) schreibt hierzu:

In this epoch, a tree standing self-consciously alone in the city would, better than any other monument or form of propaganda, evoke the environmental tragedy which indicts our economy, our culture of cities, our social order. ${ }^{8}$

Die Thematisierung der Bäume und die Würdigung eines Baumkultes in der zeitgenössischen Kunst und Kultur, - ja sogar eine Renaissance des zeitgenössischen Baumkults (Schawelka, 2004) in der abendländischen Kunst- beziehen sich nicht nur auf den, in den Vordergrund rückenden Umweltschutz, sondern verpflichten mittels Verwandlungen und Strategien 
zu einer neuen Einschätzung und Wertung des Elements Baum, zu einer zeitgenössischen Variante der althergebrachten primitiven dendrophilen Kulte.

Eine generelle Schlussfolgerung der hier vorliegenden Analyse ist es, offenzulegen wie die Kunst unserer Zeit die Haltung gegenüber den Bäumen seit uralten Zeiten und durch die gesamte Geschichte des Menschen aufgreift. Der Baum als lebendige Verbindung zwischen der Erde und dem offenen Raum, ist, wie ich schon in der Einleitung erwähnte, Objekt und Träger von Riten und heiligen Handlungen. Verwurzelt in der Erde und mit seinen Zweigen in den Himmel reichend, hat der Baum nicht selten für die Metapher der Menschlichkeit gestanden (Viladomiu, 2010).

Dieser Artikel belegt mit Kommentaren die Aussagen und Einstellungen verschiedenster Künstler, die in fächerübergreifenden und interdisziplinären Mischungen ihre Aufmerksamkeit auf dieses pflanzliche Element gerichtet haben und, dessen philosophische, ökologische, ethische und ästhetische Ausdrucksmöglichkeit erforschen. Trotz der unsicheren allgemeinen Weltlage, was die Zukunft unseres Planeten betrifft, sind es doch nicht wenige der zeitgenössischen Künstler, die ihren Blick auf dieses lebendige Produkt der Natur richten. Sie nähern sich dem Baum an, erforschen ihn, verwandeln ihn und vor allem benutzen sie ihn als lebende Metapher für unsere Furcht davor, was die Wirkung unserer Zivilisation bei der Natur anzurichten vermag.

\section{Notes}

1 Schawelka, Karl (2004), pp. 146-147.

2 Feuchter-Schawelka, Anne (2001a), pp. 5-6.

3 Viladomiu, Àngels (2013b). Llegir el Temps en l'Espai dels Arbres/Reading time in Tree Space, pp. 58-65.

4 Christov-Bakargiev, C., \& Funcke, B. (ed.) (2012), p. 289.

5 Lindman, Pia (2011). Lazy Climbers.

6 Coetzee, J.M. (2013). Berlinde De Bruyckere. Kreupelhout/Cripplewood. 55th International Art Exhibition_La Biennale di Venezia.

7 Christov-Bakargiev, Carolyn (2012). p. 34.

8 Wall, Jeff (2004). Into the Forest. Two sketches for studies of Rodney Graham's work, pp. 44-45. 


\section{References}

Baudrillard, J. (1978). Cultura y simulacro. Barcelona: Kairós, p.30. Brosse, J. (2001). Mythologie des arbres, Paris: Payot\&Rivages.

Christov-Bakargiev, C., \& Funcke, B. (ed.) (2012). dOCUMENTA (13).

Das Begleiybuch/The guidebook. Katalog/Catalog. (2012).

Ostfildern: Hatje Cantz.

Coetzee, J.M. (2013, january 25) Berlinde De Bruyckere.

Kreupelhout/Cripplewood. Paviljoen van België in Venetië | 55ste

Internationale Kunsttentoonstelling. Press statement, retrieved

September, 8, 2013, from http://www.smak.be

Corrin, L. G., Bryson, N., Kwon, M., \& Berger, J. (1997). Mark Dion.

London: Phaidon.

De Bruyckere, B. (2013) Kreupelhout/Cripplewood. In Belgian Pavillion

55th International Art Exhibition_La Biennale di Venezia. Retrieved

September, 8, 2013, from http://www.belgianpavilion.be/

Feuchter-Schawelka, A. (2001a). Carl Schildbachs "Holzbibliothek nach selbstgewähltem Plan" von 1788: Eine "Sammlung von Holzarten, so Hessenland von Natur hervorbringt”. Kassel:

Naturkundenmuseum, Stadt Kassel.

Feuchter-Schawelka, A. (2001b). Die Kasseler Holzbibliothek von Carl

Schildbach (1788). In Feuchter-Schawelka, A.; Freitag, W.; Grosser, D. (2001). Alte Holzsammlungen: die Ebersberger Holzbibliothek: Vorgänger, Vorbilder und Nachfolger. Ebersberg : Kreis-Sparkasse Ebersberg, pp. 46-51.

Jones, O., \& Cloke, P. J. (2002). Tree cultures: The place of trees and trees in their place. Oxford; New York: Berg.

Latour, B. \& Weibel,P. (ed.) ( 2005). Making Things Public. Atmospheres of Democracy. Cambridge: MIT Press and ZKM/ Zentrum für Kunst und Medientechnologie Karlsruhe.

Lindman, Pia (2011). Lazy Climbers .Retrieved September, 4, 2013, from http://lazyclimbers.blogspot.com.es/

Nogué, A. (ed.) (2013). Dibuixar un arbre/ Drawing a Tree. Barcelona: Comanegra.

Schama, S. (1996). Landscape and Memory. New York: Vintage Books. 
Schawelka, K. (2004). Heilige Eichen und andere Bäume in Kunst und Kultur, vorwiegend der Gegendwart. In Bonifatius. Eichenkult.

Erfurt: Kunsthalle, Volkskunde Museum, Stadtmuseum, pp. 146-179

Viladomiu, À. (2010). Baumkunst. The tree as an object, subject and

experimental territory of contemporary art. Barcelona: Universitat de

Barcelona. Retrieved from http://www.tdx.cat/TDX-0324110-

124043; http://hdl.handle.net/2445/35433

Viladomiu, À. (2011a). Actituds artístiques davant el canvi climàtic: del

naturalista a l'activista. Mark Dion/Hermann Josef Hack. Estúdio

3:Artistas sobre outras obras, 3, 318-323.

Viladomiu, À. (2011b). Dona-arbre de Fina Miralles. :Estúdio 4:Artistas

sobre outras obras, 4, 174-180.

Viladomiu, À. (2013a). Dibuixar el temps en l'arbre: Àlex Nogué. Gama.

Estudos artísticos, 1, 178-184.

Viladomiu, À. (2013b). Llegir el temps en l'espai dels Arbres/Reading time

in Tree Space. In Nogué, A. (ed.) (2013). Dibuixar un arbre/

Drawing a Tree. Barcelona: Comanegra, pp. 58-65.

Wall, J. (2004) Into the Forest . Two sketches for studies of Rodney

Graham's work. In Chillida, A. (ed.) (2004). Landscape\&Memory.

Madrid: La Casa Encendida, pp. 44-45.

Zybok,O.\& Stange, R. Existenz am Limit. Kunst und Klimawandel (2009).

Kunstforum, 199.

Àngels Viladomiu Canela: Profesora Agregada Interina en el Departamento de Escultura de la Facultad de Bellas Artes de la Universidad de Barcelona. España.

Contact Address: Facultad de Bellas Artes. Universidad de Barcelona. Departamento de Escultura. C/ Pau Gargallo, 4. 08028 Barcelona. España.

E-mail address: aviladomiu@ub.edu 
Instructions for authors, subscriptions and further details:

http://brac.hipatiapress.com

\section{Constructed News: Events and Rituals of Political Life}

Ramon Girona $^{1}$, Àngel Quintana ${ }^{2}$

1,2) University of Girona. Spain

Date of publication: February $3^{\text {th }}, 2014$

Edition period: October 2013-February 2014

To cite this article: Girona, R., Quintana, A. (2013). Constructed news: events and rituals of political life. Barcelona, Research, Art, Creation, Vol2(1), 81-99. doi: 10.4471/brac.2014.03

To link this article: http://dx.doi.org/10.4471/brac.2014.03

\section{PLEASE SCROLL DOWN FOR ARTICLE}

The terms and conditions of use are related to the Open Journal System and to Creative Commons Attribution License (CC-BY). 
BRAC - Barcelona Research Art Creation. Vol. 2 No. 1, February 2014, pp. 81-99

\section{Constructed News: Events and Rituals of Political Life}

Ramon Girona

University of Girona
Àngel Quintana

University of Girona

(Received: 16 September 2013; Accepted: 26 November 2013; Published: 3 February 2014)

\section{Abstract}

This text invites a reflection on early cinema, focusing on the model which gave rise to actuality film, the precursor of newsreels. Actuality film is understood not only as film which tries to document reality but as a model which purports to capture that which was, or would become, an event. The text also addresses the difference between "attraction" and "news", to conclude that news arises from a series of constructions designed to transform social impact factors, such as those elements which have shaped the chronicling of events or elements of political propaganda in a given event.

Keywords: Early cinema, actuality film, cinema of attractions, documentary, newsreel, film reconstruction. 


\section{Noticias Construidas: Acontecimientos y Rituales de la Vida Política}

Ramon Girona

Universidad de Girona
Àngel Quintana

Universidad de Girona

(Recibido: 16 Septiembre 2013; Aceptado: 26 Noviembre 2013; Publicado: 3 Febrero 2014)

\section{Resumen}

El presente texto plantea una reflexión sobre el cine de los orígenes, fijándose en el modelo que dio lugar al cine de actualidades, el antecedente de los noticiarios. La actualidad entendida no sólo como un cine a la búsqueda de documentar lo real sino como un modelo que pretendía atrapar aquello que era o se convertiría en acontecimiento. El texto también plantea la diferencia entre "atracción” y "actualidad", para concluir que la actualidad surge de una serie de construcciones encaminadas a transformar factores de impacto social, como los elementos que configuraban la crónica de sucesos, o elementos de propaganda política en un acontecimiento.

Palabras clave: Cine de los orígenes, actualidades cinematográficas, cine de atracciones, documental, noticiario, reconstrucción cinematográfica. 


\section{Documenting reality}

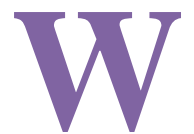

hen film historians attempt to define a specific date for the official birth of the documentary or its institutionalization, they tend to agree on Robert J. Flaherty's filming of Nanook of the north (Les Frères Revillon/Pathé Exchange; US/France, 1922) at the North Pole. The symbolic weight of Flaherty's film in the history of the documentary has been determined by the growing importance awarded over the years to British filmmaker John Grierson's canonical definition, according to which "The documentary is a creative treatment of actuality" (cited by Rotha, 1952, p.70). If we consider the emphasis acquired by the adjective "creative", this definition seems to have condemned all cinema filmed between 1895 and 1921 to oblivion, or at least to the status of simple newsreels of only ephemeral informative value.

Grierson's definition attributed a dual function to the documentary: on the one hand linking it to physical reality, while leaving aside the reproductive value of the medium, and on the other defending it as a creative pursuit that allows for a critical analysis of reality. It is true that all documentaries contain an element of falseness, since, as Stella Bruzzi asserted, no documentary can ever represent the real world. The camera cannot capture life as it is without causing interference because "the documentary always arises out of a process of collision between the camera and the subject" (Bruzzi, 2000, p.7). On the other hand, Grierson's canonical definition is not entirely correct, because many fiction movies also treat reality creatively. If we take as our starting point the discussions that took place in postwar Europe with the development of neorealism, taking in the films of Luchino Visconti and the model established by Roberto Rossellini, we see that the creative capture of reality was jeopardized in their films. Visconti felt that reality was to be constructed by seeking out a certain aesthetic of poverty, while Rossellini trusted the reproductive power of the camera and the way in which elements arising from fiction would conflict with reality, leading to the revelation of a hidden truth. Neither Visconti nor Rossellini made documentaries, but their films proposed a reflection on how cinema might be developed to creatively shape reality. ${ }^{1}$ 
Although most of the debates that have emerged on the definition of documentary have focused on realistic models and the role of the camera in capturing reality, we consider the newsreel to have played a key role. The newsreel institutionalized a system of capturing and a discourse on reality, turning it into a fundamental element for defining the value of the imprint the documentary left on both early cinema and the history of the informative image prior to the emergence of television news. Its appearance is clearly linked to the evolution of mass society, and specifically one of its manifestations: the illustrated press. This interaction helped to establish a number of information-related issues and problems that television later overcame via the creation of broadcast news. Aside from their value as a precedent for television news programmes, a further interest of newsreels is their means of generating a discourse on the ability of cinema to document the world; to certify, through the weight of photographic recordings, real processes that can be turned into images.

If we consider the origins of newsreels, we see there is a first step that comprised the capturing of real images; this first step is inscribed in the origins of the cinematographer, in the shots filmed by the Lumière camera operators, both in their immediate surroundings and in the remotest parts of the world. The relationship early cinema established with the idea of travel and a fascination with exotic faraway worlds involved searching for images of that which might become newsworthy, based on the canon established by the illustrated press of the time. In a canonical sense, Le couronement $d u$ Tsar Nicolas II (Charles Moison, Vue Lumière; France, 1896) was considered to mark the beginning of the phenomenon of the newsreel because the capturing of reality had moved towards the capturing of an event: the ritual of crowning the Tsar. The idea of capturing or reconstructing events from daily life soon expanded. Filmmakers at the Edison factory went from shooting small attractions for the company's Kinetoscopes to capturing or recreating newsworthy events of the age. Films made by a series of filmmakers with links to the Brighton school James A. Williamson, Alfred Collins, G. Albert Smith - had the clear aim of documenting their environment through the filming of events. Images of local events captured in Blackburn, in the county of Lancashire (United Kingdom) by Sagar Mitchell and James Kenyon, creators of the Mitchell \& Kenyon production company in 1897, also had an important bearing. Said 
images have today become the largest collection of documentary images to have survived from the early days of cinema (Toulmin et al (ed), 2004). Some of these images are distinctly of news items, such as different sporting images of football games, or a local parade filmed in Bradford celebrating the coronation of King Edward VII - the Bradford Coronation Procession (Mitchell \& Kenyon; UK, 1902) - which captures members of the different branches of the British Empire: India, Canada, Ireland, England, etc.

From 1908 onwards, the different systems of capturing the news became institutionalized and acquired a markedly informative character. Newsreels ceased to be isolated shots serving to complement programmes on all kinds of attractions in the emerging theatres of the age. Filming by camera operators at the French company Gaumont paved the way for Actualités Gaumont which, together with the creation of the Pathé Journal in France in 1909 - or its international spin-offs, such as British Pathé - grouped together different informative images and screened them in blocks of news. The Actualités Gaumont and the Pathé Journal, pioneers in the concept of newsreels, demonstrate that in the early days of cinema there was a clear desire to capture reality and document events taking place around the world, establishing a clear relationship with the world of journalism. Early cinema not only captured distant landscapes and urban shots, but also took an interest in events that were likely to be newsworthy. This desire to document and capture the evolution of events deemed newsworthy expanded in multiple directions during the years between the birth of cinema and the outbreak of the First World War, considered the first war in which the media image began to play a prominent role. The Great War marked a turning point in the evolution of the image because the different filming devices of the era were employed to capture images not only to create newsworthy documents, but to provide images for internal use by armies at war or in the world of medicine.

\section{News of events as cinema attractions}

To understand how images capturing reality have evolved, we must take a second to consider the definition of the concept of news. The key element that determines this notion is that the desire of the camera operator to 
document the reality appearing before the lens is no longer the only issue, as all reality would seem to be influenced by the notion of event. In the world of the press, anything that happens is seen as an event to be filmed. Early filmmakers captured all accidents and natural catastrophes, like the San Francisco earthquake of 1906. Sometimes they attempted to show certain aspects of black history. An important milestone in the relationship established between newsreels and images of events was the film by Thomas A. Edison Inc. entitled The Mob outside the Temple of Music at the Pan-American Exposition in 1901. The cameras were placed in front of the Temple of Music in Buffalo, in the state of New York, to document President William McKinley's visit to the Pan-American Exposition. Although the cameras did not capture the assassination of the president, which took place at close range while he was waving to the crowd gathered there, it did capture the agitated and anxious masses moments after his death. The camera shot, one minute in length, is filmed from distance and shows the heads of the stunned masses, while in the background movements can be detected of the group of citizens who wanted to capture the murderer, the anarchist Leon Czolgosz. Prior to the murder, the Edison Company camera operators filmed the president giving his last speech, before filming the transfer of the president's body from Buffalo to Washington.

A second milestone is that of British Pathé capturing images of the accident which caused the death of suffragette Emily Wilding Davison. The film is entitled Emily Davison throws herself under the King's Derby Horse (British Pathé; UK, 1913). Davison, considered a key figure in the struggle for women's right to vote in the UK, threw herself under the horse of King George V at the Epsom Derby on June 4, 1913. Images of the Derby report start by showing the preparations, the jockeys emerging, the spectators attending the race, etc., up until the moment when a camera randomly captures Emily Davison being hit by the monarch's horse, immediately followed by the crowd invading the track. Later, the news which testified to the event included images of the activist's funeral. The tragic death of Emily Wilding Davison turned the filming of what was supposed to be a sporting event into a document more characteristic of a chronicle of events. And finally, another milestone in the history of the genre are the images of the capture and killing of one of the most famous French bandits at the turn 
of the last century, Joseph Jules Bonnot, in Choisy-le-Roi, filmed by Pathé Journal camera operators on 28 April, 1912.

Although Filmmakers desire to create events arose out of their contact with the written press, it was also inspired in the notion of attraction formulated by Tom Gunning and André Gaudreault - a key element of early cinema (Gaudreault, 1989). To Gunning, the idea of attraction is characterized by "the existence of an element that appears suddenly, attracts our attention and disappears without developing a narrative line or coherent diegetic universe" (Gunning, 1986, p.65).

When in 1912 Franz Reichelt invited the cameras of the main newsreel companies to gather under the Eiffel Tower to witness how his batwinginspired costumes would allow him to descend comfortably to earth with no risk, what motivated the companies was attraction. Could the birdman land without killing himself? Would the birdman's leap from high be lethal? The dominant desire was to attract attention; the event was not going to change Parisian life of the age, but it did generate attraction due to the uncertainty inherent in the story of a man who would risk his life to show the effectiveness of his invention. The event ended in tragedy. It was captured by the newsreel operators, who placed their cameras on the first platform and at the foot of the Tower, and thus death in the face of the camera lens, adorned by media spectacle, ended up lending the event a certain poetry. ${ }^{2}$ In this case, attraction to the unusual is accommodated as news in the same way as attraction arising by chance was in the case of the death of Emily Davison. All of these examples opened up a path that has remained welltrodden to this day.

The difference between attraction and news resides in the fact that what in attraction is curiosity and sensory impression, in news becomes social relevance or public interest. News did nothing other than move into the territory of images those issues that the photojournalism of the day had institutionalized: official acts, political commemorations, events, wars, etc. In the early days of cinema, the idea of documenting the event to turn it into news did not always involve a certification of truth, because what matters is not the guarantee of reality implicit in the image but rather the way in which the image is able to shape an occurrence that has turned into an event. 
Newsreel images were subject to two basic limitations from the very beginning: distance and time. These two constraints meant that when the camera arrived at the event it was either too late or distance impeded capturing images of what was happening. Images of the San Francisco earthquake in 1906 do not show the moment of the tragedy, but rather the destroyed houses, the work of the firefighters and horse-driven ambulances passing by. The cameras captured the effects of the tragedy, but not the earthquake itself. However, together with these images, in 1906 the Biograph Company filmed studio-reconstructed images using miniature models of the crumbling buildings and the fire. ${ }^{3}$ Georges Méliès reconstructed Éruption volcanique à la Martinique (Star Film; France, 1902) in a studio, attempting to reproduce the tragedy that caused the awakening of a volcano Mont Pelée in the centre of Martinique. The cameras could not be there and it was necessary to recreate, through simulation, a certain reality effect, playing with models, sets and pyrotechnics. Georges Méliès also recreated L'affaire Dreyfus (Star Film; France, 1899) at the Robert-Houdin Theatre, in eleven scenic pictures.

Edwin S. Porter shot the execution of the anarchist who assassinated President William McKinley for the Thomas A. Edison Inc. under the title Execution of Leon Czolgosz with Panorama of Auburn Prison (Thomas A. Edison Inc.; US, 1901). The film is of interest because it mixes documentary image with reconstructed fiction. In this case, the problem arose because no camera operators were granted permission to attend the execution first hand. We initially see a panoramic shot, followed by a travelling shot from a vehicle in front of the actual walls of Auburn Prison. The two images were captured on October 29, 1901, the same day that the anarchist was to be executed. The shot serves to certify the presence of the cameras, the fact of having been there. Porter gives the images an added realism by showing a train moving outside the prison. A dissolve out moves us from the background to the distant background and allows us to enter the reconstruction of the event using actors in the Edison studio. A group of actors playing prison guards approach Czolgosz' cell and remove the actor who plays him from it. Another dissolve takes us to the electric chair in which he is to be executed. The group of guards moves with the prisoner from the left to right of the frame, establishing a minimal narrative continuity between shots. The image of the prisoner strapped to the electric 
chair is a frontal image, which attempts to capture the many details of the situation. According to the Edison catalogue, it is thought that Porter based his reconstruction of the events on the detailed chronicles appearing in the press of the time. The film ends with the seizures of the accused caused by the electric shock, as we see smoke coming out from behind the chair and a doctor certifying his death, emphasizing all of the movements so that the action in the general shot is clear. As Mary Ann Doane suggests with regard to the film, it is interesting to note that the desire to reconstruct the execution in the electric chair was closely related to the role of electricity as a new source of economic power in those years. In line with this, the PanAmerican Exposition, where President McKinley died, took place in Buffalo so as to advertise the power of electricity from turbines activated with water from Niagara Falls (Doane, 2002).

In Spain, as demonstrated by Begoña Soto, the film Asesinato y entierro de Don José Canalejas (Iberia Cines; Spain, 1912) mixed a reconstruction of the assassination of the Spanish Prime Minister on 12 November, 1912 based on images reconstructed from the press of the time - with documentary footage of the funeral (Soto Vázquez, 2012). The first part was produced as fiction, centring on the moment when a young anarchist shoots the Prime Minister from behind while he looks into a bookstore window. Professional actors were used in the reconstruction, including Pepe Isbert - later known for his starring roles in such films as Bienvenido Mr. Marshall (UNINCI; Spain, 1952) and El verdugo (Interlagar Films/Naga Films/Zebra Films; Spain/Italy, 1963), both by Luis Garcia Berlanga - who played the anarchist Manuel Pardiñas, author of the murder.

The mixture of reality and fiction, of document and reconstruction, generated a new order of discourse regarding the concept of truth in the news. The truth, then, was not determined by what happened but by the construction processes carried out in parallel by the press, and by the way it is revealed; or what François Jost has defined as feintise. Jost believes that a number of concepts that continue to appear in discourses on both what is real and what is false - lying, the virtual, the truth or misleading appearance - do not conform with what early cinema was attempting to achieve. La feintise - or that which is being feigned - is "the element that lends a document a vivid dimension” (Jost, 2001, p.94). Audiovisual feigning is not a deceit, but rather the system of creating a certain degree of trust in 
viewers, to the point that they stop worrying about whether what they see is real or simulated. Knowing whether the images of the attack on José Canalejas are true or false is of no importance, because what was important to viewers of the time was the act of perception, allowing them to experience what they saw as if they had been there themselves. To accomplish this effect, what is feigned must fit the codes by means of which the photographic images of an event in the illustrated press were previously created.

It is important to note that cinema emerged at a key moment in the development of the written press and the graphic media and soon also played a key role in creating a certain imaginary in current affairs. Despite the relationship established between cinema and the news, we must consider the early days of cinema as an intermediate space in which there was a legacy from other forms, such as the painting of events, images projected in magic lantern shows, graphic images in the Mondo Novos, cartoon strips illustrating events in the press and the legacy of popular shows in which current events often figured, as is the case with wax museums. In this last sphere we must consider, as stated by Vanessa R. Schwartz, that the wax museum reflected reality and helped turn it into a show, especially tragic events, along with panoramas, dioramas and the morgue (Schwartz, 1998). Among the objectives of the principal wax museums created in the late nineteenth century - the Musée Grévin in Paris or Eden Musée in New York, for example - was that of creating a space to show visual information regarding events. Some of these museums incorporated as part of their shows magic lantern projections of current affairs, depicting some themes that would later be filmed, such as military parades, royal visits, events and military conflicts.

\section{Newsreels and the creation of the image of political power}

The construction of newsreel models was also a key factor in the emergence of new systems of relationship with political power. The ritualization of power on the basis of its ornamental and monumental nature, the royal procession, and the deification of the monarch underwent a radical change with the advent of the camera. The monarch was no longer someone exhibited before a particular community of subjects, but rather someone 
who could use the power of the moving image to make their image omniprescent or to publicize their acts as something newsworthy that would be spread easily through the media. However, the relationship between image and power was not an easy one in this regard. Some monarchs were slow to understand the symbolic significance of cameras as key elements in the emergence of a new mass society. Studying the relationship between the camera and power is interesting because it highlights the difference between the old world and the new. While in the old European monarchies the cinematic device was not fully assimilated by the different power systems, in the United States the first president of the cinematographic age, William McKinley, actively used it in his campaigning, relating it to the new image technologies emerging in the late nineteenth century. In an attempt to understand this distinction, we shall focus mainly on a comparison between the way in which the Spanish monarchy was filmed by Segundo de Chomón and the images of McKinley's campaign captured by Edison camera operators. A prominent element of this comparison is the position those in power award the camera to allow more insight into their rituals.

In 1902, Segundo de Chomón and his wife, Julienne Mathieu, opened a workshop in Barcelona to work on the aniline colouring of films the French company Pathé distributed at fairs and variety theatres. Among the documentary films shot by Chomón and still preserved in the archives of the Autonomous Government of Catalonia's Film Libraries, there is an incomplete, enigmatic film entitled Réception de SM Alphonse XIII à Barcelone (Pathé Frères; France/Spain, 1904). Despite its eloquent title, the strength of the film does not lie in its value as a historical document, but in how its structure reveals that those in power did not consider newsreels key to projecting their public image. The film, No. 1082 in the Pathé catalogue, depicts a public ceremony of great political significance at the time. It shows a moment from the official visit by the young King of Spain, Alfonso XIII, to Barcelona in April 1904. The monarch, who had just turned eighteen, travelled to Catalonia with his mother, María Cristina. Shooting followed the model instituted by Lumière operators for the images of the coronation of Tsar Nicholas II shot in Moscow. Segundo de Chomón situated the camera in an unfavourable position in the middle of the audience that prevented him from clearly capturing the majesty of the 
monarchical ritual. The images he did capture reflect the inability of the camera to establish a minimum control over randomness, and bear witness to the monarchical ritual without any shots of the dignitaries who accompanied the king being recorded by the cinematographer. So what did this documentary really show? Objectively, we can say that the images basically show a crowd of spectators looking for a gap in the crowd so as to observe the monarch up close. The figure of the king is completely eclipsed by the bodies in the audience.

If we analyse the documentary shot from the perspective of the classical model of composition, in which the main figure occupies the centre of the space and the secondary elements acquire a merely decorative function, we can say that in the only filmed images that remain from the reception Barcelona offered Alfonso XIII, the monarch is almost a spectre located in a collateral position relative to the centre of the action: a blurred figure that emerges sporadically from the audience at one end of the frame. The protagonist of the shot is the audience who receive him.

In the foreground of the shot is a group of women taking out their handkerchiefs to greet someone important leading the procession passing before them. After the first line, we find some empty space flanked by a group of spectators, mostly male, who are actively seeking a spot from which to observe royalty in the flesh. The crowd mass to form a human wall that fills the entire visual field. Between the wall of bodies, hats and handkerchiefs, we discern some signs of the presence of the entourage: the top of a canopy of golden columns, indicating that under the ornament moves the blessed figure of the monarch. The feathers of an army dress hat reveal that the royal entourage is quite large and that the ceremony seeks to possess that solemnity characteristic of large-scale monarchical ceremonies inspired in absolutism. Faced with the saturation of its direct field of vision, Chomón's camera is powerless to reflect the solemnity of the event. The camera operator has no special angle from which to view it.

Réception de sa majesté Alphonse XIII à Barcelone is a cinematographic news report that represents the attitude held by certain sectors of European political power regarding the presence of cameras intended to record specific events. The presence of the camera as a device is ignored; it can only be situated in the discrete position of the public and the images end up reflecting all the limitations that any individual located in the crowd might 
experience. In 1904, when Segundo de Chomón shot these images, there did not exist among most European monarchies an awareness of the political role that cinema would come to assume, nor of the way in which the camera could transform the event into a document for posterity. Nor did they yet envision that the cinematographer would become a key instrument in constructing and disseminating the rituals of political power.

The title of Chomón's film hides, as previously stated, the microstructure of a story in which there is a protagonist - the king - and an action - the reception. It also establishes an order of discourse that serves to guide the viewer while constructing a particular story. The title brings an order to a chaotic reality that the camera was unable to produce. In his book Temps et récit, Paul Ricoeur has shown how temporal integration is the basis of every story. From the moment we use memory to order time which has passed, and we present chronologically the basic actions that took place during this space in time, we are organizing a story. The act of imitating the world is completely determined by the synthesis we establish of the phenomena and actions that take place in this universe (Ricouer, 1983).

In Segundo de Chomón's cinematographic news report, the point of reference is observed from a single viewpoint, as in the shots filmed by the Lumière brothers, the film being recorded with the intention of building a single shot without the need for editing. Despite this, as André Gaudreault has shown in his analysis of elements that attest to the existence of editing in early cinema, different stops of the camera reveal a primitive form of editing, as they break up the time unit of the shot (Gaudreault, 2000). Nevertheless, in Chomón's film there is a certain uniformity. In the construction of the shot a series of signs betray the camera operator's movements with the camera and demonstrate how during filming he tried, unsuccessfully, to overcome the obstacles that stood between him and the event he wanted to shoot. Therefore, Chomón's film cannot be the objective and mechanical reproduction of an event because it reveals the presence of subjectivity. Newsreels highlight the existence of a subject responsible for this narrative who is struggling to order the world and establish a discourse based on reality.

This conflictive relationship between the old European monarchical power and film is also evident in the process that led to the shooting of the coronation of Edward II of England in London. In this case, the initial 
outdoor position of the camera was a privileged one; the problem came with the reconstruction of the ceremony to crown the monarch, which took place at Westminster Abbey. Different companies (Charles Urban Warwick Trading Company, Gaumont, Hepworth and Biograph) requested permission to film in the space between Constitution Hill and Buckingham Palace. However, due to the future monarch suffering from appendicitis, the coronation was postponed from the initial date of June 26, 1902 to August 9 of the same year (Brown and Barry, 1999).

The different companies were given permission to film the procession between Buckingham Palace and Westminster Abbey, passing through The Mall and Parliament Square. The camera operators of the different companies sought to take up the best positions and some, like the Gaumont operators, attempted to devise systems that would allow them to film panoramic shots of the procession. Unlike the Spanish case, the positions of the operators were key and it is estimated that 40 films were made of the procession, in addition to those shot by the film makers Mitchell and Kenyon of side events that took place in some cities in northern England. As revealed by Stephen Bottomore, the problem arose when the Office of Works, responsible for giving permits for the filming of the actual event, decided that no camera operator could be allowed inside Westminster Abbey to film the ceremony (Bottomore, 2012). As a result, entrepreneur Charles Urban commissioned Georges Méliès to rebuild the coronation ceremony using actors. Méliès filmed a few days before the ceremony, drawing on the protocol established by Lord Esher, who was in charge of the ritual. ${ }^{4}$ Two different versions were made, one for the British audience and one for international audiences. The reconstructed images were broadcast together with documentary images of the procession.

The images of the coronation of Edward VII and the cinematic report the reception of HRH Alfonso XIII in Barcelona show how the rhetoric of power worked by means of what Louis Marin has identified as the process of ritualizing figures in the royal procession, the symbolic force of whom is achieved by establishing links with the rituals of religious liturgy (Marin, 1991). Thus, for example, the thalamus under which Alfonso XIII sits at the Barcelona reception was an instrument used by the Church to remove the pyx from the tabernacle and parade it through the secular world. As a person blessed with divine power, the king occupied the same position as 
the body of Christ. This symbolic weight is also found in Méliès' reconstruction of the coronation ceremony, which left aside fey artifices, typical of the films of his production company, Star Films, to acquire a more "realistic" tone. The viewer of the time fully understood the symbolism, and thus it reinforced worship of the figure of the monarch as a representative of the divine.

In the United States in 1896, as researched by Charles Musser, the cinematographer played a key role in the presidential election campaign (Musser, 2012 and also Auerbach, 1999). Of the images captured by cameras of the American Mutoscope Co., two were key in the election process. The first, entitled McKinley at home (American Mutoscope and Biograph Company; US, 1896) was filmed by W.K.L. Dickson, owner of the aforementioned company, at the candidate's summer residence in Canton (Ohio) (Spehr, 2008). The other image shot of President McKinley showed him arriving on the Empire State Express via the New York Central Railroad. These two images were edited alongside images of the actor Joseph Jefferson playing Rip Van Winkle, and other images of cadets at West Point and also shots of Niagara Falls. This group of images was used in the election campaign as an indication of the candidate's Americanness. McKinley's short term as president - he was murdered, as we have seen, in September 1901 - was marked by the presence of cameras, even in the moment immediately prior to his death.

While on the old continent of Europe the rituals of power followed the symbolic order of ceremonial policy, in the New World the idea was established of relating politics to the new technologies of the age, using film to bring the image of the politician closer to the spectators, creating a new relationship between power and information systems. The act of inviting the American Mutoscope Co. camera operator to film in the garden at the summer residence of the Republican candidate denotes a radical paradigm shift in the way the image of power was constructed. On the one hand, the idea of the cinematographer having an unfavourable position with regard to some systems of power was anulled, and on the other the idea of using the event - the news - to strengthen the public image of the powerful was left behind. The cameras visited the candidate's garden to show his familiarity and generate an electoral propaganda policy that would remain effective for many years to come. 
The study of cinema newsreels not only allows us to reflect on what was filmed but also begs the question of what was missing from this type of film. It is clear that we are dealing with a model of the image that is determined by a series of ideological factors - race, power, gender, colonialism, etc. - to reveal systems that end up being institutionalized as news programmes. It is also important to consider not only the mindsets of the era, but also the systems of censorship that limited certain areas of visibility. The passage from isolated newsreels to news programmes Pathé, Gaumont, Fox, etc. - involves viewing the world as a large news map. In this context, the news unit will be conceived by following the guidelines established by the written press, to the point that images will be progressively determined by the textual component, which will be manifested through all kinds of intertitles, generating systems of segmentation but also classifications of news. Moreover, the examples studied certify that actuality does not arise from a desire to create an image of the world, but from a series of constructions designed to transform factors with a visual impact or elements of political propaganda into an event.

To conclude, it would be appropriate to point out that, in the case of newsreels, an interesting phenomenon often takes place that demonstrates both their value as news reports of the age and their reuse in subsequent film edits, which transform and manipulate them, placing them at the service of a certain discourse. Newsreels thus become an important audiovisual archive used as a basis for designing the unconscious imaginary of an era. This phenomenon sees newsreels of the age reused in some canonical examples of compilation films such as The Fall of the Romanov Dynasty (Esfir Shub, Sovkino; Soviet Union, 1927) or Paris 1900 (Nicole Védrès, Panthéon Productions; France, 1947), which use images from prior to 1914 as their basis. In many cases, images from the past take on another life, but also another meaning. Their reuse takes place not only in canonical films but in all kinds of historical documentary based on archive footage, which is made to fit the relevant verbal discourse or editing idea. The problem that ultimately arises with the use of images as an archive is seen in the debate between their value as a document of reality or as a document of ways of thinking or institutionalizing what is newsworthy. 


\section{Notes}

${ }^{1}$ Regarding realist construction and debates arising in neorealism, one of the authors of this article has discussed this theme in the following book: Àngel Quintana, Fábulas de lo visible. El cine como creador de realidades (Barcelona, Acantilado, 2003). In fact, although the majority of their films were fiction, both Rossellini and Visconti directed a number of documentaries. Rossellini made India: Matri Bhumi (1959), and also did some documentary work for television such as L'India vista da Rossellini (1959), Sicilia, idea di un'isola (1967) or Intervista a Salvador Allende: La forza e la ragione (1971). On the other hand, Visconti worked on the collectively made documentary Giorni di Gloria (1945), about the Nazi massacre at the Fosse Ardeatine in Rome.

2 About Franz Reichelt see: Bazin, A. (1998) Morts tous les après-midi. In Bazin, A., Le cinéma français de la Libération à la Nouvelle Vague. Paris: Cahiers du cinéma, 367-373. And about the film: Death Jump - Eiffel Tower (British Pathé; France, 1912)

${ }^{3}$ San Francisco: Aftermath of Earthquake (American Mutoscope \& Biograph; US, 1906)

4 Le sacré d'Edouard VII (Georges Méliès, Star Film/Warwick Trading Company; France/UK, 1902)

\section{References}

Auerbach, J. (1999). McKinley at Home: How Early American Cinema Made News, American Quartely, 51 (4): 797-832. Retrieved December 5, 2013, from http://www.jstor.org/stable/30041673 Bazin, A. (1998). Morts tous les après-midi. In: Bazin, A, Le cinéma français de la Libération à la Nouvelle Vague. Paris : Cahiers du cinéma, pp. 367-373

Bottomore, S. (2012). Filming and « Faking » a News Event - The Coronation of Edward VII (1902). In Quintana, A. and Pons, J. (Eds.), La construcció de l'actualitat en el cinema dels orígens/The construction of news in early cinema. Girona: Museu del Cinema. Col·lecció Tomàs Malloll/Ajuntament de Girona, pp. 51-65. Brown, R. and Barry, A. (1999). A Victorian Film Enterprise: the History of British Mutoscope and Biograph Company, 1897-1915. Trowbridge: Flick Books.

Bruzzi, S. (2000). New Documentary: a critical introduction. London: Routledge.

Doane, M. A. (2002). The Emergence of Cinematic Time. Harvard: Harvard University Press. 
Gaudreault, A. (1989). Le cinéma des premiers temps: un défi à l'histoire du cinéma? In Aumont, J., Gaudreault, A. \& Marie, M. (Eds.) Histoire du cinéma. Nouvelles approches. Paris : Publications de la Sorbonne/Colloque de Cerisy, pp.49-63.

Gaudreault, A. (2000). The Diversity of Cinematographic Connections in the Intermedial Context of the Turn of the Century. In: Popple, S \& Toulmin, V. (Eds.) Visual Delights: Essays on the Popular and Projected Image in the 19th Century. Trowbridge: Flicks Books, pp. 8-15.

Gunning, T. (1986). The Cinema of Attractions: Early Film, Its Spectator and the Avant-Garde. Wide Angle, 8 (3-4), 63-70.

Jost, F. (2001). La télévision du quotidien: Entre réalité et fiction.

Bruxelles : De Boeck/INA.

Marin, L. (1991). On Representation. Palo Alto: Stanford University Press. Musser, Ch. (2012). Cinema, Newspapers and the US Presidential Election of 1896. In Quintana, A. \& Pons, J. (Eds.), La construcció de l'actualitat en el cinema dels orígens/The construction of news in early cinema. Girona: Museu del Cinema. Col-lecció Tomàs Malloll/Ajuntament de Girona, pp. 65-84.

Ricoeur, P. (1983). Temps et récit. Vol 1. Paris: Éditions du Seuil. Rotha, P. (1952). Documentary Film. London: Faber and Faber.

Schwartz, V. R. (1998). Spectacular Realities. Early Mass Culture In Finde-Siècle Paris. Berkeley /Los Angeles/London: University of California Press.

Soto Vázquez, B. (2012). Actualidad reconstruida/reconstrucción de la actualidad. El caso de Asesinato y entierro de Don José Canalejas (Iberia Cines, 1912). In Quintana, A. \& Pons, J. (Eds.) La construcció de l'actualitat en el cinema dels orígens/The construction of news in early cinema. Girona: Museu del Cinema. Col·lecció Tomàs Malloll/Ajuntament de Girona, pp. 167-179. Spehr, P. C. (2008). The Man Who Made Movies: W. K. L. Dickson. New Barnet (Herts): John Libbey.

Toulmin, V. Popple, S. \& Russell, P. (Eds.) (2004). The Lost World of Mitchell and Kenyon: Edwardian Britain on Film. London: British Film Institute. 
Ramon Girona: Professor of Audiovisual Narrative and

Coordinator of the Degree in Advertising and Public Relations at the University of Girona.

Contact Address: Plaça Ferrater Mora, 1. 17071 Girona. Spain.

E-mail address: ramon.girona@udg.edu

Àngel Quintana: Professor of History and Theory of Cinema and Director of the Master on Communication and Cultural Studies at the University of Girona.

Contact Address: Plaça Ferrater Mora, 1. 17071 Girona. Spain. E-mail address: angel.quintana@udg.edu 
Instructions for authors, subscriptions and further details:

http://brac.hipatiapress.com

\section{Teresa Margolles. Reiterar la Violencia}

Maria Campiglia ${ }^{1}$

1) University of Barcelona. Spain

Date of publication: February $3^{\text {th }}, 2014$

Edition period: October 2013-February 2014

To cite this article: Campiglia, M., (2013). Teresa Margolles. Reiterar la Violencia. Barcelona, Research, Art, Creation, Vol 2(1), 100-125. doi: 10.4471/brac.2014.04

To link this article: http://dx.doi.org/10.4471/brac.2014.04

\section{PLEASE SCROLL DOWN FOR ARTICLE}

The terms and conditions of use are related to the Open Journal System and to Creative Commons Attribution License (CC-BY). 


\section{Teresa Margolles. Reiterating Violence}

Maria Campiglia

University of Barcelona. Spain

(Received: 8 December 2013; Accepted: 7 January 2014; Published: 3 February 2014)

\section{Abstract}

For over two decades, the work of Teresa Margolles has held an important position in Mexico's artistic circuit, and in the last few years it has been consolidated at an international level, with exhibitions at important fairs and biennials as well as important awards. But what view does it offer in relation to our present environment?

It has been argued that the importance of her work lies in its capacity to make the violence we live today in Mexico visible to the spectator, thus giving the victims a voice. She maintains that the basic sense of her work is to make evident the fact that the victims are individuals with particular stories and not just numbers.

The present article attempts to challenge these arguments based on an analysis of the procedures she follows to create her work. Are we looking at the art of social protest or are we merely witnessing a violent exercise perpetrating itself twice on the same body?

Keywords: Teresa Margolles, Mexico, contemporary art, ethic, violence. 


\section{Teresa Margolles. Reiterar la Violencia}

Maria Campiglia

Universidad de Barcelona. España

(Recibido: 8 Diciembre 2013; Aceptado: 7 Enero 2014; Publicado: 3 Febrero 2014)

\section{Resumen}

Desde hace más de dos décadas el trabajo de Teresa Margolles ocupa un destacado lugar en el circuito artístico mexicano, y durante los últimos años ha logrado consolidarse a nivel internacional, exhibiéndose en importantes ferias y bienales y siendo acreedor a prestigiosos reconocimientos. ¿Pero qué clase de mirada en relación a nuestro entorno ofrece?

Suele argumentarse que la importancia de su obra radica en visibilizar la violencia que se vive hoy en México, permitiendo la aparición de la voz de las víctimas. Y ella sostiene que el sentido fundamental de su trabajo consiste en evidenciar que las víctimas son individuos, con historias particulares y no simples números.

El presente artículo intenta cuestionar estos argumentos a partir de un análisis en torno a los procedimientos seguidos para la realización de sus obras. ¿Será que nos encontramos frente a un arte de denuncia o simplemente somos testigos de un ejercicio de violencia perpetrándose dos veces sobre el mismo cuerpo?

Palabras clave: Teresa Margolles, México, arte contemporáneo, ética, violencia. 


\section{Maria Campiglia - Teresa Margolles}

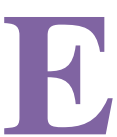

l trabajo de Teresa Margolles ocupa sin duda un importante lugar en el circuito del arte mexicano, que en más de un sentido lo ha defendido, difundido y peleado por conseguir su internacionalización. No es decir poco que se ha expuesto en la Sala de Arte Público Siqueiros, el Museo de Arte Moderno, el Museo Experimental EL ECO, el Museo de la Ciudad de México, el Museo de Arte Carrillo Gil o el Museo Universitario de Arte Contemporáneo, y que no sólo ha contado con el apoyo de becas y estímulos a la creación artística sino que su obra forma parte de importantes colecciones tanto públicas como privadas.

Ha logrado también ocupar un sitio a nivel internacional, participando entre otros en la 7 Bienal de Berlín, la 4 Bienal de Liverpool, la 5 Bienal d'art contemporain de Lyon, MANIFESTA 7 European Biennial for Contemporary Art y la 53 Bienal de Venecia. En 2012 ganó Artes Mundi, uno de los premios en efectivo más importantes en el mundo del arte, y para el 2014 está ya programada en diversos eventos, como la feria de arte madrileña ARCO.

Y si bien se trata de un trabajo que evidentemente resulta problemático (no sólo por las temáticas que aborda y los materiales que utiliza, sino porque plantea una serie de interrogantes de carácter ético), pareciera ser fácilmente asimilado por los circuitos de producción y consumo artístico.

No se ha escrito poco sobre su obra, pero resulta sorprendente que más allá de críticas puntuales y superficiales, es realmente difícil encontrar publicados argumentos que la cuestionen; contamos en cambio con numerosos textos de reconocidos teóricos y curadores que defienden la importancia de su quehacer.

Tanto en internet, como en la prensa, aparecen frecuentemente declaraciones que pretenden señalar su relevancia. En enero de 2013, por ejemplo, cuando se notificó que los Países Bajos decidieron otorgarle el Premio Príncipe Claus, el Embajador Hogewoning argumentó que esta decisión se debía a: "su valor e integridad en la ruptura de los convencionalismos artísticos y sociales; y por la manifestación pública de la verdad contra la influencia y complicidad del gobierno en la violencia y pobreza, no sólo en México, sino en el mundo entero." 
Este evidente interés por su obra, así como la falta de cuestionamientos críticos, nos permite saber que su voz no da cuenta de una manera aislada de entender la realidad, sino que se trata de un tipo de mirada y sensibilidad compartida con importantes sectores de la sociedad en general, y del mundo del arte en particular. Con el objeto de revisar cuál es su naturaleza, y cuáles son los principios a partir de los cuales opera, es que se plantea el presente trabajo.

Suele argumentarse que la relevancia de la obra de Margolles consiste en visibilizar los increíbles niveles de violencia de la sociedad mexicana, así como la absoluta desprotección en la que se encuentran los sectores más pobres de la misma. Se sugiere entonces que es una herramienta que nos permite entender nuestra realidad y posicionarnos en relación a ésta.

Sin embargo su trabajo no parece producir en el espectador otra cosa que no sea parálisis y miedo; no motiva a la acción sino que insiste en la impotencia. Dista también mucho de incentivar cualquier clase de sentimiento empático con los grupos más vulnerables, pues opera a partir de la reproducción de la lógica que pareciera querer despojarlos de su condición humana.

A lo largo de este texto se revisarán los procedimientos seguidos para la realización de sus obras, por lo que me he visto obligada a introducir una serie de detalles siniestros; pero sin estos no sería posible entender cuál es el lugar desde el que opera y cuáles son los límites que parecemos atribuirle al quehacer artístico.

\section{Bienal de Venecia 2009}

En un momento en que los cadáveres tanto de víctimas de la delincuencia organizada como de presuntos narcos abatidos por el gobierno no paraban de acumularse y el aparato discursivo de la presidencia hacía malabares para intentar justificar la conveniencia de su iniciativa de "guerra contra las drogas", Cuauhtémoc Medina y Teresa Margolles pusieron literalmente en jaque al equipo diplomático mexicano con la presentación del proyecto ¿De qué otra cosa podríamos hablar? en la 53 Bienal de Venecia.

El pabellón mexicano, que ocupó el palacio renacentista Rota-Ivancich (sin limpiarse ni restaurarse), exhibió entonces una serie de trabajos que evidenciaban los costos de la política estatal. 


\section{Maria Campiglia - Teresa Margolles}

Fue aquí donde se realizó Limpieza, una acción que consistió en trapear diariamente el piso del pabellón con agua y sangre de víctimas de la delincuencia organizada en México.

Se mostraron también Narcomensajes, telas impregnadas en sangre sobre las que se bordaron con hilo de oro una serie de mensajes emitidos por el narco mexicano: Ver, oír y callar. Hasta que caigan todos tus hijos. Así terminan las ratas. Para que aprendan a respetar.

Y se exhibieron: Sangre recuperada, instalación de telas con las que se limpiaron lugares en los que fueron encontrados cuerpos de personas asesinadas. Bandera arrastrada, acción que consistió en arrastrar un pedazo de tela con sangre recogida en escenas de ejecuciones producidas en el norte de México. Ajuste de cuentas, una colección de Joyas de oro engarzadas con fragmentos de vidrio provenientes de "ajustes de cuentas", que habían sido recogidos en diversas escenas de crimen.

Como era de esperar la muestra causó revuelo, y se levantaron algunas voces que exigían cuidar la ya muy deteriorada imagen exterior del país. Cualquier pretensión en torno a hacer de la Bienal un espacio destinado a la promoción de la representación nacional se cayó a pedazos con la participación de Teresa Margolles y Cuauhtémoc Medina. En palabras de Medina (2009):

¿De qué otra cosa podemos hablar? es, claro, la réplica a una interdicción. La frase encierra una reacción visceral ante la expectativa de las élites mexicanas de que por proteccionismo de la imagen nacional o por sostener las ilusiones del turismo, preferirían que guardáramos un compungido silencio ante la falta de discreción que ha tenido la sociedad de masacrarse ruidosa, voraz y espectacularmente en público. Vana ilusión. (p.29)

La exhibición fue acompañada de un cuidado catálogo, en el que se revisaba desde distintos ángulos los costos de la "guerra contra las drogas", y que incluía, entre otros, el texto de Antonio Escohotado "La cruzada farmacológica. Veinte años después”, en el que se realiza una disertación en torno a la importancia de acabar con la política antidrogas dictada por los Estados Unidos, y proponiendo en cambio adoptar medidas como las seguidas por diversas naciones europeas de "control de daños". 
Fue a partir de la Bienal de Venecia que la obra de Margolles se consolidó a nivel internacional y que pudo comercializarse por primera vez de manera exitosa. Diversos críticos argumentaron que el sentido de la misma consistía en realizar un comentario político y que su importancia residía en la construcción de una memoria colectiva que recuperaba las voces procedentes de la gente asesinada. ¿Pero efectivamente da cuenta de la serie de voces que quieren ser silenciadas? ¿Cuáles son los principios a partir de los cuales se articula?

Si bien la propuesta para la bienal fue pertinente en términos políticos, es importante detenerse a reflexionar en relación a cómo fueron realizadas esas piezas y qué tipo de mirada en relación a nuestro entorno arrojan. Para hacerlo, no podemos analizarlas de manera aislada, sino que deberíamos revisarlas como parte de la producción de Margolles y su particular forma de entender el sentido y límites de la producción artística.

Los estudios del trabajo de Margolles suelen dividir sus primeras obras de producciones más recientes; y si bien es cierto que el discurso de una persona puede cambiar con el tiempo, y que sería tan injusto como inútil juzgar lo que se hace por lo que se ha hecho, o lo que se dice por lo que se ha dicho, en el caso de Margolles la similitud de los procedimientos seguidos para la realización de piezas de ambos períodos sugieren que esta división constituye un error de análisis.

Parto de la premisa de que el trabajo de Margolles mantiene una clara línea de continuidad en términos técnicos y formales, por lo que su obra temprana no puede entenderse como algo escindido de lo que actualmente desarrolla. Y sostengo que, para entender sus producciones recientes, resulta particularmente esclarecedor fijar la mirada en sus primeras obras y declaraciones, realizadas en tiempos donde importantes sectores de la escena artística mexicana no parecían sentirse obligados a asumir posturas "políticamente correctas".

\section{Primeros trabajos}

Margolles realizó sus primeras obras como parte del colectivo Semefo, que se mantuvo activo de 1990 a 1999. Sus miembros fundadores fueron Arturo Angulo, Carlos López y Teresa Margolles, pero pertenecieron al mismo en 


\section{Maria Campiglia - Teresa Margolles}

distintas épocas Arturo López, Víctor Basurto, Juan Pernás, Juan Luis García, Antonio Macedo y Aníbal Peñuelas.

Tomaban el nombre del Servicio Médico Forense: Semefo, que es la dependencia policiaca mexicana encargada de guardar y realizar necropsias a los cadáveres de gente asesinada o bien de aquellos cuerpos no reconocidos, no reclamados, o cuyos familiares no cuentan con los recursos económicos para enterrarlos.

El colectivo, que operó durante poco menos de diez años, realizó una serie de piezas y acciones, que si bien resultan poco articuladas en términos conceptuales, tuvieron un fuerte impacto en la comunidad artística local. Morales Mendoza (2006), retoma la afirmación de Carlos López: “realmente fue más la fama, fuimos más famosos que buenos, fue más mito, realmente hicimos muy pocos performances”. (p.144)

Su trabajo inició con la realización de conciertos y performances underground que incorporaban fuertes dosis de teatralidad. Se trataba de acciones violentas que buscaban convertir al público no sólo en depositario sino en agente activo del ejercicio de violencia.

Nos interesaba mucho que no nada más [que no sólo] el público fuera un espectador pasivo sino que se integrara al evento, y la forma de integrarlo era por medio de la violencia física, entonces era una agresión directa al público, y el público de alguna manera como defensa también contestaba a los golpes y cuando menos pensaba ya estaban ellos haciéndolo casi todo. (Morales Mendoza, 2006, p.56)

Se intentaba colocar al espectador en situaciones que lo llevaran a sacar su parte más violenta y de esta forma parecían pasar un rasero que igualaba la manera de actuar del público y el colectivo. Pretendían atacar la ética, la moralidad y "las buenas conciencias" practicando un arte dirigido a "quebrantar sigilosamente la sensibilidad del indagador." (Morales Mendoza, 2006, p.56)

Se trataba de obras que buscaban producir horror mediante la demostración de su disposición a violentar cualquier clase de norma. Margolles relata: “Se retaban Mónica Salcido y el Sr. Angulo, se retaban a ver quién era el más macizo, y yo iba con la cámara o como testigo sin que ellos supieran nada del otro; la cámara era el testigo a ver quién era el que hacía la acción más insólita.” (Morales Mendoza, 2006, p.158) 
Y sostenían que era la morbosidad lo que permitía que el público se involucrara con la obra. Margolles argumentó:

Yo pienso que la gente es... o sea, como público eres súper morboso, incluso el público de arte es morboso. Y lo que pasa es que la gente no lo quiere admitir. No quieren admitir que es algo natural la morbosidad que tenemos. Y aquí estaba como cobijado en la oscuridad, estaba con nosotros. Los motivábamos a sacarlo porque sentían que no había nada que lo retuviera. (Morales Mendoza, 2006, p.158)

El deseo por escandalizar y atrapar al espectador despertando su morbosidad fue explotado por el colectivo de diversas formas, pero una de las más evidentes consistía en incluir en sus performances a personajes que definían como "bizarros”, como un tal faquir Melchor, del que Margolles habló de la siguiente manera:

Es un fakir que, como que yo pienso que en su demencia senil que tiene le dio por el sexo, es un faquir sexual, entonces todo en la relación con el mundo tiene que ver con el sexo, y sobretodo el sexo anal, y entre sus cosas fantásticas, se mete botellas por el ano, se saca listones. Hizo uno increíble, se puso en el culo cohetes y estaba de nalgas disparando cohetes, entonces que participara con nosotros nos gustaba mucho para tener personajes bizarros, nos gustaba muchísimo la bizarrez. (Morales Mendoza, 2006, p.41)

Este primer período de Semefo, de performances abiertamente violentas, terminó con un evento en el que colgaron un ataúd que, según declaraciones del grupo, había sido exhumado por ellos mismos. ${ }^{1}$

Se trataba de una acción que violentaba al espectador no sólo por la repulsión que parecía provocar la cercanía con un cuerpo muerto, sino porque los hacía formar parte de algo evidentemente ilegal y que rebasaba toda clase de norma moral. En entrevista con Morales Mendoza, Margolles señala:

Descubrimos, por ejemplo, que la gente se aterraba igual si estábamos haciendo death metal en vivo y acciones así violentas, con sangre y cosas así... que si les presentábamos por ejemplo el ataúd, pinche ataúd de Arte 


\section{Maria Campiglia - Teresa Margolles}

Jóven, fue sólo eso ¿no?, un ataúd colgado ahí, un ataúd que era real, que habíamos sacado de la tierra, y que estaba ahí, con eso la gente se aterró. Era nada más... nos dimos cuenta que era esa manera de terror psicológico. (Morales Mendoza, 2006, p. 145)

Al ataúd lo titularon Larvarium y al hacerlo pretendieron dar una suerte de "estocada final", que al tiempo de colocar al muerto como un simple depósito de larvas (despojado ya de cualquier rastro de humanidad), se valía del latín probablemente como una forma de burlarse del medio artístico y sus pretensiones de refinamiento intelectual.

Larvarium $^{2}$ les dio visibilidad y les permitió acceder a espacios de exhibición y becas de producción artística. En los años siguientes realizaron diversas piezas con cadáveres de animales o de gente, que de ninguna forma pretendían emitir un comentario de carácter político, ni establecer ninguna clase de posicionamiento en términos de responsabilidad social.

Fue a partir de 1996 que empezaron a trabajar con una serie de objetos procedentes de víctimas anónimas de la violencia en la Ciudad de México.

Dermis, exhibida en México en La Panadería y el Museo de Arte Carrillo Gil, y en diferentes lugares en España, como El Ojo Atómico, consistió en la presentación de piel tatuada de cadáveres extendida sobre aros metálicos y diez sábanas de hospital marcadas con el logotipo del Instituto Mexicano del Seguro Social (IMSS), manchadas con fluidos dejados por cuerpos anónimos a los que se les había practicado una autopsia.

El logotipo impreso en las sábanas evidenciaba la estandarización y automatización del manejo de los cuerpos dentro de la institución, así como la profunda desigualdad existente en la sociedad mexicana, donde la población que no cuenta con recursos económicos carece de facto de toda clase de derechos (incluso después de la muerte).

El material, obtenido probablemente mediante un acto de corrupción de algún funcionario público, no sólo parecía hacer un comentario en torno al estado de una de las instituciones púbicas más importantes de México sino a la forma en que esos cuerpos fueron tratados.

Del mismo año es Fluidos ${ }^{3}$, pieza para la que se colocaron 240 litros de agua con la que se lavaron cadáveres en un enorme contenedor de vidrio iluminado con luces blancas. Un año más tarde Mineralización estéril ${ }^{4}$ fue mostrada en el Centro Nacional de las Artes. Era también un contenedor de 
vidrio, pero esta vez podían verse en su interior huesos de personas obtenidos de crematorios públicos.

Corresponden también a este período Catafalco $^{5}$, moldes de yeso sacados de cadáveres a los que se les había practicado una autopsia y una mesa con Ropa de cadáver ${ }^{6}$, que se presentó en el Centro Cultural de Arte Contemporáneo y en la Galería Cruce de Madrid.

El trabajo realizado por el colectivo durante los últimos años en que se mantuvo activo, y que fue defendido por algunos críticos argumentando que permitía visibilizar la situación social de México y sus instituciones, seguía concentrándose en formular estrategias para violentar al espectador, “derramando violencia” para producir lo que ellos llamaban "terror psicológico”.

Se trataba de una violencia que el público se viera obligado a llevar consigo, literalmente, como en una instalación donde el pelo recolectado en distintas morgues de la Ciudad de México fue puesto en el suelo para que se adhiriera a los zapatos de los visitantes. ${ }^{7} \mathrm{O}$ bien, que se la llevara en la cabeza, a modo de amenaza, como en la exhibición de ocho barriles ${ }^{8}$, acompañados de una ficha de sala escrita por Santiago Sierra en la que se explicaba que estos habían sido usados para hervir huesos de cadáveres en la Facultad de Medicina, y se describía con absoluto lujo de detalle el procedimiento al que son sometidos los cuerpos, el olor que emanan, la consistencia y color de la grasa que desprenden. Los barriles, al igual que el caldero de la bruja que cocina a los niños mal portados, amenazaban al espectador con los posibles "horrores de su destino".

Sería fácil suponer que un trabajo como el que realizaba Semefo quedara confinado a círculos de exhibición completamente marginales. La serie de violaciones producidas en el terreno moral, ético y legal para la realización de sus piezas, harían pensar por lo menos en una dificultad para la asimilación de su discurso.

Pero esto de ninguna manera fue así; su obra fue recibida calurosamente por el círculo del arte en México, que desde muy temprano les abrió acceso a importantes espacios de exhibición y les otorgó premios y estímulos a la creación artística.

José Luis Barrios (2004) afirma que: "Nacidas en condiciones de inclemencia, las nuevas prácticas artísticas no podían ser piadosas.” (p.380) 


\section{Maria Campiglia - Teresa Margolles}

La década de los noventa en México estuvo claramente marcada por el desencanto en relación a la realidad social. Los evidentes costos sociales que supuso la instauración del neoliberalismo más que activar el interés de los artistas por participar en la vida política, parecieron dar lugar a la aparición de una serie de trabajos que evidenciaban tanto el escepticismo como el desencanto.

Se trató de una época que fue terreno fértil para el desarrollo de propuestas en torno a lo abyecto, y en la que abundaron obras con un lenguaje claramente cínico.

Y eso es propiamente lo que define lo posmoderno, que es un arte cínico pero no es un arte crítico, porque la crítica siempre trae un momento de conciencia política y de condición crítica de los procesos sociales. La vanguardia por eso se caracteriza.

Esa generación en general, y en México es muy característico, se focaliza a esta especie de estética de la travesura, donde por ejemplo, si tú ves las primeras acciones de Semefo, que son radicalísimas, no hay ninguna construcción crítica del proceso. (Barrios, J.L, comunicación personal, agosto 24, 2012)

La comunidad artística parecía muy dispuesta a la asimilación de este tipo de propuestas, por lo que Semefo fue programado con extrema facilidad por instituciones locales.

Semefo quedó instaurado como un componente esencial de las formas de arte de crisis que emergieron en México en los años 90, en buena medida porque su negociación con lo espantoso operaba como referente límite de una zozobra común. Fue precisamente su tajante anti-humanismo lo que lo diferenció del conjunto de los otros artistas y colectivos que provenían de la contracultura del período. (Medina, 2009, p.17)

Pero la dinámica planteada por el grupo pareció llegar a su límite. ¿Cómo "ir más allá" sin acabar preso? José Luis Barrios sostiene que "esa práctica, en términos de su poética, se agotó muy rápido o llegó hasta donde tenía que llegar.” (Barrios, J.L, comunicación personal, agosto 24, 2012)

Antes del año 2000 el grupo se desintegró y Margolles comenzó a trabajar sola. Sus piezas cobraron un carácter distinto a las realizadas dentro 
del colectivo, pero no puede hablarse de una ruptura tajante, ya que mantuvo en más de un sentido la línea conceptual y estrategias formales de realización seguidas por el grupo. (Esto queda claro, por ejemplo, en la discusión que existe en relación a quién debería atribuirse la autoría de la pieza Lengua $^{9}$, realizada en el año 2000, momento en que el colectivo ya se había disuelto, pero directamente relacionada con la obra de Semefo.)

Margolles, ya de manera independiente, rápidamente encontró un nutrido grupo de “seguidores” y un lugar propio dentro de la escena artística local. Obtuvo de manera temprana becas estatales para la creación artística, accedió a la crítica y a diversos mecanismos de difusión de obra, así como a los principales centros de exhibición.

\section{Materiales}

La materia prima con la que decidió trabajar Margolles siguió incluyendo fragmentos o fluidos de cadáveres, así como objetos que han estado en contacto con los mismos.

No necesariamente se apresura a explicitar la procedencia de los materiales, sino que en muchas ocasiones los presenta de forma que a primera vista parezcan algo inocuo y bello.

Cuauhtémoc Medina señala que en estos casos usa el material a modo de trampa, y que como cualquier trampa requiere de un cebo. El cebo sería la aparente belleza del material, que nos invita a entrar. En palabras de Medina: "Era imposible saber cuántos de esos participantes tenían clara la naturaleza de la trampa que la artista había dispuesto, donde la carnada era la expectativa postminimal de un arte de satisfacción visual y simplicidad.” (Medina, 2003)

Margolles se vale siempre de materiales de “naturaleza aterradora”, pero muchas veces logra formular estrategias que invitan al contacto. El agua con la que han sido lavados cadáveres en morgues de la Ciudad de México ha sido utilizada "bellamente" para hacer burbujas, como En el aire ${ }^{10}$ y para crear vapor, como en Vaporización. ${ }^{11}$

Utiliza también otros líquidos de manera engañosa: sangre, grasa y formol han formado parte de diferentes obras. Fluidos ${ }^{12}$ por ejemplo, consistió en la colocación de grasa y formol en un contenedor de vidrio 


\section{Maria Campiglia - Teresa Margolles}

iluminado de tal manera que las formas y tonalidades de los materiales parecieran dar cuenta de algo delicado y hermoso.

En estos casos se pretende que el público se enfrente a la pieza desconociendo el tipo de material usado. Tomarlo por sorpresa, hacerlo entrar, y una vez dentro develar el engaño. Es justamente en el momento en que se corren los velos cuando se construye la obra: El espectador se entera de haber sido llevado, sin querer, a transgredir un límite que lo descoloca y violenta.

En el hall del museo los niños juegan bajo las burbujas que vienen de la pieza de Teresa Margolles En el aire, 2003. Corriendo, riendo, atrapándolas, están fascinados por el brillo, delicadas formas que desde el techo flotan y se rompen en su piel.

[...]

El momento de placer naif se torna en repulsión: se han enterado de que el agua proviene de morgues de la Ciudad de México, que ha sido usada para limpiar cuerpos después de una autopsia. Carece de importancia que el agua haya sido desinfectada; el estigma de la muerte torna lo bello en horroroso. (Medina, 2003)

El impacto de estas piezas está estrechamente relacionado con la posibilidad de que el espectador se aproxime a las mismas sin haber realizado ninguna clase de lectura o acercamiento previo (algo difícil para aquellos que conocen la trayectoria de Margolles). Lo que se busca es obligarlo a transgredir sus propios límites, colocándolo donde voluntariamente no lo haría.

Se dice que cuando presentó Vaporización en el Museo de Arte Contemporáneo de Nueva York, Susan Sontag escribió en el libro de visitas de la exposición: "Toqué a la muerte".

Otro material usado con frecuencia por Margolles es el vidrio. Dos toneladas de cristales de parabrisas estallados durante tiroteos en la Ciudad de México fueron utilizados para pavimentar una calle degradada en la ciudad inglesa de Liverpool en la acción Sobre el dolor ${ }^{13}$, realizada en el 2006. Una intervención que introducía en el espacio una infinidad de “encantadores” reflejos. 
Ha usado también fragmentos de vidrio que han quedado en las calles como resultado de ajustes de cuentas, o que estaban incrustados en cuerpos de víctimas de la violencia para realizar joyas ${ }^{14}$.

Pero no siempre es ambivalente la naturaleza de los materiales usados por Margolles, que en algunos casos se presentan de manera crudísima, sin ninguna clase de maquillaje, como Lengua, que se reduce a la presentación de un pedazo de cuerpo: una lengua.

En todos estos casos la materia aparece como algo amenazante. Amenaza por la repulsión y el miedo que produce estar en contacto con ella o frente a ella, y amenaza también al presentarse como posible destino. Lo que muestra Margolles, en última instancia, son una serie de cuerpos violentados, que son de otros, pero que en más de un sentido aparecen en el imaginario como nuestros.

El espectador es obligado a presenciar el oprobio de cuerpos que le refieren al propio, mientras Margolles se asegura de colocarlo en el lugar de observador pasivo al tiempo en que le deja intuir los detalles que supuso la realización de la obra.

Los materiales son presentados de tal forma que producen una mezcla de impotencia, enojo y miedo.

\section{El lugar de la legalidad}

Buena parte de la obra de Margolles es posible sólo a partir de la violación de una serie de normativas que supondrían consecuencias de carácter penal. ${ }^{15}$ Trabaja con cadáveres, o con tejido y fluidos procedentes de los mismos, que en algunos casos pertenecen a individuos que han sido asesinados, por lo que se encuentran sujetos a procesos de investigación pericial y su tratamiento debería estar reservado a instancias policiales.

Pero es sorprendente que si bien todas estas operaciones se hacen públicas no sólo nunca se le ha levantado una demanda o se le ha incautado alguna pieza, sino que siempre ha contado con el cobijo institucional.

Un ejemplo clarísimo de esto es que el Museo Universitario de Arte Contemporáneo (MUAC) cuenta en su colección con dos obras de Semefo, Mineralización estéril y Larvarium. Tiene también Encobijados ${ }^{16}$, de Margolles, comprada en el 2008 a la Galería de Arte Peter Kilchmann. Las tres piezas fueron realizadas a partir de procedimientos más que dudosos. 


\section{Maria Campiglia - Teresa Margolles}

Gran parte del material que Margolles ha utilizado para realizar sus primeras obras provenía de las instalaciones de Semefo, donde ella misma trabajó. Semefo no depende directamente de una institución médica, sino de la Procuraduría General de la República, ${ }^{17}$ y del dictamen que éstos llevan a cabo se desprenden responsabilidades penales (en caso de haber elementos que hagan suponer un posible homicidio).

Usa el material "que queda" después de que la policía ha hecho su trabajo, por lo que en principio no entorpece el proceso de investigación: Objetos y cuerpos cuyo rastro jurídico aparentemente no es significativo, pues han sido analizados previamente.

Sin embargo es innegable que Margolles desvía, saquea y vacía de sentido materias y procedimientos propios del ámbito jurídico.

Para Memoria fosilizada ${ }^{18}$ se ahogaron en una plancha de hormigón 247 objetos personales de gente muerta, y al hacerlo la pieza evidentemente los despojó de su sentido jurídico.

En obras más recientes el material es recogido directamente de la escena del crimen, después de que los peritos han hecho su trabajo. La recolección puede realizarse tanto gracias a la ineficiencia como a la corrupción de cuerpos policiales y a los vacíos en términos de legislación.

Margolles interpela la noción de legalidad y la manera de operar de diversas instituciones aparentemente destinadas a su cumplimiento, parasitando su estructura y visibilizando una serie de mecanismos institucionales no sólo ineficientes sino completamente corruptos.

Su práctica artística debe su existencia a la relajación de los servicios policiales mexicanos. Sus obras exponen con enorme franqueza la situación de ese aparato, al tiempo que son resultado de la complicidad de la artista con ese mismo sistema.

El hecho de que a lo largo de los años las instituciones estatales mexicanas hayan promovido activamente el arte de Margolles es muestra de su talento para habitar una laguna legal y política. Sería imposible poner en cuestión sus métodos sin denunciar al mismo tiempo las peculiares normas tanto de la morgue como del sistema cultural. En este sentido su obra es menos una transgresión que un reflejo del estado deteriorado de la ley. Si su arte ocupa un espacio de tolerancia, es gracias a la complicidad e ineficiencia institucional. (Medina, 2001, p.31) 
Esta línea argumental propone que aquello que permitimos da cuenta de lo que somos, por lo que la importancia del trabajo de Margolles radicaría en mostrar lo que somos como sociedad. Se trata de una afirmación que en más de un sentido resulta innegable, pero quizás también simplificadora.

Para la Séptima Bienal de La Habana, en el 2000, Margolles introdujo a Cuba grasa humana procedente de morgues; para Grumos sobre la piel, realizada un año más tarde, llevó a España exactamente el mismo material; y en la Bienal de Venecia, del 2009, trabajó con sangre presuntamente procedente de asesinatos.

Operar tanto desde las lagunas existentes en términos de legislación como desde la corrupción no sólo es posible en México, sino que puede hacerse en países con realidades sociales y políticas supuestamente muy distintas.

\section{Uso de las personas y participación pasiva}

Margolles necesita apelar a distintas personas para la realización de sus obras. Para algunos de sus primeros trabajos, cuya materia prima eran fragmentos de cadáveres, requirió del permiso de familiares. Ella relata que, a pesar de formar parte del personal de la morgue, y por lo tanto tener que portar una bata blanca, siempre vestía de negro.

Porque al ir como de luto, los familiares de muertos en la morgue me identifican con uno de ellos y me hablan como a un igual, en lugar de como a alguien que manipuló el cadáver de su ser querido y así se elimina la fina pared que separa la sala de las autopsias. (Torrijos, marzo 23, 2003)

Ahí [en la explanada de Semefo] escucho las voces temblorosas de las madres reclamando el cuerpo de los hijos, es ahí donde hablamos de impunidad y donde les muestro mi trabajo y podemos trabajar en conjunto. (Chávez Santiago, 2010, p.40)

En los trabajos que realizó mientras formaba parte del personal de la morgue, la manera en que abordaba a los deudos, así como el momento en que lo hacía, no representan un dato menor: La fragilidad y la impotencia 


\section{Maria Campiglia - Teresa Margolles}

intervenían sin duda para hacer posibles acuerdos que seguramente no habrían podido realizarse de otra forma.

En estos, como en otros casos en los que ha requerido el permiso de familiares para obtener cuerpos completos, o fragmentos de los mismos, sistemáticamente ha aprovechado el estado de indefensión y extrema pobreza de los deudos, a partir de acuerdos a todas luces insensibles en relación a la situación que éstos atravesaban.

Entierro $^{19}$ resulta particularmente estremecedor, fue posible gracias a la obtención del cuerpo de un bebé que nació muerto y cuya madre no tenía dinero para enterrarlo, Margolles señala: "tenía dos opciones: donar el cuerpo a la medicina o donarlo al arte, y decidió donarlo al arte.” (Chávez Santiago, 2010, p.43)

Diversos críticos han argumentado que gracias a la pieza se creó un entierro portátil, sin el cual el cuerpo habría ido a parar a una fosa común, ¿pero qué clase de sepulcro es el que se le ofreció?

Culturalmente lavar el cuerpo antes de enterrarlo es entendido como una forma de prepararlo, de limpiarlo para el tránsito que la muerte supondría. Por supuesto constituye también el ritual a partir del cual el vivo se despide de quien ha perdido, por lo que tradicionalmente se practica de manera íntima por la madre o la partera, en el caso de recién nacidos.

Pero en este caso un video de ocho minutos muestra el cuerpo del bebé (previamente plastinizado) que no es lavado por su madre, sino sumergido en productos químicos por las manos enguantadas de Margolles. Posteriormente el cuerpo fue introducido en hormigón en inicio de fraguado. No hay ni un dejo de "compasión” en el tratamiento que se le da a la madre, o al cuerpo de su hijo muerto.

Otras piezas no requirieron la autorización de familiares, pero involucraron directamente a otras personas, como Grumos en la piel ${ }^{20}$ En esta acción, realizada en España en 2001, un joven, presuntamente ligado al tráfico de drogas, se prestó para que su torso y brazos desnudos fueran untados con grasa proveniente de cadáveres. La serie de fotografías con las que se registró, nos muestran sólo un cuerpo pasivo sobre el que Margolles, con guantes, actúa. La violencia que esta actuación supuso, y la diferencia en relación al lugar en que Margolles se coloca a sí misma y aquel en que coloca a los otros, resulta perfectamente visible en el uso de guantes. 
Obras más recientes se plantean como "abiertas a la participación colectiva”, de las que la más conocida es aquella presentada en la 53 Bienal de Venecia, donde nada menos que familiares de víctimas de la violencia eran los encargados de fregar con agua y sangre el suelo del pabellón.

Para La promesa, ${ }^{21}$ presentada recientemente en el MUAC, una serie de voluntarios realizaron la tarea de dispersar escombros. En la muestra, una de las participantes, al ser interrogada sobre lo que hacía, respondió susurrando: "no puedo hablar; parte de la obra consiste en que permanezcamos en silencio".

Y es que Margolles apela a otros para la realización de sus piezas, pero aparentemente no les da ningún margen de acción, sino que los participantes deben limitarse a realizar aquello que se les ha propuesto.

Los voluntarios se benefician en la medida en la que son invitados a sumarse a un proyecto que permite la visibilización de una problemática que les es afín, pero no participan en la construcción del sentido de la obra, ni pueden "hacer uso de micrófono". No participan tampoco en las ganancias que la pieza genera.

Pero en vista de que el argumento que ha llevado a Margolles a tener acceso no sólo a espacios de exhibición sino a obtener importantes reconocimientos a nivel internacional es que su trabajo constituye un ejercicio de memoria y permite la aparición de una serie de voces que quieren ser silenciadas, vale la pena preguntarnos, ¿en qué sentido hay espacio para la voz del otro? ¿Nos encontramos frente a un arte de denuncia o simplemente somos testigos de un ejercicio de violencia perpetrándose dos veces sobre el mismo cuerpo?

\section{Reflexiones en torno a la memoria}

Sin vacilar Margolles tuvo una idea sobrecogedora: ofreció a la madre del joven un ataúd para llevar a cabo los ritos funerarios del asesinado, a cambio de un fragmento de su cadáver a fin de exponerlo como ready made. Margolles llegó incluso a sugerir que le gustaría adquirir precisamente la lengua o el pene... En todo caso su ofrecimiento no pareció haber ofendido a sus familiares, que, forzados por las circunstancias y el convencimiento de que en cierto modo rendían un homenaje a su ser querido, aceptaron dar la lengua a cambio de un ataúd 


\section{Maria Campiglia - Teresa Margolles}

de metal. El trato no era nada malo para Margolles misma, quien por entonces poseía no uno sino dos ataúdes... (Medina, 2001, p.31)

En relación a este mismo caso relata Margolles:

Me comentaron un día que había un cuerpo que podría interesarme. Era el de un muchacho muy joven. [...] Hablé con la madre y quise pedir que me diera el pene, pero cuando iba a pronunciar la palabra pene me salió lengua. La madre, por supuesto, reaccionó indignada, algo completamente normal, mi trabajo fue convencerla para que el cuerpo de su hijo hable sobre las miles de muertes anónimas que la gente no quiere tener en cuenta. Finalmente me la dio y la llevamos a Bellas Artes que es, además, el lugar de los velorios de personajes célebres en México. (Silva, junio 10, 2011)

¿De qué habla esa lengua? ¿En qué sentido es capaz de cumplir con la promesa realizada de dar voz a las miles de voces anónimas de la ciudad?

Según refiere Coco Fusco en su artículo La insoportable pesadez de los seres: el arte en México después de Nafta, para la primer exhibición de la pieza Lengua Margolles invitó a la inauguración a los parientes del joven muerto, quienes se sintieron ofendidos porque ni en los programas ni en la ficha de sala se mencionaba su nombre. "Que alguien acepte la transformación de una parte de su cuerpo en obra de arte y que además exija su reconocimiento va más allá de lo imaginable”, argumenta Fusco (2001, p.18). Pero, ¿cómo no exigir ese mínimo acto de reconocimiento de la identidad del muerto si, según declaraciones de Margolles, el acuerdo se logró gracias a convencer a la madre de que la obra aseguraría su memoria?

Margolles sostiene que su trabajo muestra aquello que no quiere ser visto, y que pretende evidenciar que las víctimas de la violencia en México son individuos, con historias particulares y no simples números. ¿Pero en qué sentido trata a los restos como provenientes de un individuo con una historia?, ¿qué queda que pudiera denotar la identidad y la vida de estos sujetos?

El rescate de la humanidad del otro, de su individualidad, exige resistirse a la objetualización del sujeto, reconocer que el resto da cuenta de un ser humano; por lo que la manera en que se obtienen, el tratamiento que se les da y la forma en que se exhiben es sin duda significativo. 
Las mecánicas de intercambio (como dar un ataúd, pero sólo a cambio de un fragmento del cuerpo), y de corrupción (para que funcionarios públicos "se hagan de la vista gorda"), parecieran entender al cuerpo simplemente como un objeto más que puede introducirse en la lógica del arte-mercado.

Y el tratamiento que se le da a los restos dista mucho de poder calificarse como "delicado" o "compasivo". Telas mojadas con sangre de gente asesinada, que se mezclan con tierra, o con basura, que son restregadas por el suelo, usadas para fregarlo o simplemente arrastradas (como en Limpieza $a^{22}$ o Bandera arrastrada ${ }^{23}$ ).

Presentados de esta manera los restos no parecerian dar cuenta de seres humanos, sino que se reducen a su condición matérica, objetual, que lo que despierta es principalmente repulsión, impotencia y miedo.

¿Quién podría “cobijar” esos cuerpos? ¿Quién sería capaz de reconstruir con ellos una historia y reconocerla como propia? No podemos perder de vista que la memoria supone un acto de apropiación, de interpretación, de posicionamiento que rescata la humanidad de la víctima, que no se agota en el texto de un cuerpo mancillado sino que le da sentido y lo coloca en un contexto.

Tampoco carece de significación que ella trabaje con cuerpos de gente que podría haber sido asesinada, o con objetos personales de los mismos, y que por tanto están inmersos en una investigación. Margolles aleja al objeto de su función pericial (que aunque ineficiente y corrupta, en todo caso pretende hacer un análisis, una reconstrucción de lo sucedido en aras de entender y en el mejor de los casos resarcir de alguna manera el daño).

La autopsia, por ejemplo, supone un tremendo ejercicio de violencia que se ejerce sobre el cuerpo, pero lo que pretende es ofrecer una explicación en torno a la manera en que se produjo la muerte, dándole a la sociedad y a la familia, herramientas para tal vez llegar a entender lo sucedido.

Pero Margolles sólo registra la herida producida en el cuerpo, haciéndonos testigos y depositarios de una doble violencia, dejándonos en shock.

Una manera de actuar que no parece alejarse mucho de la mecánica del narco; consiste en ponernos en la nariz, una y mil veces, cuerpos segmentados, trozos de carne, grasa y sangre que sabemos provienen de personas pero que se presentan de tal forma que resulta extremadamente 


\section{Maria Campiglia - Teresa Margolles}

difícil reconocer en ellos su condición humana. Cuerpos que parecieran limitarse a la condición repulsiva a la que han sido reducidos tanto por sus victimarios como por la "intervención artística".

No cabe duda que su trabajo da cuenta de una realidad social sobrecogedora y la enuncia con una claridad sin precedentes, ¿pero es capaz de detonar una reflexión en torno a la misma? Lo que se recupera es el daño infligido al cuerpo, la herida que no parece poder convertirse en cicatriz.

No hay espacio para la regeneración, pues su trabajo tiene un efecto inmovilizador, por lo que no podría distar más de calificarse como un arte politizado.

Dotada de una increíble capacidad de amoldarse, Margolles pareciera ser capaz de coserse un ropaje acorde a cada momento, de manera que las interrogantes que su trabajo plantea parezcan pertinentes en contextos muy distintos. Sus obras, en términos formales, han mantenido una línea de continuidad a lo largo de más de dos décadas, pero su argumentación en relación a la pertinencia y sentido de su quehacer se ha modificado diametralmente.

"A mí me parece bello, me parece muy bella una imagen de un paredón quemado lleno de humo y con unos empalados" (David, 2012, p. 320), decía en el 93 Margolles, y sería hoy una declaración impensables para alguien cuyo trabajo se sostiene en términos conceptuales argumentando la importancia de la denuncia de la violencia social.

O bien sostenía: "Quiero denunciar la muerte violenta y desdramatizar la muerte en general, así como concienciar a la gente de la vida y de que lo que queda cuando morimos es sólo el cascarón” (Torrijos, marzo 23, 2003), cuando hablar del cuerpo como un cascarón parece un auténtico sinsentido para quien insiste en que cada cuerpo da cuenta de un individuo, y que es importante mirar las historias particulares.

Durante la década de los noventa, tiempos en que el mundo del arte en México parecía bastante desencantado de la política y se mostraba receptivo en cambio a poner a prueba los límites y sentido de la práctica artística, obras similares a las realizadas recientemente, sostenían que el arte era herramienta para herir la sensibilidad del espectador y se enunciaban como abiertamente antihumanistas.

Pero hoy, en tiempos donde a las obras de arte suele exigírseles importantes dosis de "corrección política”, el trabajo de Margolles no sólo 
logra extrañamente la supervivencia, sino que pareciera hacer de su voz la más "correcta” de las voces.

Se sostiene que su trabajo actual no pretende herir, por el contrario, pareciera prometer estar dotado de funciones digamos "curativas" en términos sociales. Y sin embargo salta a la vista la similitud de algunas de las obras y los procedimientos seguidos para su realización en ambos períodos.

Cuauhtémoc Medina, el principal apoyo conceptual con el que ha contado Margolles desde hace ya varios años debe tener razón... No hay un intento de diálogo, es una trampa. Medina, curador del Pabellón de México en la 53 Bienal de Venecia, cierra el texto con el que presenta el trabajo de Margolles de la siguiente manera:

Pero aquí no se pretende ningún diálogo. Al curador le resulta delicioso compartir que la etimología griega de la palabra "escándalo" (skandalon) significa "trampa u obstáculo para hacer caer.” Lo que sigue...

En una ciudad fantasma llamada México, 2009. (Medina, 2009, p.35)

\section{Conclusiones}

El presente trabajo pretende demostrar que hay una línea de continuidad en el trabajo de Margolles, por lo que sus primeras producciones no pueden entenderse como algo radicalmente diferente a sus propuestas actuales: Nos encontramos fundamentalmente frente a un cambio discursivo en la manera de validarlos.

Margolles trabaja con restos de gente que proviene de los sectores más desprotegidos de nuestra sociedad, de los más pobres, aquellos que de facto no cuentan con ninguna clase de derechos. Pero no pareciera haber ningún indicio de un intento por dignificarlos, por reafirmar su humanidad; por el contrario, logra reducirlos a su condición objetual e introducirlos sin mayor dificultad a la lógica de arte-mercado.

Trabaja también con familiares de víctimas de la violencia. El análisis de la manera concreta en que ella les solicita la autorización que requiere para realizar algunos de sus trabajos, o bien las tareas que les hace desempeñar en caso de obras que directamente los incluyen, pone de manifiesto su evidente incapacidad de establecer empatía con esas personas 


\section{Maria Campiglia - Teresa Margolles}

y las situaciones que atraviesan. Las piezas tampoco parecieran ser capaces de despertar en el espectador un sentimiento empático, o recuperar la historia particular de aquel que ha muerto y su familia: se trata de personas que son mostrados de manera tan simple, tan reductiva, que resulta imposible obtener algún rasgo que dé cuenta de su particularidad, de su humanidad.

Los voluntarios que participan en sus obras (sean o no familiares), ocupan un lugar pasivo, limitándose a realizar las tareas que ella ha propuesto: Son excluidos tanto del proceso de construcción de sentido de la pieza como de las ganancias que la misma genera.

Frecuentemente construye sus piezas a partir de materiales cuyo tratamiento legalmente debe restringirse a instancias policiales. Pero opera tanto desde los vacíos en términos de legislación como desde la corrupción. Y sin embargo Margolles cuenta con un importante cobijo institucional, que le ofrece espacios de exhibición, le otorga becas y premios, le compra piezas. ¿Cómo entender esto?

No creo que aquellos que defienden su trabajo lo hagan necesariamente desde un lugar cínico o simplemente morboso. En absoluto. Creo más bien que se debe a que vivimos en una sociedad con unos niveles de violencia tan increíbles, tan desproporcionados, que no sabemos cómo posicionarnos en relación a la misma.

Margolles reproduce las lógicas más descarnadas de nuestra sociedad. Actúa aprovechando su maquinaria de funcionamiento, diseñada de tal forma que dificulta el entendimiento y por tanto la toma de postura crítica. Es por esto que cuestionar lo que su trabajo convoca resulta particularmente importante en este momento.

\section{Agradecimientos}

Este trabajo forma parte de la investigación de tesis doctoral que actualmente realizo en el programa "La realidad asediada. Posicionamientos creativos", Facultad de Bellas Artes, Universitad de Barcelona. Tutorizada por el Dr. Miquel Planas, Dr. Miquel Quilez y Dr. Francisco Carballo. Se contó con el apoyo del Consejo Nacional de Ciencia y Tecnología (CONACYT), México, gracias a una beca para realizar estudios en el extranjero 


\section{Notas}

1 Larvarium, 1992, Semefo (Arturo Angulo Gallardo, Carlos López Orozco y Teresa Margolles), 176 × 70 x 70 cm. Ataúd exhumado, cadenas y ganchos de metal, Colección UNAM.

2 Según declaraciones de Arturo Angulo se exhumaron tres ataúdes, titulados Larvarium fase I, II y III.

3 Colectivo Semefo, Fluidos, 1996, medidas variables. Realizado con el auspicio de la beca Jóvenes Creadores.

4 Colectivo Semefo, Mineralización estéril, 1997. Actualmente forma parte de la colección del Museo Universitario de Arte Contemporáneo (MUAC).

5 Colectivo Semefo, Catafalco, 1997, medidas variables.

6 Colectivo Semefo, Ropa de cadáver, 1997, 280 × 70 × 60 cm.

7 Colectivo Semefo, Sin título, 1998, medidas variables.

8 Colectivo Semefo, Sin título, 1997, medidas variables.

9 Teresa Margolles. Lengua. 2000, medidas variables.

10 Teresa Margolles, En el aire, 2003, medidas variables.

11 Teresa Margolles, Vaporización, 2001, medidas variables.

12 Colectivo Semefo, Fluidos, 1996, medidas variables.

13 Teresa Margolles, Sobre el dolor, 2006, medidas variables.

14 Teresa Margolles, Ajuste de cuentas, 2007, medidas variables. Joyería con incrustaciones de vidrio.

15 Suponen también una serie de violaciones de normas de carácter sanitario que no tendría sentido abordar aquí.

16 Teresa Margolles, Encobijados, 2006, medidas variables. Mantas utilizadas para envolver víctimas de la delincuencia organizada. Actualmente pertenece a la Colección de Arte Contemporáneo de la UNAM.

17 Equivalente al Ministerio Español del Interior.

18 Semefo, Memoria fosilizada, 1998, 10 x 240 × $240 \mathrm{~cm}$. Diversos objetos contenidos en una plancha de hormigón.

19 Teresa Margolles, Entierro, 1999, 15.5 x 66 x 43 cm. Cadáver de bebé inmerso en un bloque de hormigón.

20 Teresa Margolles, Grumos en la piel, 2001. Serie fotográfica en la que registra la aplicación de grasa de cadáveres sobre la piel de un presunto distribuidor de drogas.

21 Teresa Margolles, La promesa, 2012, medidas variables. Instalación con escombros de una casa demolida en Ciudad Juárez.

22 Teresa Margolles, Limpieza, 2009. Fregado de suelo con agua y sangre de víctimas de la delincuencia organizada. Pabellón de México en la 53 Bienal de arte en Venecia.

23 Teresa Margolles, Bandera arrastrada, 2009. Revolcado de tela con sangre recogida en escenas de ejecuciones producidas en el norte de México. 


\section{Maria Campiglia - Teresa Margolles}

\section{Referencias}

Barrios, J.L. (2004). Los descentramientos del arte contemporáneo: de los espacios alternativos a las nuevas capitales (Monterrey, Guadalajara, Oaxaca, Puebla y Tijuana). En Hacia otra historia del arte en México. Disolvencias (1960-2000), (pp. 340-380). Ciudad de México, México: Conaculta.

Chávez Santiago, A. (2010). La huella que deja el cuerpo: concepto y obra de Teresa Margolles, Tesis de maestría no publicada, UNAM, Ciudad de México, México.

David, M. (2012). SEMEFO. 1990-1999. De la morgue al museo. Ciudad de México, México: UAM.

Fusco, C. (2001). La insoportable pesadez de los seres: el arte en México después de Nafta. Atlántica: Revista de arte y pensamiento, 29, p 16-34.

Medina, C. (2001). Zonas de tolerancia: Teresa Margolles, Semefo y más allá. Revista Parachute, 104, pp.31-52.

Medina, C. (2003, julio 9). El Ojo Breve / La muerte infiltrada, recuperado el 1 de agosto de 2012, de http://www.scribd.com/fullscreen/41058819

Medina, C. (2009). Espectralidad Materialista. En: Teresa Margolles. ¿De qué otra cosa podemos hablar? Catálogo del Pabellón de México. 53 Bienal de Venecia, (pp.15-32). Ciudad de México, México: CONACULTA, UNAM, INBA, Patronato de Arte Contemporáneo AC. Morales Mendoza, L. (2006). De la oscuridad a la Metonimia. Un ensayo sobre Semefo y Teresa Margolles, Tesis de maestría no publicada, UNAM, Ciudad de México, México.

Silva, R. (2004). El arte revulsivo de Teresa Margolles. Agua de cadáver, recuperado el 10 de junio de 2012, de http://www.lainsignia.org/2004/enero/cul_068.htm

Torrijos, G. (2003). Un lienzo mortuorio se convierte en arte, La Prensa, Crónicas del Istmo, 23 de marzo de 2003, recuperado el 1 de diciembre de 2013 de http://mensual.prensa.com/mensual/contenido/2003/03/23/hoy/revista/9 17357.html 
Maria Campiglia: Estudiante de doctorado de la Facultad de Bellas Artes de la Universidad de Barcelona y docente en la Escuela Nacional de Pintura, Escultura y Grabado "La Esmeralda" México, D.F.

Contact Address: Copilco 162, edificio 33, departamento 204, Delegación Coyoacán, CP. 4360, México, D.F.

E-mail address: maria_campiglia@yahoo.com.mx 
Instructions for authors, subscriptions and further details:

http://brac.hipatiapress.com

\section{Oriol Vaz-Romero Trueba, El Artista y el Juguete. Viajes al Imaginario Occidental, desde la Antigüedad al Romanticismo}

Michel Manson ${ }^{1}$

1) Université Paris XIII (U.F.R. Lettres, Sciences de l'Homme et des Sociétés). France

Date of publication: February $3^{\text {rd }}, 2014$

Edition period: October 2013-February 2014

To cite this article: Manson, M. (2013). Recensión de la tesis de Oriol VazRomero Trueba, El Artista y el Juguete. Viajes al imaginario occidental, desde la Antigüedad al Romanticismo (Review of the doctoral thesis). Barcelona, Research, Art, Creation, Vol 2(1), 126-135. doi: 10.4471/brac.2014.05

To link this article: http://dx.doi.org/10.4471/brac.2014.05

\section{PLEASE SCROLL DOWN FOR ARTICLE}

The terms and conditions of use are related to the Open Journal System and to Creative Commons Attribution License (CC-BY). 
BRAC - Barcelona Research Art Creation. Vol. 2 No. 1, February 2014, pp. 126-135

\section{Review}

Vaz-Romero Trueba, Oriol. (2011). El Artista y el Juguete. Viajes al imaginario occidental, desde la Antigüedad al Romanticismo. (Tesis doctoral inédita). Universitat de Barcelona, España. Université Paris XIII, Francia. ${ }^{1}$

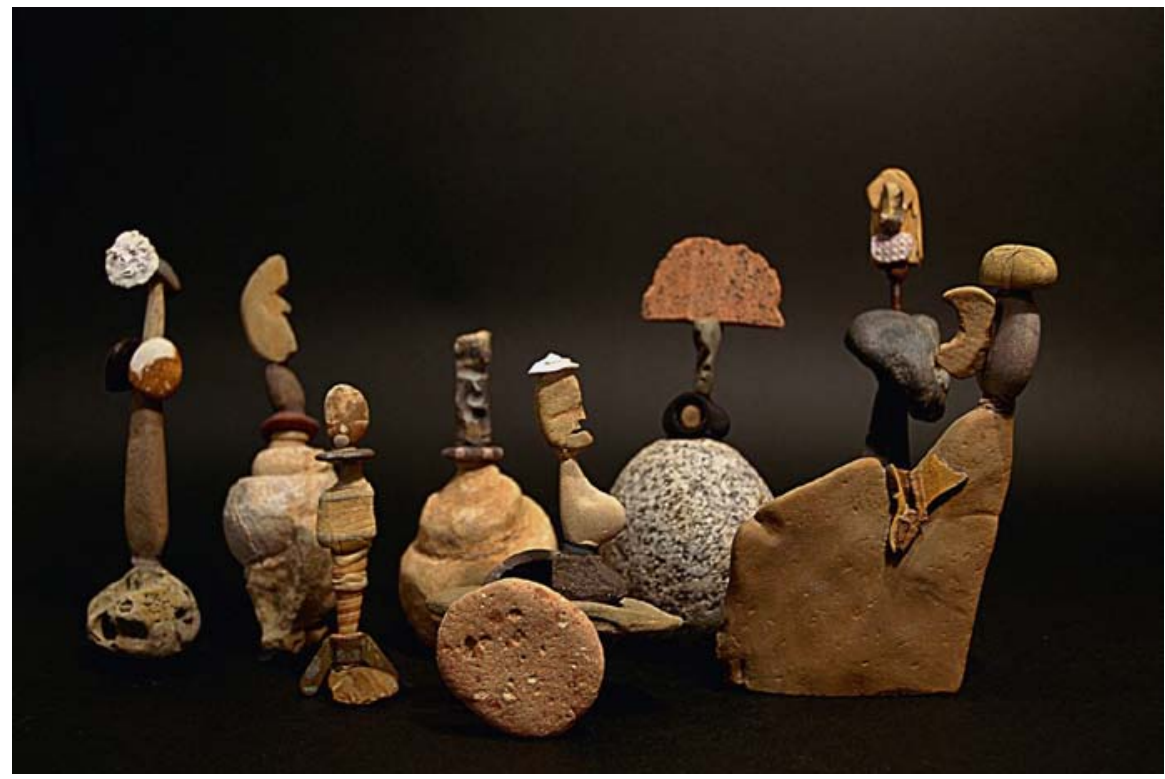

Figure 1. Oriol Vaz-Romero Trueba, Juguetes de piedra (Serie «Sibilas»), 2006. Piedra, conchas y hierro. Colección del autor. 
Conociendo la lenta y ardua acogida del juguete por parte del mundo académico, me reconforta saber que, en plena redacción de estas páginas, el Consejo de Gobierno de la Universitat de Barcelona ha galardonado al autor de esta tesis con el premio extraordinario de doctorado ${ }^{2}$. Pero no empezaré hablando de las cualidades académicas de Oriol Vaz-Romero Trueba, puesto que el autor es, ante todo, un pintor y escultor que ha encontrado en el asombro su principal fuente de creación. Un asombro que le transporta a los imaginarios lúdicos de su infancia y que le llevó a construir entre 2006 y 2008 un conjunto de esculturas de piedra que calificaba de « juguetes » (fig. 1). Reflexionando sobre el estatuto de esta familia de obras antropomórficas, y tratando de comprender los vínculos escurridizos entre la imaginación creadora del artista y el imaginario lúdico del niño, Oriol Vaz artista se embarcaba sin saberlo en un largo y difícil viaje especulativo cuya culminación ha sido esta tesis.

A primera vista, el propósito de tal investigación se nos antoja particularmente arriesgado: se trata de encajar en un único trabajo la visión personal sobre el juguete, nacida de la intuición creadora del escultor, y un estudio histórico sobre los juguetes, desde la Antigüedad hasta el Romanticismo, abordándolos a la vez como objetos fabricados, ligados a una técnica y a un sistema de mercado particulares, y como objetos imaginados por una cultura que les dota de significado. Esta aproximación, que pretende reconciliar el Arte con las Humanidades corresponde a una metodología que Oriol Vaz llama «binocular», inspirándose de Elliot Eisner, profesor emérito de Arte y Educación en la Stanford Graduate School of Education ${ }^{3}$. Este planteamiento le ha supuesto manejar un número insólito de disciplinas: historia e historia del arte, arqueología, filología y filosofía —no sólo la rama de la Estética-, así como las ciencias sociales. Para llevar a buen puerto estos « viajes », que son ciertamente itinerarios personales, el autor ha sabido formar una hermenéutica incisiva ahondando en cada disciplina y haciendo circular los conocimientos sin presentarse, no obstante, como especialista de todas ellas. 


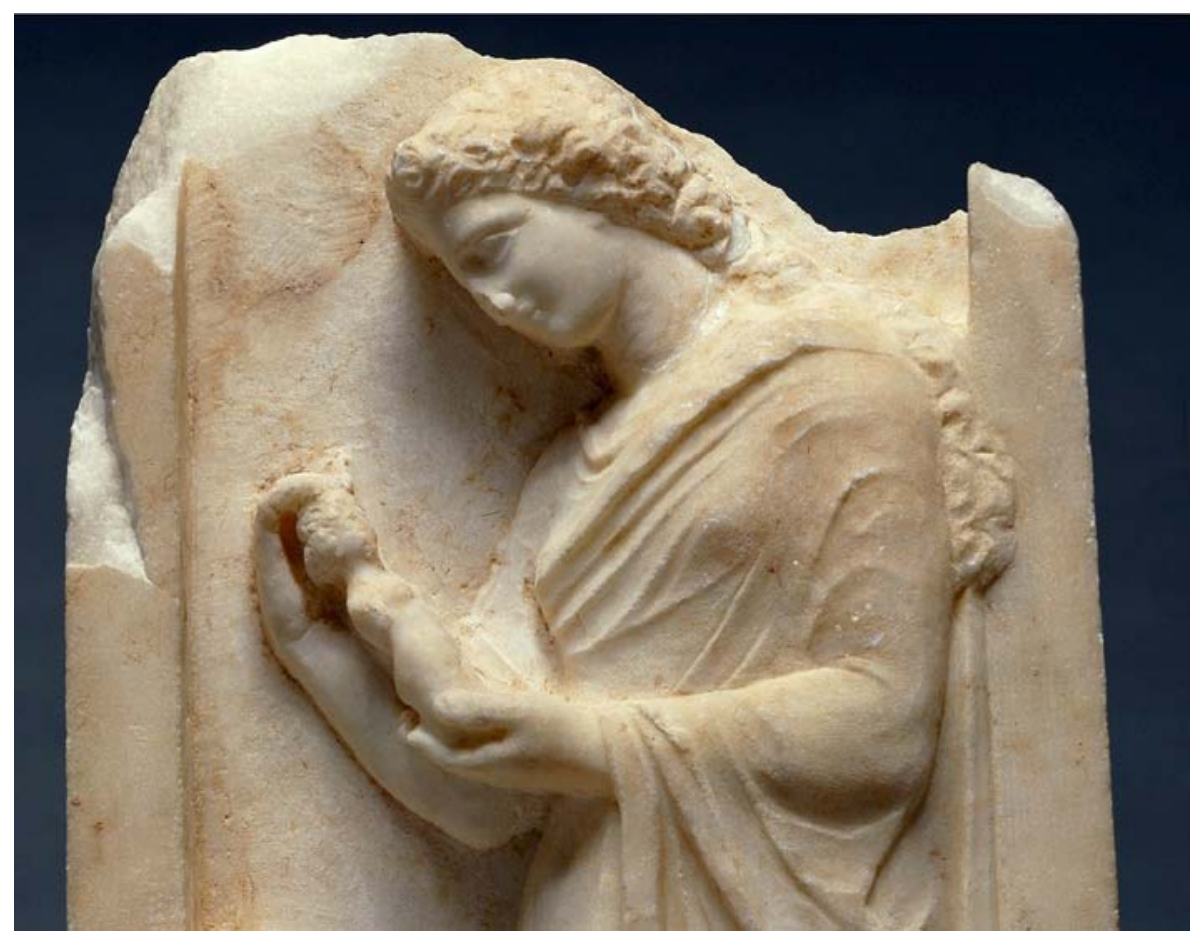

Figure 2. Una joven muchacha contempla su muñeca. Estela funeraria ática, c. 360 a.C. Mármol pentélico, 72.5 x 36 x 12.5 cm. (C) J. Paul Getty Trust

La investigación documental resultante se traduce en una bibliografía internacional de más de 2.500 referencias — pp. 2030-99- en español, francés, inglés, italiano y alemán. Pero no hay que olvidar, asimismo, el escrutinio sistemático de fondos y bases de datos de 62 museos y 20 archivos o bibliotecas especializadas de países como Estados Unidos (fig. 2), Reino Unido, Alemania, Francia, España e Italia (fig. 3). Una parte importante de los documentos recogidos todavía no había sido publicada y su confrontación aporta nuevas luces sobre la historia de la infancia y sobre la propia historia del juguete. En este sentido, el estudio iconográfico es absolutamente extraordinario, esclareciendo el desarrollo teórico con 
abundantes ilustraciones y aumentándolo, al final, con 915 imágenes suplementarias, reunidas en el cuarto volumen de la tesis, todos los documentos habiendo sido referenciados con gran precisión. El profesor Vaz-Romero se ha esforzado en retrasar los contextos de cada imagen o fuente filológica, saliendo al paso de los debates eruditos y matizando con pertinencia y finura todo el análisis.

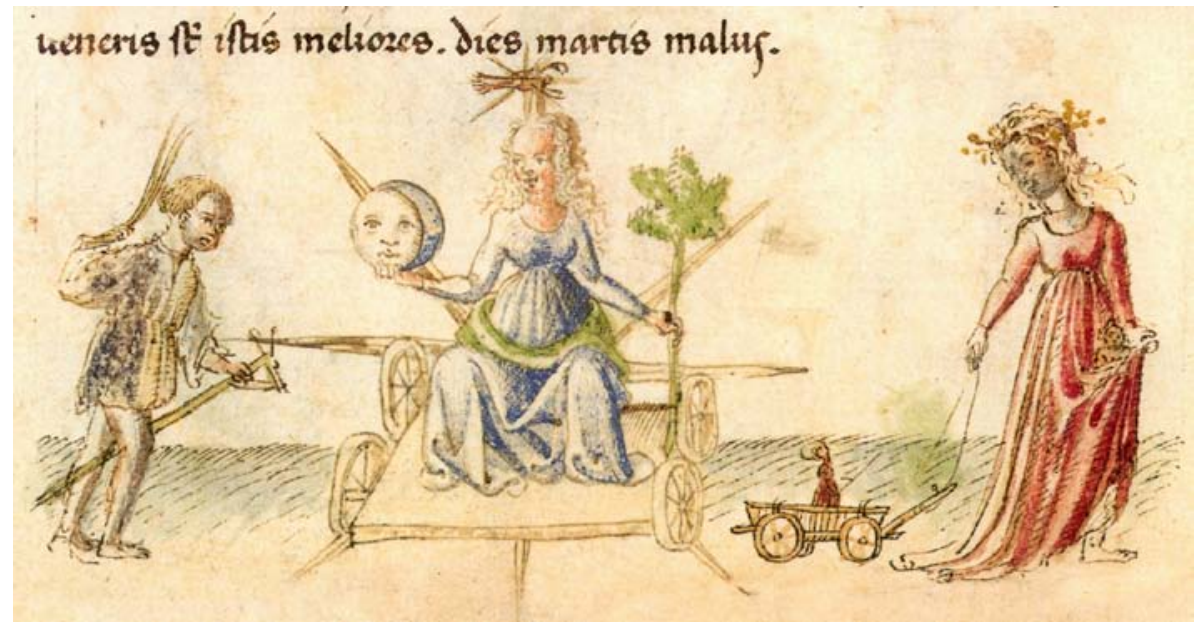

Figure 3. Alegoría de la Luna, bajo el signo de Cáncer, junto a dos niños con juguetes, s. XV. Liber physiognomiae, MS. Lat. 697, fol 4v. (C) Biblioteca Estense, Módena

Definido como un «recipiente simbólico del asombro del niño », el juguete es equiparado con la obra de arte, también percibida como recipiente de asombro. Oriol Vaz demuestra con acierto que esta cualidad « poiética » del asombro no constituye por casualidad el fundamento estético de los románticos, quienes hicieron del niño el paradigma del genio creador. De hecho, la experiencia del asombro está íntimamente ligada a la imaginación: a esa que el niño pone en funcionamiento cuando juega y también esa que el artista aviva cuando vislumbra y plasma su obra. El asombro se convierte así en concepto heurístico, en un hilo conductor que permite sondear los 
imaginarios occidentales sobre el juguete, midiendo la relación entre juego y arte, entre niño y artista. Para dar mejor cuenta de esta historia, partiendo de la Antigüedad, el autor ha elaborado un modelo teórico que relaciona el asombro y el entusiasmo con los mecanismos de la imaginación, con el acto creador y con la recepción de la obra creada, en una organización dinámica que adquiere formas distintas según cada contexto histórico estudiado. Gracias a este novedoso instrumento hermenéutico, la diversidad de usos del juguete en cada cultura sobresalen con más claridad y se organizan en estructuras llenas de significado. La presentación que acabamos de hacer apenas describe la sutileza de los resultados. Pero, en vez de desarrollar estos aspectos teóricos, nos parece más interesante para el lector resaltar algunas de las aportaciones de este trabajo relativas a conocimientos sobre la propia historia del juguete, especialmente en lo que atañe a las representaciones artísticas.

En el pasado, habíamos aportado algunas pistas en el campo de la investigación ${ }^{4}$, pero Oriol Vaz las ha proseguido, ampliado y completado. Tomemos el ejemplo del juguete en la arqueología y en el arte de la Península ibérica ${ }^{5}$. No contento con citar las publicaciones ya existentes sobre los juguetes antiguos encontrados en España ${ }^{6}$, el autor recapta informaciones dispersas de objetos — antiguos y medievales_-, relegadas en publicaciones de antiguas excavaciones, en catálogos de exposición, en actas de congresos de arqueología y en revistas eruditas. Estudiando los artefactos procedentes de las culturas musulmana y cristiana, ha tratado en cada caso de situarlos en relación con el sentimiento de infancia de la sociedad de ese preciso momento. Su iniciativa revela, por ejemplo, que la cultura hispanomusulmana, a pesar de ser reticente al arte figurativo, no dudó en crear para sus niños diversos silbatos y juguetes antropomórficos o zoomórficos. En comparación, la artesanía del juguete en la España cristiana parece, según los documentos aquí reunidos, mucho más sobria, excluyendo los juguetes ofrecidos a los niños de la aristocracia, a menudo traídos desde París o Nuremberg.

El profesor Vaz-Romero se apoya luego en fragmentos literarios del siglo XVII para demostrar la existencia de juguetes llegados incluso a manos de las clases medias. Ciertas figuritas de arcilla, fechadas entre los siglos XVI y XVII, encontradas en excavaciones urbanas pueden efectivamente ser 
interpretadas como juguetes modestos. Aborda entonces el campo de la representación artística, empezando por los manuscritos iluminados, los libros grabados y luego la pintura. Oriol Vaz muestra con claridad que, en sus comienzos, el arte español se resistió a representar juguetes, a diferencia de lo que ocurre en la pintura flamenca o alemana (fig. 4) y, aunque en menor medida, también en la pintura inglesa, francesa o italiana. En el caso de los niños de la Realeza, el lienzo pintado por Sánchez Coello de los infantes don Diego y don Felipe -1579—, así como los cuadros de Juan Pantoja de la Cruz de la infante Ana —1602 y 1607_-, representada sola o junto a su hermano Felipe IV, no muestran juguete alguno, sino amuletos y campanillas. En cambio, Cornelis Vermeyen, en 1577, no duda en colocar una muñeca en la mano de la hija de Carlos II —pp. 1552-3—. Los retratistas del Norte de Europa, venidos a la Corte española, son sensibles a los juguetes puesto que representan para ellos el símbolo mismo de la infancia. Si Velázquez acepta colocar un sonajero en las manos del enano que acompaña al joven Baltasar Carlos — 1631—, lo hace precisamente para alejarlo del infante, quien deberá abandonar cuanto antes los placeres del juego para aceptar las responsabilidades de la Corona.
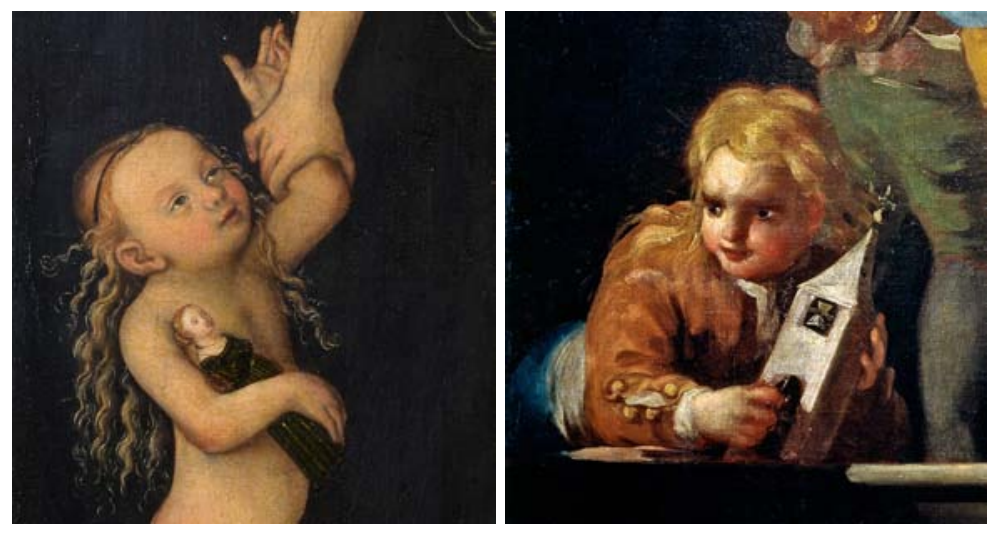

Figure 4. Lucas Cranach el Viejo, Caritas, 1537-1550. Óleo/tabla, 56.3 x 36.2 cm. (C) National Gallery, Londres.

Figure 5. Francisco de Goya y Lucientes, Muchachos jugando a soldados, 1779. Óleo/lienzo, 146 x 94 cm. (C) 2013 Museo Nacional del Prado. 


\section{Michel Manson - El Artista y el Juguete}

Como nos sugiere el autor, tenemos que esperar a Goya para que la mirada sobre la infancia se propague y enternezca, reparando más y mejor en sus juegos y juguetes. Así lo revela la serie de cartones para tapices realizada entre 1777 y 1785, como las dos versiones de Muchachos jugando a soldados, donde aparece un juguete raramente representado: un campanario de madera con una campanita que puede ser repicada (fig. 5). Todas estas representaciones de juegos infantiles populares habían sido proyectadas para los aposentos de los Príncipes de Asturias en el palacio de El Pardo. Oriol Vaz ha estudiado más a fondo el programa decorativo de estas « habitaciones infantiles » en una reciente publicación en Francia ${ }^{7}$ y sigue obteniendo nuevos documentos que esperan salir a la luz próximamente. Cada vez con más frecuencia a partir de Goya, los pintores de la burguesía van a representar al niño con su juguete, prefiriendo aquellas situaciones en las que este silencioso objeto hace acto de presencia. Los retratos infantiles se liberan así de la rigidez centenaria propia de la estética cortesana, rehuyendo los remilgos, como en el retrato pintado en 1819 por Agustín Esteve de los hijos de los duques de Medinaceli, donde el niño aparece sentado sobre un caballo-balancín, sosteniendo la muñeca de su hermana.

El profesor Vaz-Romero ha sabido reunir, a pesar de la complejidad del contexto hispánico, un número representativo de obras, explicándolas en relación con la historia general de la infancia y con la imagen que del juego se hicieron las sociedades europeas hasta las puertas del siglo XX. En un magistral desarrollo, el autor pone de relieve el cambio de paradigma que supuso el movimiento romántico, que hizo del juego infantil una lectura plenamente positiva, no sólo en términos pedagógicos, sino también filosóficos y estéticos, alejándose por completo de la noción de frivolidad con la que la tradición escolástica tan a menudo había despreciado esta actividad. Por el contrario, los románticos hacen del juego la mayor potencia creadora del niño, asociándola de manera insólita a la creatividad del poeta, del místico y del artista, llegando incluso a pensar que el adulto nunca llegará a igualar la fuerza poética de su infancia. Los juguetes, a los que el niño insufla vida en sus escenografías lúdicas, se convierten por esta razón en objeto de incontables retratos y representaciones. 


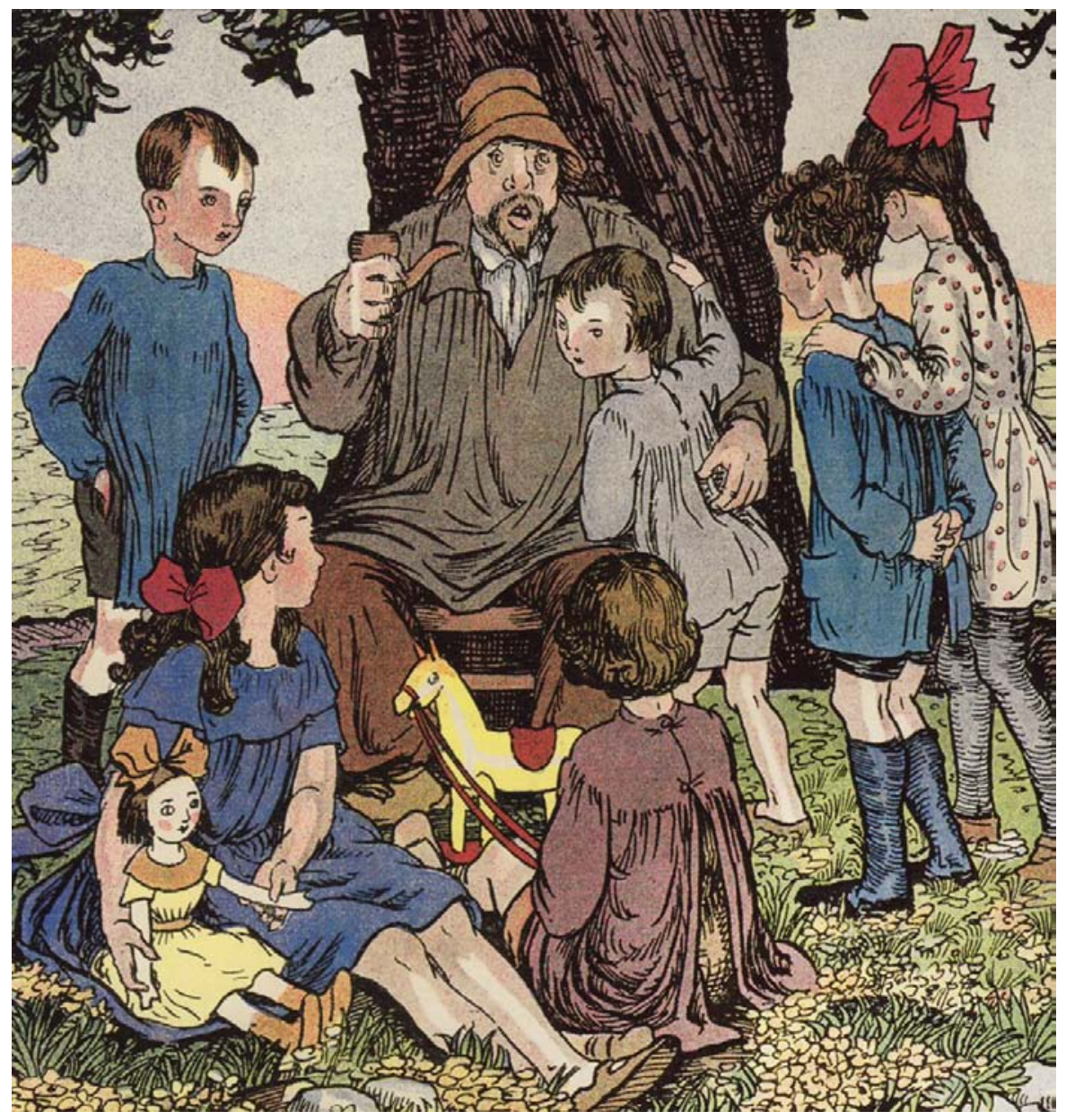

Figure 6. Lola Anglada, El viejo cazador contaba a los niños la historia de la Perdiz de oro, en: H. Monquet, Le Bon Roi Ortolan. París, Librairie Hachette, 1929, p. 63. Colección de Oriol Vaz. 


\section{Michel Manson - El Artista y el Juguete}

En esta nueva colecta iconográfica, que concierne a todos los países, cabe señalar el lugar inédito que Oriol Vaz otorga a los artistas catalanes de finales del siglo XIX y principios del XX. El apego a la infancia de estos creadores nos brinda escenas conmovedoras, como ese niño enfermo - hijo del pintor - jugando entre sábanas con sus juguetes, obra del pintor Ricard Canals - p. 1743 - . Debe hacerse una mención especial a Lola Anglada, cuyas litografías e ilustraciones de libros infantiles aportan a las viñetas con juguetes un frescor y dulzura irrepetibles, haciéndonos partícipes de la intimidad de sus pequeños protagonistas (fig. 6). Mirada delicada también la de Joaquim Renart sobre su hija dormida, abrazada a su muñeca, esbozada en sus Cuadernos de 1912 y 1917 — p. 1792—. Oriol Vaz ha tomado en cuenta las fuentes iconográficas más humildes, como los grabados populares y las estampas, las ilustraciones de periódicos o de libros infantiles, hojas de aleluyas y carteles navideños, soportes, todos ellos, difundidos a gran escala y portadores de sensibilidades muy distintas de las que hallamos entre las clases acomodadas a las que iban destinadas las pinturas de caballete.

Hasta ahora, no he tomado más que el ejemplo de la historia del arte puesta al servicio de una reflexión sobre la relación entre el juguete, el niño y el artista. Pero no he mencionado los capítulos que en esta tesis trascienden la cultura hispánica y que justifican la mención internacional con la que esta tesis fue distinguida. Valga recordar la relación que el autor establece entre el juguete animado y la larga historia de los autómatas y las estatuas vivas. Para ello, habría sido necesario reseguir la vasta compilación de textos, acompañados por los doctos y refinados comentarios del profesor VazRomero. Debo rendirme finalmente a la evidencia: es casi imposible hacer una recensión de un trabajo tan enorme, tan nutrido y exuberante. En estos « viajes al imaginario occidental » del juguete, cada lector puede encontrar su propio camino. Hallará relatos impensables y materiales sorprendentes, enfoques e iluminaciones inéditas sobre nuestra cultura europea, reflexiones estimulantes sobre los primeros juguetes de la historia humana e incluso interpretaciones místicas del gesto lúdico del niño. Por todo ello, es imposible abandonar esta tesis sin tener ganas de profundizar en una o en varias de las pistas que el autor ha desbrozado con gran entusiasmo y generosidad. ¡Esperamos con impaciencia los libros y artículos que Oriol 
Vaz-Romero Trueba no va a dejar de escribir a partir de ahora y que, de hecho, ya ha comenzado a publicar!

\author{
Michel Manson. Université Paris XIII \\ manson@lshs.univ-paris13.fr
}

\title{
Notas
}

${ }^{1}$ Dirigida por los profesores Miquel Quílez Bach (Universitat de Barcelona) y Michel Manson, (Université Paris XIII), leída el 2 de noviembre de 2011 en Barcelona. 3 vol. de texto en castellano (con 2201 págs.), 2 vol. de planchas con 915 imágenes (1365 págs.); 1 vol. conteniendo el resumen de la tesis en francés (119 págs.). Con esta tesis, Oriol Vaz-Romero Trueba se ha doctorado en Bellas Artes, en Barcelona, y en Ciencias de la Educación, en París.

${ }^{2}$ Acuerdo del Consell de Govern de la Universitat de Barcelona (23 de julio de 2013), otorga a Oriol Vaz-Romero Trueba el premio extraordinario de doctorado correspondiente al curso académico 2011-2012.

${ }^{3}$ Eisner, E.W., The enlightened eye. Qualitative inquiry and the enhancement of educational practice. New York y Toronto, Macmillan, 1991, p. 199.

${ }^{4}$ Manson, M., Jouets de toujours, de l'Antiquité à la Révolution, París, Fayard, 2001; "L'enfant, ses jeux, ses jouets, dans l'estampe et dans l'art au XVIIIe siècle », en: Péristyles. L'Enfant dans la Ville et dans l'Art au XVIIIe siècle N²6 (diciembre de 2005), p. 50-61; " Histoire du jouet dans l'art, approche anthropologique, 1450-1650 », en: Annali della Facoltà di Lettere e Filosofia, Università di Siena, vol. XXVI, 2005, Fiesole, Cadmo, 2007, p. 129-64; « Les jouets du Pavement de la cathédrale de Sienne (1475-1545), et l'originalité de Domenico Beccafumi », en: Sacro e profano nel duomo di Siena. Leggere l'arte della Chiesa, Quaderni dell'Opera No10-12, Siena, 2008, p. 227-52.

${ }^{5}$ Vaz-Romero Trueba, O., L'artiste et le Jouet..., Op. cit. (Parte III, cap. X, 4): « El Juguete en España desde la Reconquista a las Luces », pp. 1515-1620.

${ }^{6}$ Trabajos anteriores y posteriores al artículo fundamental de Alberto Balil, « Muñecas Antiguas en España », en: Archivo Español de Arqueología, vol. XXV, Nº105-106, 1962, pp. 70-85.

${ }^{7}$ Vaz-Romero Trueba, O., « Métamorphoses de la chambre d'enfant dans l'imaginaire des artistes espagnols (1775-1936) », en: Strence No4, 2012 (http://strenae.revues.org/832). 


\section{B.R:A}

Instructions for authors, subscriptions and further details:

http://brac.hipatiapress.com

\section{List of Reviewers}

Date of publication: February $3^{\text {th }}, 2014$

To cite this article: (2014). List of Reviewers. Barcelona, Research, Art, Creation, Vol 2(1), 136. doi: 10.4471/brac.2014.06

To link this article: http://dx.doi.org/10.4471/brac.2014.06

\section{PLEASE SCROLL DOWN FOR ARTICLE}

The terms and conditions of use are related to the Open Journal System and to Creative Commons Attribution License (CC-BY). 
BRAC - Barcelona Research Art Creation. Vol. 2 No. 1, February 2014, p. 136

\section{List of Reviewers}

The editors of the Barcelona Research Art Creation, we wish thank the reviewers for their contributions to the quality of the journal during 2013.

Agustí, Eugènia

Àlex Nogué Joan Descarga Miquel Planas

Editors

Berenguer, José

Boncompte, Conxita

Dahó, Marta

de Laiglesia, Juan Fernando

Fusté, Jaume

Garí, Clara

Hernández, Fernando

Herranz, Yolanda

Martí, Antònia

Puig, Eloy

Valera, Alberto

Vaz, Oriol

Vela, Alicia

Velilla, Carlos

Vila, Antònia 